Pacific Northwest

National Laboratory

Operated by Battelle for the

U.S. Department of Energy

\section{Laboratory Measurements of the Unsaturated Hydraulic Properties at the Vadose Zone Transport Field Study Site}

\author{
M.G. Schaap \\ P.J. Shouse \\ P.D. Meyer
}

May 2003

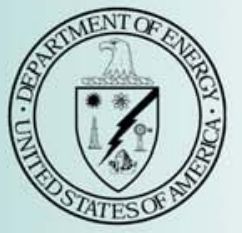

Prepared for the U.S. Department of Energy under Contract DE-AC06-76RL01830 


\title{
DISCLAIMER
}

This report was prepared as an account of work sponsored by an agency of the United States Government. Neither the United States Government nor any agency thereof, nor University of California, nor Battelle Memorial Institute, nor any of their employees, makes any warranty, express or implied, or assumes any legal liability or responsibility for the accuracy, completeness, or usefulness of any information, apparatus, product, or process disclosed, or represents that its use would not infringe privately owned rights. Reference herein to any specific commercial product, process or service by trade name, trademark, manufacturer, or otherwise does not necessarily constitute or imply its endorsement, recommendation, or favoring by the United States Government or any agency thereof, or University of California, or Battelle Memorial Institute. The views and opinions of authors expressed herein do not necessarily state or reflect those of the United States Government or any agency thereof.

\author{
PACIFIC NORTHWEST NATIONAL LABORATORY \\ operated by \\ BATTELLE \\ for the
}

UNITED STATES DEPARTMENT OF ENERGY

under Contract DE-AC06-76RL01830

Printed in the United States of America

\author{
Available to DOE and DOE contractors from the \\ Office of Scientific and Technical Information, \\ P.O. Box 62, Oak Ridge, TN 37831-0062; \\ ph: (865) 576-8401 \\ fax: (865) 576-5728 \\ email: reports@adonis.osti.gov
}

Available to the public from the National Technical Information Service, U.S. Department of Commerce, 5285 Port Royal Rd., Springfield, VA

22161

ph: (800) 553-6847

fax: (703) 605-6900

email: orders@ntis.fedworld.gov

online ordering: http://www.ntis.gov/ordering.htm 


\title{
Laboratory Measurements of the Unsaturated Hydraulic Properties at the Vadose Zone Transport Field Study Site
}

\author{
M.G. Schaap ${ }^{(a)}$ \\ P.J. Shouse ${ }^{(b)}$ \\ P.D. Meyer
}

May 2003

Prepared for

the U.S. Department of Energy

under Contract DE-AC06-76RL01830

Pacific Northwest National Laboratory

Richland, Washington 99352

(a) UC Riverside, Dept. of Environmental Sciences, Riverside, CA

(b) George E. Brown Salinity Laboratory, USDA/ARS, Riverside, CA 



\section{Summary}

This report presents sampling and measurement procedures and measurement results for 60 samples from the S-1, S-2, and S-3 bore holes at the Vadose Zone Transport Field Study Leak Simulation Test Site, located at the Sisson and Lu (1984) injection site in the 200 East Area of the Hanford Site. Measured data include particle size distributions (19 points), bulk densities (and bulk density-derived porosity), water retention characteristics (16 static points), and saturated and unsaturated hydraulic conductivities.

The coring and sub-sampling procedures led to partially, and occasionally completely, disturbed samples. Textural analyses showed that most of the samples could be classified as sand, some as loamy sands, and two as sandy loams. The multi-step outflow method failed for seven samples, yielding 53 samples for which hydraulic parameters were available. Van Genuchten and Brooks-Corey water retention parameters were determined using static retention points (derived from multi-step outflow time series). Inverse analyses of the multi-step outflow data yielded additional unsaturated hydraulic conductivity parameters. Unfortunately, the inverse analyses had some problems in reaching stable solutions. Therefore, we sometimes fixed saturated and residual water contents and saturated hydraulic conductivities at initial values. Even then, it was not possible to reach a solution for two samples leaving the total number of samples for which inverse solutions were available at 51. We also noticed that Brooks-Corey inversions were of lesser quality than van Genuchten inversions. We suggest that BrooksCorey inversions be treated carefully and that, where possible, the far more reliable direct fits of the Brooks-Corey curve to the static retention data be used.

The data gathered in this effort are for the most part reported in the appendix. Raw, outflow time series data from the multi-step outflow procedure are not included. An electronic version of the data is available from the first and third authors. 



\section{Acknowledgments}

The samples discussed in this report were taken from cores provided by Glendon Gee, Andy Ward, and George Last of Pacific Northwest National Laboratory as part of the Vadose Zone Transport Field Study, Hanford Science and Technology Project funded by the U.S. Department of Energy Richland Operations Office. Mark Rockhold of Pacific Northwest National Laboratory provided valuable review of the data and this report. The work discussed in this report was supported by the U.S. Department of Energy Environmental Management Science Program. 



\section{Contents}

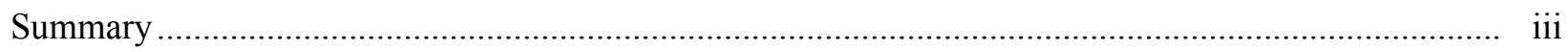

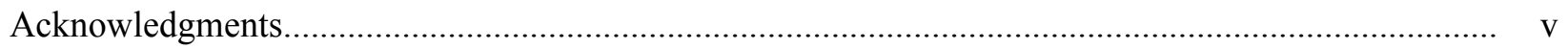

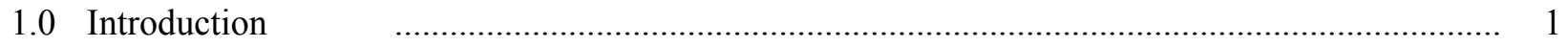

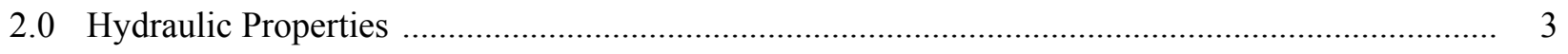

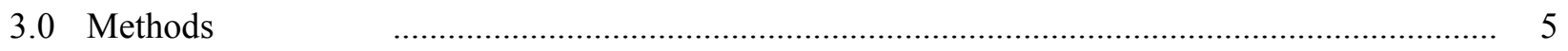

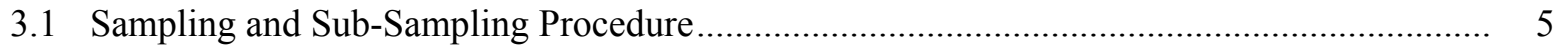

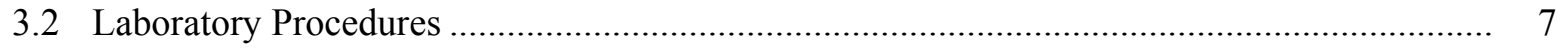

3.2.1 Saturated Hydraulic Conductivity ....................................................................... 7

3.2.2 Water Retention and Multi-Step Outflow Measurements ...................................... 7

3.2.3 Direct Fit of the Retention Parameters to Static Retention Data ................................ 9

3.2.4 Inverse Determination of Unsaturated Hydraulic Parameters ................................... 10

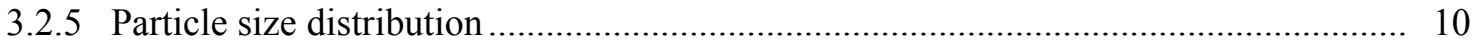

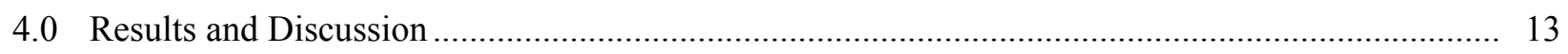

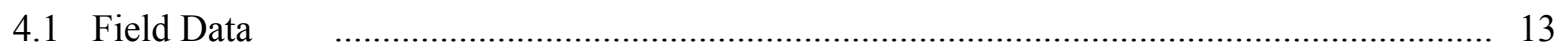

4.2 Particle Size Distributions, Bulk Density and Saturated Hydraulic Conductivity ................. 13

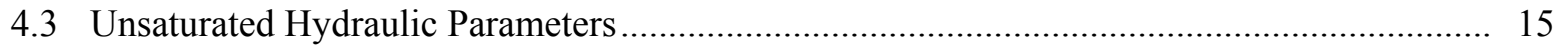

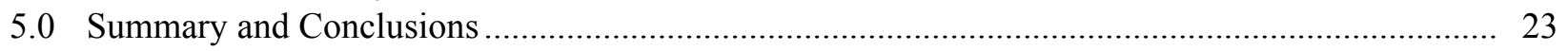

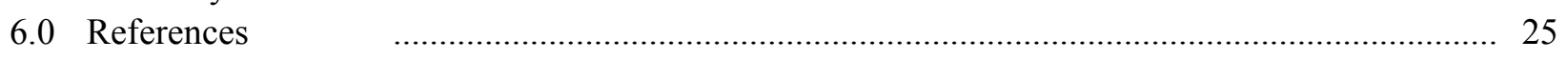

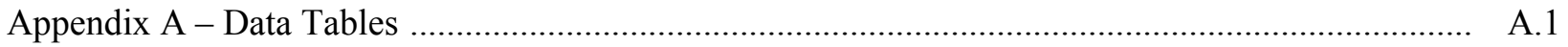

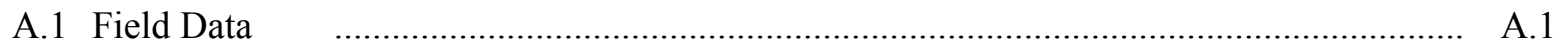

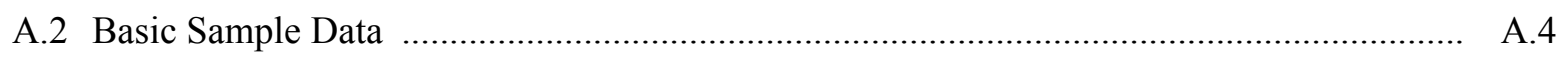

A.3 Particle Size Distribution Data ….............................................................................. A. A

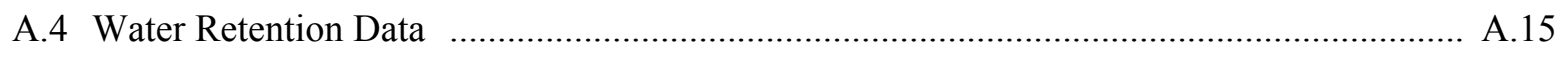

A.5 Directly Fitted "van Genuchten” Parameters …............................................................ A.23

A.6 Directly Fitted "Brooks-Corey” Parameters .................................................................... A.26

A.7 Inversely Modeled “van Genuchten” Parameters .......................................................... A.29

A.8 Inversely Modeled "Brooks-Corey" Parameters .............................................................. A. A2

\section{Figures}

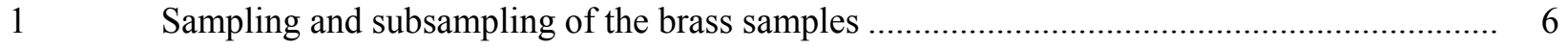

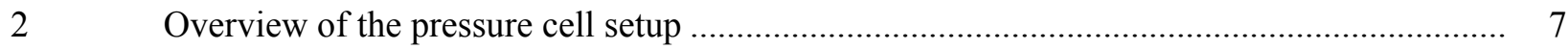

3 Schematic drawing of the multi-step outflow method ............................................... 8

$4 \quad$ Typical example of the time series of the multi-step outflow method ............................... 9

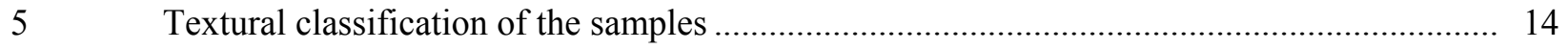

$6 \quad$ Textural distribution of a sand, loamy sand, and a sandy loam ...................................... 14

$7 \quad$ Saturated hydraulic conductivity versus sand percentage .............................................. 15

$8 \quad$ Saturated hydraulic conductivity versus porosity ..................................................... 15 
9 Distributions of the direct fits of Brooks-Corey versus van Genuchten parameters ............. 19

10 Inverse optimizations versus direct fits of the van Genuchten parameters ......................... 20

11 Inverse optimizations versus direct fits of the van Brooks-Corey parameters ..................... 21

\section{Tables}

1 Statistical characterization of the hydraulic data 


\subsection{Introduction}

Assessing the environmental impact of past and future activities at the Hanford Site often makes use of models that simulate the hydrological processes in and around the disposal facilities. Presently, the appropriateness of the models is being tested using data obtained in past and recent on-site field experiments. Complicating factors are the depth of the unsaturated zone and the high degree of vertical variability in the sediments, resulting in a high degree of spatial variability in hydraulic properties. This report describes an effort to measure unsaturated hydraulic properties at the Vadose Zone Transport Field Study Leak Simulation Test Site, located at the Sisson and Lu (1984) injection site in the 200 East Area of the Hanford Site in Washington State. The information presented in this report partly complements a report by Last and Caldwell (2001) who described the core sampling done at this site during the summer of 2000. This report describes the sampling and measurement methodologies for determining water retention and hydraulic conductivity in the lab, and presents some analysis of the results. The appendices present the majority of the data collected, but do not include the raw multi-step outflow data. The data reported here are also available from the first or third authors in electronic format as a spreadsheet file. 



\subsection{Hydraulic Properties}

Soil hydraulic properties are required to model transport of water and solutes in the vadose zone. A broad array of methods currently exists to determine soil hydraulic properties in the field or in the laboratory (Dane and Topp 2002). Field methods allow for in-situ determination of the hydraulic properties but have uncertainties about the actual sample volume. Laboratory measurements often require more sample preparation but do allow a larger number of measurements and a better control of the experimental conditions.

The hydraulic characteristics necessary to calculate flow and transport in porous media are water retention and saturated and unsaturated hydraulic conductivity. Water retention characteristics are commonly given as the water content $\left(\theta\right.$, with units of $\mathrm{cm}^{3}$ of water per $\mathrm{cm}^{3}$ of soil) versus a capillary pressure ( $h$, usually defined in $\mathrm{cm}$ of water pressure). The notation followed in this report will assume that $h$ is negative for unsaturated soils. The water content of nearly all porous media decreases with increasingly negative capillary pressures. For reference, plant life is generally possible for pressures between 0 and $-1.510^{4} \mathrm{~cm}$, while extremely dry desert soils may have even lower pressures (and very low water contents). The shape of the water retention characteristic, however, is strongly dependent on soil texture, porosity, and other factors. The strongest changes in water content are generally present around the "air entry" value, which is generally the capillary pressure where the most common pore-size drains.

Saturated hydraulic conductivity, $K_{s}$, provides the water conductivity at zero or positive capillary pressure (i.e., when the soil is completely saturated with water). Unsaturated hydraulic conductivity provides the water conductivity in terms of capillary pressure, $K(h)$, or water content or relative saturation $\left(K\left(S_{\mathrm{e}}\right)\right.$, discussed below). Measurement of unsaturated conductivity is generally difficult, cumbersome, and expensive. Reasons for this are that unsaturated hydraulic conductivity can vary many orders of magnitude within a pressure range between 0 and $-10^{3} \mathrm{~cm}$ and substantial data analyses (e.g. inverse modeling) are often needed. Reduction in conductivity with decreasing pressure is especially strong for pressures smaller than the air entry value (or water contents smaller than the water content at the air-entry pressure).

For modeling and other numerical or graphical purposes, it is often convenient to provide the water retention and unsaturated hydraulic conductivity characteristics in functional form. For this purpose, the van Genuchten (1980) and Brooks-Corey (1964) equations are commonly used to describe the water retention characteristic with four adjustable parameters. Combining the van Genuchten and Brooks-Corey equations with the Mualem (1976) pore-size distribution model yields an unsaturated hydraulic conductivity expression for which two additional adjustable parameters are required. The van Genuchten (1980) equation for water retention is:

$$
S_{e}(h)=\frac{\theta(h)-\theta_{r}}{\theta_{s}-\theta_{r}}=\frac{1}{\left(1+|\alpha h|^{n}\right)^{1-1 / n}}
$$


Substitution into the Mualem (1976) model yields a closed-form expression for the unsaturated hydraulic conductivity characteristic,

$$
K\left(S_{e}\right)=K_{0} S_{e}^{L}\left[1-\left(1-S_{e}^{1 / m}\right)^{m}\right]^{2}
$$

where $m=1-1 / n$. To make an easy comparison with the van Genuchten equation possible, we use a modified notation for the Brooks-Corey (1964) equation in which we replaced the bubbling pressure $h_{\mathrm{b}}$ with $1 / \alpha$

$$
S_{e}(h)=\frac{\theta(h)-\theta_{r}}{\theta_{s}-\theta_{r}}= \begin{cases}\frac{1}{|\alpha h|^{\lambda}} & h<-1 / \alpha \\ 1 & h \geq-1 / \alpha\end{cases}
$$

The corresponding equation for the unsaturated hydraulic conductivity characteristic is given by

$$
K\left(S_{e}\right)= \begin{cases}K_{0} S_{e}^{2+L+2 / \lambda} & h<-1 / \alpha \\ K_{0} & h \geq-1 / \alpha\end{cases}
$$

In these equations $S_{e}$ is the relative saturation, $\theta$ is the water content, $h$ is the pressure head, $K\left(S_{e}\right)$ is the unsaturated hydraulic conductivity function, and $\theta_{r}$ and $\theta_{s}$ denote the residual and saturated water contents, respectively. $K_{0}$ is the matching point at saturation, and $\alpha, n, \lambda$, and $L$ are curve shape parameters. Generally, $\alpha$ is interpreted as the inverse of the air-entry pressure, $n$ and $\lambda$ are pore distribution parameters, and $L$ is a pore connectivity or pore continuity parameter (Mualem 1976). The hydraulic characteristics defined by Eqs. (1) and (2), or Eqs. [3] and [4] contain 6 unknown parameters: $\theta_{r}, \theta_{s}, \alpha, n$ (or $\lambda$ ), $L$, and $K_{0}$. We did not a-priori assume that $K_{0}=K_{\mathrm{s}}$ as Schaap and Leij (2000) showed that $K_{0}$ is often much smaller than $K_{\mathrm{s}}$ because of the effects of macropore versus matrix flow. 


\subsection{Methods}

\subsection{Sampling and Sub-Sampling Procedure}

The hydraulic data that are presented in this report were obtained from samples derived from three boreholes, S-1, S-2, and S-3, at the Sisson and Lu Site in the 200 East Area of the Hanford Site (officially, the 299-E24-111 Experimental Test Well Site). A site description, borehole logs, and related data are described in Last and Caldwell (2001). To give a comprehensive description of the way the samples were obtained we quote Last and Caldwell (2001) while adding some images to their description. Figure references were added and refer to figures in this report.

Each borehole was drilled using a Mobile Drill 61 drill rig and $25 \mathrm{~cm}$ (10 in.) OD hollowstem auger flights (Fig. 1a). The upper $4 \mathrm{~m}$ (13 ft) of each borehole was drilled with a pilot bit inside the hollow-stem auger to keep drill cuttings out. Once the borehole was advanced to the

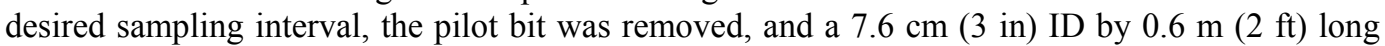
splitspoon sampler was lowered to the bottom of the borehole. The sampler was then driven into relatively undisturbed materials in front of (i.e., below) the auger flights using a drive hammer weighing up to $227 \mathrm{~kg}$ (500 lbs.). Once the sampler had been driven the length of the sampler, or to refusal, the sampler was withdrawn and taken to the breakdown table for disassembly and subsampling (Fig. 1b). However, at times, during difficult retrievals, the sampled materials were not retained by the sampler, and thus not recovered from that particular sampling interval. Once the sampler was retrieved from the borehole, the pilot bit was again lowered into the auger flights and the borehole advanced to the next sampling interval.

Once the splitspoon sampler was taken to the breakdown table and disassembled, one half of the sample barrel was removed to expose the four $15 \mathrm{~cm}$ (6 in.) long Lexan core liners (Fig 1c) and a cursory inspection was made to evaluate the representativeness and the vertical heterogeneity of the various geologic strata. The most intact and representative core liners were selected for analysis and/or archiving, marked with an up arrow, and labeled in accordance with the Pacific Northwest National Laboratory's (PNNL) procedure PNL-MA-567, DO-2. The selected core liners were carefully removed from the sample barrel in a way that would minimize the loss of material out of the liner (Fig 1d). The liners were then capped and transferred to the field laboratory for archiving and further subsampling. Remaining sample was then recapped, sealed and refrigerated.

Each splitspoon sampling run was identified by a unique number, and each sample liner was labeled relative to its position within the splitspoon sampler. For boreholes S-2 and S-3, the bottom most (deepest) liner was designated as "A" and the top most (shallowest) liner designated as "D", in accordance with procedure PNL-MA-567, DO-2. Note, however, that the liners for borehole S-1 were labeled just opposite to this with "D" being the deepest sample liner and "A" being the shallowest. Each sample was labeled not only with the unique sample and liner number, but also with the borehole number, the depth interval, and the date of sample collection. [Last and Caldwell, 2001, pp. 1-4]

The procedures for determining hydraulic properties at the GEBJ Salinity Laboratory require $6 \mathrm{~cm}$ high, $5.6 \mathrm{~cm}$ O.D. (5.3 cm I.D.) samples that are smaller than the $7.6 \mathrm{~cm}$ Lexan liners from the splitspoon sampling. The smaller cores were obtained by sub-sampling the continuous splitspoon samples. To this end, we taped a $1 \mathrm{~cm}$ spacer ring to the top and bottom of a brass sampling ring using duct tape. A 2-kg hammer was subsequently used to ram the spacer-sampling ring assembly into the Lexan core liners (Fig. 1e). At times, several blows were necessary to insert the core ring below the top surface of the liners. We carefully extracted the spacer-sampling ring assembly (Fig. 1f) and removed the spacer ring (Fig. 1g.). 

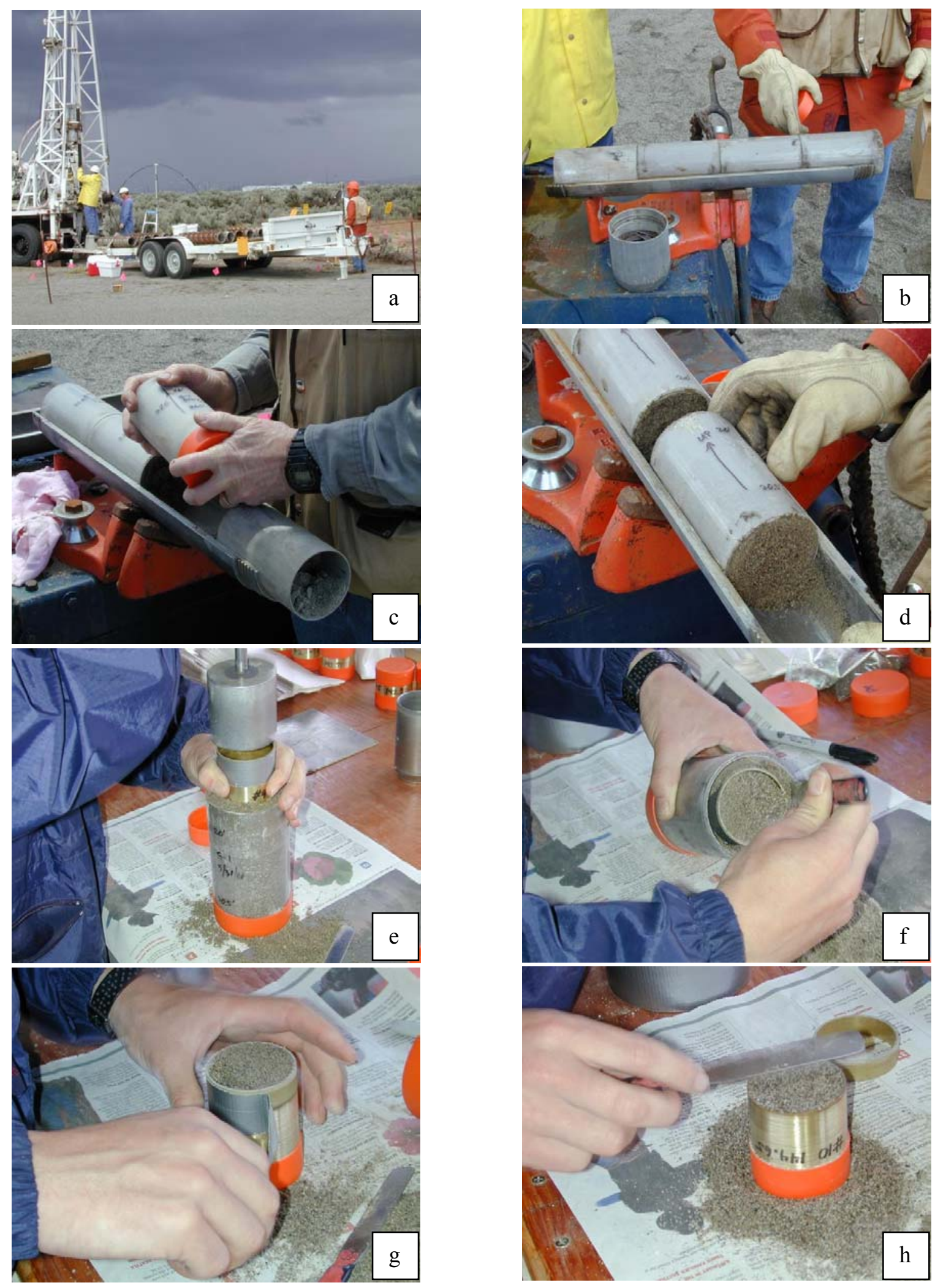

Figure 1. Splitspoon core sampling (a-d) and brass ring subsampling (e-h). Pictures taken by P.D. Meyer and G.W. Gee. 
The exposed material was then carefully removed with a knife such that the material in the ring had a level surface (Fig. 1h). Some loose samples were not obtained with this procedure. Instead we filled the brass core ring by hand from the loose material (mostly material from incompletely filled liners). A total of 60 samples were obtained, 33 for borehole S-1, 12 samples for S-2, and 15 for S-3. The brass rings were capped and stored for transport. The samples were taken as carry-on luggage for airplane transport to the GEBJ Salinity Lab (Riverside, CA). Additional material (about $200 \mathrm{~g} / \mathrm{sample}$ ) was put in ZipLock $^{\mathrm{TM}}$ bags and shipped by commercial courier. At the GEBJ Salinity Lab, the samples were stored in a dark, cold (5 C) storage room until the hydraulic measurements started.

The relative violence used in the coring process (drilling rig and sub-sampling) probably resulted in samples that did not completely preserve the natural structure of the parent material. We observed that finer material seemed to stick to the Lexan liner, whereas coarser material was located in the center of the cores. This may have been due to sorting caused by the hammer blows while retrieving the splitspoon samples (George Last, personal communication, May 31, 2000). Because we took the brass rings mainly from the center, there may thus be a bias towards coarser material. Sometimes the brass ring did not go in straight because a small pebble was blocking the insertion. During the sample insertion, we also observed that the material of several samples rose above the rim of the brass ring. We assume that the samples are semi-undisturbed at best. Because of confinement during the two coring processes we expect that the bulk density increased somewhat, though it is difficult to say by how much.

\subsection{Laboratory Procedures}

\subsubsection{Saturated Hydraulic Conductivity}

Saturated hydraulic conductivity $\left(K_{\mathrm{s}}\right)$ was determined with the constant head method (Reynolds et al. 2002), after the samples were used in the multi-step outflow method.

\subsubsection{Water Retention and Multi-Step Outflow Measurements}

At the GEBJ Salinity Lab the samples were stored in a cold storage room until the samples could be admitted to the multistep outflow setup. This setup consists of 22 pressure cells (Dane and Hopmans 2002) with each sample enclosed between two sample holders (Figure 2). The bottom sample holder contains a porous plate ( 1 bar high flow ceramics, Soil Moisture, Santa Barbara, CA) and is connected to a graduated cylinder with a pressure transducer to measure the water level. The sample holder at the top is connected to a pressure regulator that allows air pressures between zero and 1 bar to be applied. Control hardware and software take care of data registration. Figure 3 is a schematic of a single pressure cell.

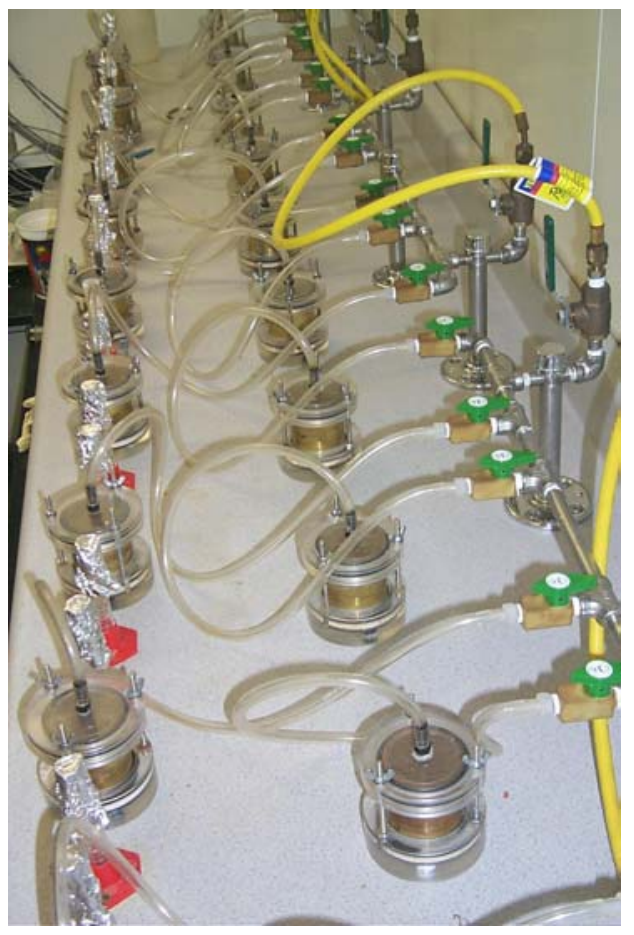

Figure 2. Overview of the pressure cell setup. 


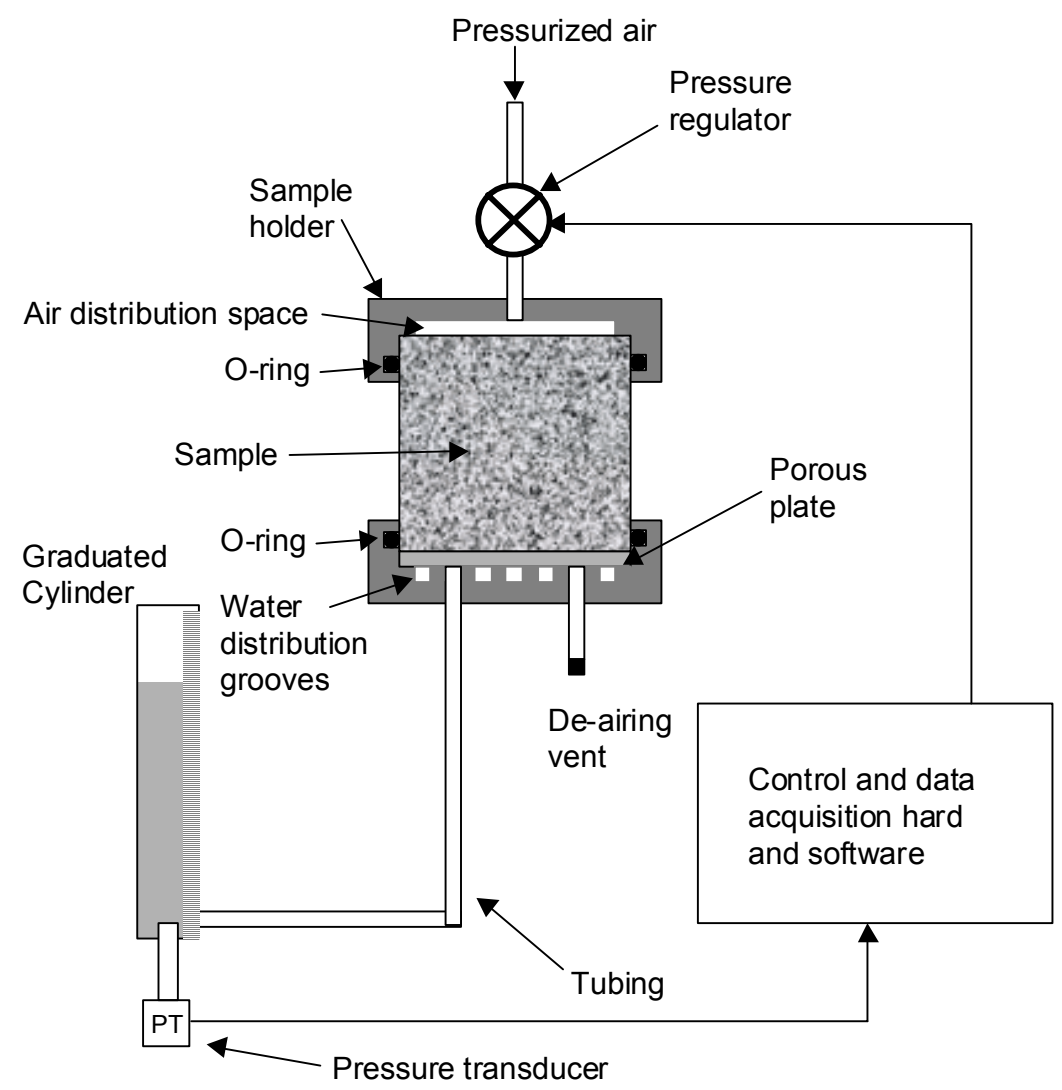

Figure 3. Schematic of the multi-step outflow measurement device.

The measurements start by saturating the sample, after which the air pressure is increased in periodic increments. Each pressure increase will drive water out of the sample, through the ceramic plate and into the burette where the time-series of the outflow volume is registered with a pressure transducer. Static equilibrium occurs when the outflow stops, leaving an opportunity to determine a water retention point. Subsequently, the air pressure is raised again until the maximum pressure is reached. We performed the measurements at $-12,-20,-30,-50,-100,-150,-220,-300,-330$, and $-460 \mathrm{~cm}$ of capillary pressure (approximate values). A typical outflow pattern, showing seven clearly visible pressure steps, is shown in Figure 4. The multi-step outflow method failed for seven samples (numbers 7, 25, 28, 29, 30, 37, 58), mainly because the coarseness of the material caused air leakage between the brass ring and the O-ring. Final water content was determined by drying the samples at $105 \mathrm{C}$. This measurement also yielded the dry bulk density of the samples. 


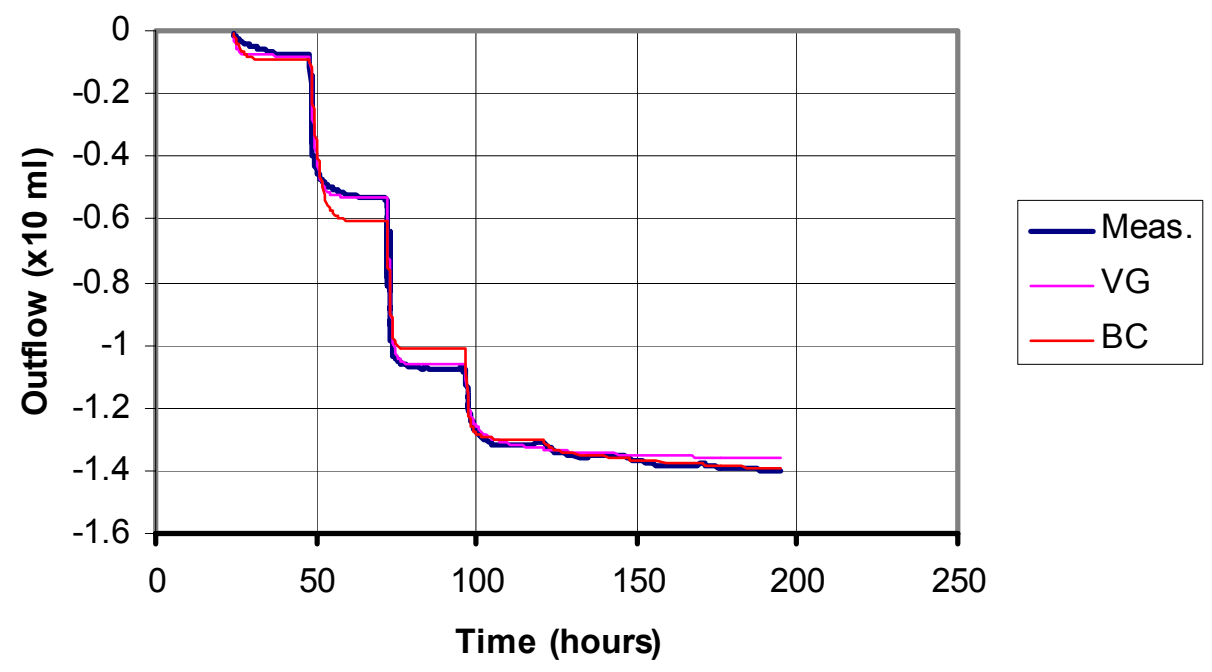

Figure 4. Typical time series example for the multi-step outflow method (blue line). The measurement starts at $\mathrm{t}=25$ hours. Also shown are inverse simulations based on the Mualem-Brooks-Corey (BC, red) and Mualem-van Genuchten (VG, pink) models.

In addition to the multi-step outflow method, separate disturbed samples of about ( $30 \mathrm{~g})$ were used to determine water retention points at $-330,-550,-730,-1000,-3000,-8000$, and $-15000 \mathrm{~cm}$ with a pressure apparatus (Dane and Hopmans 2002). Results for the $-330 \mathrm{~cm}$ pressure points of the pressure apparatus and the multi-step outflow were compared for consistency and the multi-step outflow determination was repeated if results diverged too much. For each sample, a total 15 or 16 static retention points were determined with the combined results of the multi-step outflow and the pressure apparatus. In addition, the time-series of outflow and the pressure apparatus data were used to inversely determine the unsaturated hydraulic conductivity and retention parameters.

\subsubsection{Direct Fit of the Retention Parameters to Static Retention Data}

The van Genuchten curve (VG, Eq.[1]) and the Brooks-Corey (BC, Eq. [3]) curve were fitted to the static water retention data using non-linear optimization software (MATLAB, Mathworks, Natick, MA). In order to arrive at realistic fitted parameters we applied the following constraints on the parameters: $\theta_{\mathrm{P}}>0, \theta_{\mathrm{s}}<=$ porosity, $0<\alpha<1,1<n<20$ (VG), and $0<\lambda<20$ (BC). The objective function that was minimized was

$$
\Phi(\mathbf{b}, \boldsymbol{\theta})=\sum_{\mathrm{i}=1}^{N_{\theta}}\left[\theta^{*}\left(h_{i}\right)-\theta\left(h_{i}, \mathbf{b}\right)\right]^{2}
$$

where $N_{\theta}$ is the number of static water retention measurements, $\theta^{*}\left(h_{i}\right)$ is the water content for measurement $i$ at a pressure head of $h_{i}, \theta\left(h_{i}, \boldsymbol{b}\right)$ is the water content estimate by the VG or the BC equation, and $\mathbf{b}$ is the parameter vector (consisting of $\theta_{r}, \theta_{s}, \alpha$, and $n$ or $\lambda$ ). 


\subsubsection{Inverse Determination of Unsaturated Hydraulic Parameters}

We used the observed time series of outflow to inversely determine the unsaturated hydraulic parameters $\theta_{r}, \theta_{s}, \alpha, n, L$, and $K_{0}$ using the HYDRUS-1D model (Šimůnek et al. 1998b). The governing equation for one-dimensional isothermal Darcian water flow in a variably saturated, rigid, isotropic porous medium is given by the Richards equation:

$$
\frac{\partial \theta}{\partial t}=\frac{\partial}{\partial z}\left[K\left(\frac{\partial h}{\partial z}+1\right)\right]
$$

where $z$ is the vertical coordinate positive upwards and $t$ is time. Equation [6] was solved numerically using the finite element method for a given set of initial and boundary equations, and using Eqs. [1] and [2] for the Mualem-van Genuchten formulation and Eqs. [3] and [4] for the Mualem-Brooks-Corey variant.

The objective function $\Phi$ to be minimized during the parameter estimation is defined as:

$$
\Phi(\mathbf{b}, \mathbf{q})=\sum_{i=1}^{N_{q}} w_{q, i}\left[q^{*}\left(z, t_{i}\right)-q\left(z, t_{i}, \mathbf{b}\right)\right]^{2}+\sum_{\mathrm{j}=1}^{N_{\theta}} w_{\theta, j}\left[\theta^{*}\left(h_{j}\right)-\theta\left(h_{j}, \mathbf{b}\right)\right]^{2}+w_{k}\left[K_{s}-K_{0}\right]^{2}
$$

where $N_{q}$ is the number of outflow measurements, $q^{*}\left(z, t_{i}\right)$ is a specific outflow measurement at time $t_{i}$ at location $z, q\left(z, t_{i}, \boldsymbol{b}\right)$ is the corresponding modeled outflow for the vector of optimized parameters $\boldsymbol{b}$ (e.g., $\theta_{r}, \theta_{s}, \alpha, n$ or $\left.\lambda, L, K_{0}\right)$, and $w_{q, i}, w_{\theta_{j},}$, and $w_{k}$ are weights associated with individual measurements of outflow, water content, and saturated hydraulic conductivity, respectively. Other terms in Equation 7 were defined previously. The measured static water retention points and the saturated hydraulic conductivity are taken into account with the second and third terms. The weights applied were $w_{q, i}=4 \quad \forall i$, $w_{\theta, j}=2 \forall j$, and $w_{k}=1.5 \forall k$. The parameter optimization scheme in HYDRUS-1D is based on Marquardt's (1963) method, which has proven to be very effective in many applications involving nonlinear least squares fitting.

In some cases when all six hydraulic parameters are optimized, the inverse solution is ill-posed and yields no acceptable solution. In such cases, we fixed some parameters to initial values that remained constant during the optimization. This was sometimes necessary for $\theta_{\mathrm{r}}$ and/or $\theta_{\mathrm{s}}$ as only the difference of these parameters will affect the measured outflow. Occasionally it was also necessary to fix $K_{0}$ at a reasonable value because the multi-step outflow data contained no near-saturated data (the first point is at $-12 \mathrm{~cm}$ pressure).

\subsubsection{Particle size distribution}

After determining the hydraulic properties we measured the particle-size distribution of the samples by wet-sieving (Gee and Or 2002) for weight fractions at sizes smaller than 2000, 1400, 1000, 700, 500, $355,250,180,147,105$, and $90 \mu \mathrm{m}$, and by sedimentation in water (Gee and Or 2002) with size 
boundaries approximately at $53,43,31,22,10,5,3$ and $1.5 \mu \mathrm{m}$. Due to low clay contents, the smallest particle sizes have a relatively high error ( $1.25 \%$ weight fraction). The gravel content was determined as the fraction that did not pass the $2000 \mu \mathrm{m}$ sieve. In most cases, the gravel size was just greater than 2000 $\mu \mathrm{m}$ but smaller than $5 \mathrm{~mm}$. The fraction boundaries below $90 \mu \mathrm{m}$ vary slightly from sample to sample as the time between readings determines the particle size. The 19 particle size fractions were summarized

into sand, silt and clay fractions. The silt boundary $(50 \mu \mathrm{m})$ was derived from the fractions at 53 and 43 $\mu \mathrm{m}$ boundaries by log-linear interpolation (i.e., the particle-size was log transformed before linear interpolation). 



\subsection{Results and Discussion}

\subsection{Field Data}

Appendix A provides a listing of the data gathered in the field. Section A.1 includes the ring number to identify the samples as well as the corresponding field designation so that the samples can be crossreferenced with the information in Last and Caldwell (2001). Also listed is the top and bottom depth of the Lexan liners from which the sub samples were taken and the approximate position of the sub sample in each liner (top, middle, or bottom). Sample personnel and some subjective field remarks are also listed in Section A.1. Sixty samples were taken with samples 46, 57, 58, 59 and 60 having partially missing field designations. Samples 1, 2, 4, 28, 29 through 33, 39, and 41 should be considered to be partially or completely disturbed.

\subsection{Particle Size Distributions, Bulk Density and Saturated Hydraulic Conductivity}

Figure 5 illustrates the textural classification of the 60 samples. As was already apparent in the field, the samples are all coarse textured. Most samples fall into the "Sand" textural class, 13 have Loamy Sand textures, and just two can be classified as Sandy Loams. The sand percentage is always greater than $72.5 \%$, clay percentages are always lower than $7.5 \%$, and silt percentages range between 6 and $22 \%$. Figure 6 shows the textural distributions of a Sand (sample 10, 98.5\% sand and $1.25 \%$ clay), Loamy Sand (sample 52, 85.2\% sand and 5.0\% clay), and a Sandy Loam (sample 41, 72.5\% sand and $4.9 \%$ clay). We note that the textural distribution of the Sand and Loamy Sand are similar for sizes greater than $500 \mu \mathrm{m}$, indicating that they have a similar content of coarse sand. The difference between the two classes becomes apparent at the sizes below $500 \mu \mathrm{m}$, with the Loamy Sand almost exhibiting a bi-modal particlesize distribution. The Sandy loam appears to have a more uniform particle-size distribution without a clearly dominating particle size. Gravel, sand, silt, and clay percentage data is listed in Appendix A, Section A.2. Detailed particle size distribution data is listed in Section A.3.

Section A.2 also shows that the bulk density ranges between 1.39 and $1.71 \mathrm{~g} / \mathrm{cm}^{3}$, with an arithmetic average value of $1.57 \mathrm{~g} / \mathrm{cm}^{3}$. Bulk density was not determined for seven of the 60 samples, mainly because the water retention curve was not determined because of repeated air-leakage in the Multi-Step outflow apparatus. Also shown in Appendix A.2 is the porosity, $\phi$, which is calculated as $\phi=1-\mathrm{BD} / 2.65$, where $\mathrm{BD}$ is the dry bulk density and 2.65 is the assumed density of the solid phase. The porosity ranges between 0.35 and $0.47 \mathrm{~cm}^{3} / \mathrm{cm}^{3} / \mathrm{cm}^{3}$, with an average value of $0.41 \mathrm{~cm}^{3} / \mathrm{cm}^{3}$. The bulk density and porosity are most likely affected by the coring and sub sampling of the samples. It is possible that the bulk density is higher (porosity lower) in the samples as compared to the in situ material. With the data present it is impossible to say how great this effect might be.

Section A. 2 shows that the saturated hydraulic conductivity of the samples ranges between 36 and $9100 \mathrm{~cm} /$ day. The saturated hydraulic conductivity clearly increases with the sand percentage, as shown in Figure 7. Likewise, $K_{\mathrm{s}}$ increases with porosity (Figure 8). Table 1 provides summary statistics (minimum, maximum, averages, and standard deviations) for the observed $K_{\mathrm{s}}$ values). A more elaborate 
statistical interpretation of the relations between textural, bulk density data, and hydraulic data is underway.

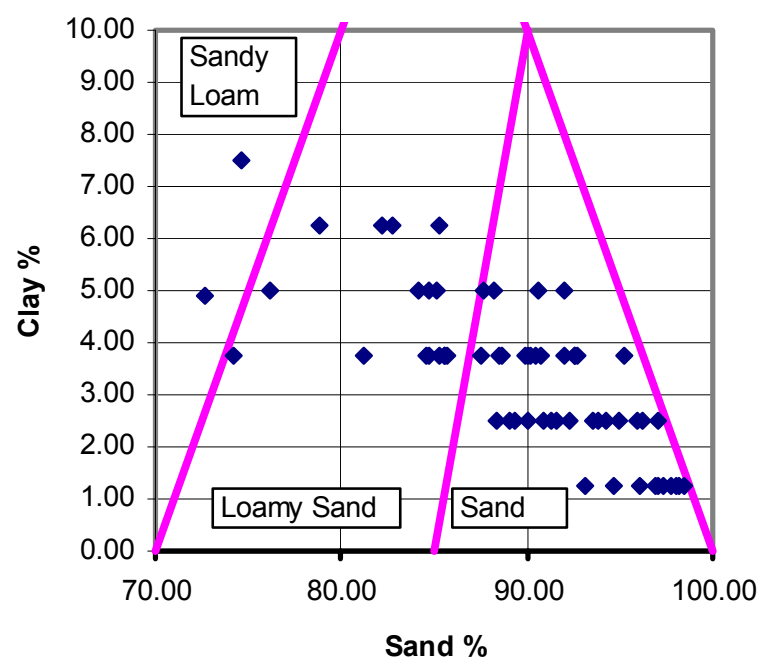

Figure 5. Textural classification of the samples. The lines indicate the boundaries between the sand, loamy sand, and sandy loam textural classes. For reasons of clarity, only a small part of the textural triangle is shown.

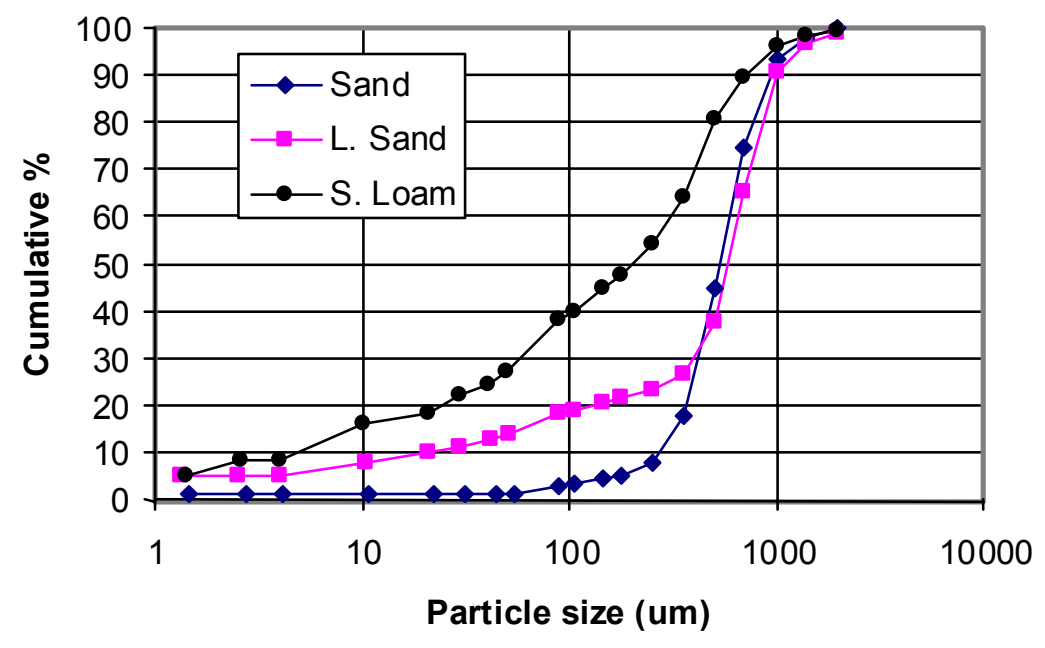

Figure 6. Textural distribution of a sand (sample 10), loamy sand (sample 52), and a sandy loam (Sample 41). The symbols indicate particle size class boundaries. 


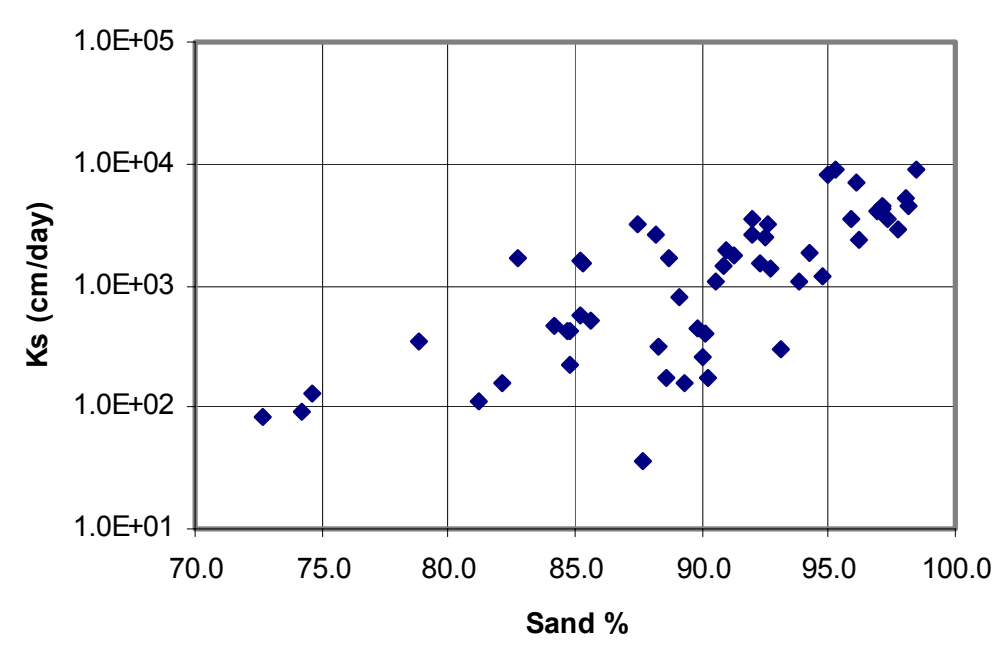

Figure 7. Saturated hydraulic conductivity versus sand percentage. Note the logarithmic vertical axis.

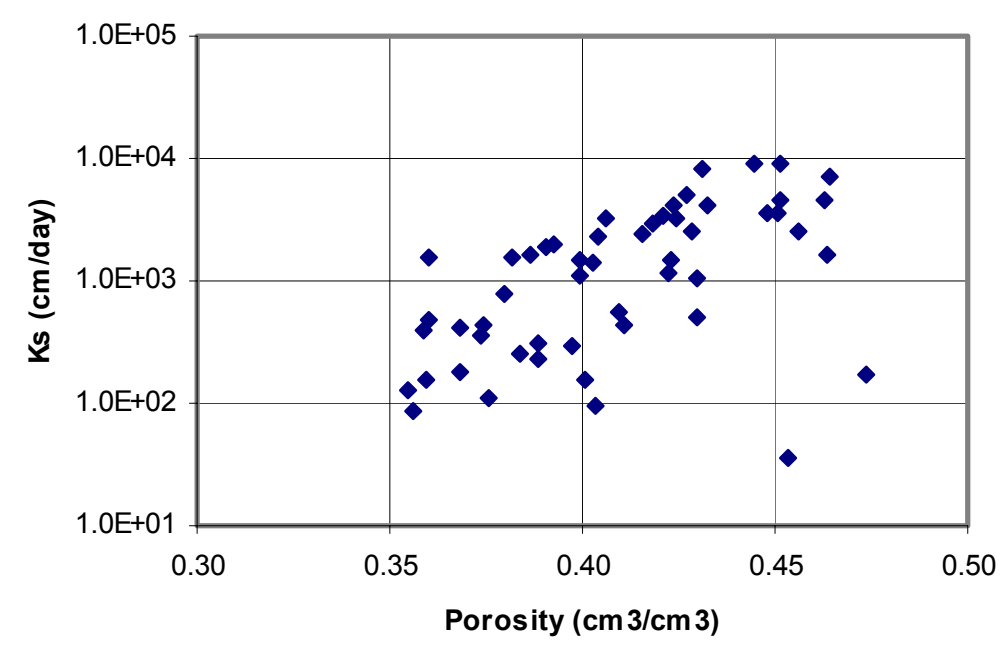

Figure 8. Saturated hydraulic conductivity versus porosity.

Note the logarithmic vertical axis.

\subsection{Unsaturated Hydraulic Parameters}

The water retention data is listed in Appendix A, Section A.4. Results for direct fits of the van Genuchten and Brooks-Corey equations to these data are listed in Sections A.5 and A.6, with summary statistics appearing in Table 1. Figures 9a through $9 \mathrm{~d}$ provide an overview in the ranges of individual 
parameters, as well as the similarity of equivalent VG and BC parameters. Figure 9e shows the range in root mean square errors (RMSE), defined here as:

$$
R M S E=\sqrt{\frac{\sum_{i}^{N}\left[\theta^{*}\left(h_{i}\right)-\theta\left(h_{i}, \mathbf{b}\right)\right]^{2}}{N-n_{p}}}
$$

where $\theta^{*}$ and $\theta$ are the observed and fitted water content, respectively, $h$ is the soil water pressure, and $\mathbf{b}$ is the parameter vector (consisting of $\theta_{r}, \theta_{s}, \alpha$, and $n$ or $\lambda$ ). The number of points $(N)$ is corrected with the number of parameters ( $n_{\mathrm{p}}$, equal to four).

Figure 9 shows that while the Brooks-Corey and van Genuchten parameters are reasonably correlated for $\theta_{\mathrm{r}}, \alpha, n$ or $\lambda$, no clear correlation is present for the $\theta_{\mathrm{s}}$ parameter. The lack of correlation is probably due to the fact that the first retention point is situated at approximately $12 \mathrm{~cm}$ suction, and further because of difficulties of fitting $\theta_{\mathrm{s}}$ for the Brooks-Corey equation due to the discontinuity at $1 / \alpha$ (see Eq. [3]). It also appears that the assumption $\lambda=n-1$ that is often made (e.g., Rawls and Brakensiek 1985; Carsel and Parrish 1988) appears valid for $\lambda<1$ (i.e. $n<2$, see Figure 9d). For larger values of $n$, the value for $\lambda$ is overestimated when this relation is used. The relationship between $\lambda$ and $n$ presented in Lenhard et al. (1989) is also shown in Figure 9d and appears to better represent the correlation between these parameters. Table 1 shows minimum, maximum, average value, and standard deviation of the estimated parameters and RMSE values. Alpha values for the Brooks-Corey Equation are, on average, lower than those of the van Genuchten fits, while the RMSE values for BC are also somewhat lower than the RMSE values for the $\mathrm{VG}$ equation.

Results of the inverse optimizations for the van Genuchten and Brooks-Corey parameters appear in Figures 10 and 11. Here, the inverse estimates of the parameters are plotted versus their counterparts from the direct fit to the static retention data. We note that parameter values were plotted even when they were not optimized (see Sections A.7 and A.8). For the van Genuchten parameters (Figure 10) there appears to be a reasonable correspondence between the inverse solution and the direct fit, although there is some scatter as well. However, the inverse solution for the $\alpha$ parameter appears to be generally lower than that of the direct fit as is also clear from Table 1 where the average value for $\alpha$ for the direct fit is $0.078 \mathrm{~cm}^{-1}$ versus $0.051 \mathrm{~cm}^{-1}$ for the inverse solution. Inverse solution $n$ values appear to be somewhat higher than the direct fit values. RMSE values appear in Figure 10e and Table 1; the values are, on average, approximately twice as large as the values for the direct fits to the static retention data. We note that RMSE values for the inverse solutions were not corrected for the (four) degrees of freedom because the inverse parameters were mainly optimized on outflow data. Table 1 also shows that inversely optimized $K_{0}$ values are more than one order of magnitude lower than the measured $K_{\mathrm{s}}$ values. This seemingly confirms findings by Schaap and Leij (2000) who found that $K_{0}<<K_{\mathrm{s}}$. However, we have to note that the inverse solutions were very insensitive to the actual value of $K_{0}$, mainly because the first reliable data point in the pressure cell outflow is at $-12 \mathrm{~cm}$ pressure. Results for $K_{0}$, although lower than $K_{\mathrm{s}}$, are probably not very reliable. Average values for $L$ are 0.5 , confirming Mualem (1976) but we also note that there is a wide range of variation (between -3.1 and 4.4 ). 
Similar graphs for the Brooks-Corey data show considerably more scatter, as can be seen in Figure 11. Our experience was that many of the inversions of the Mualem-Brooks-Corey equations were illposed problems and yielded unstable parameter values (i.e., different initializations gave widely varying inverse solutions). Many unsatisfying solutions were found for Brooks-Corey parameters, such as shown in Figure 4 for sample 2. This figure shows that the van Genuchten solution adequately matches the observed outflow pattern. The Brooks-Corey solution, however, provides a poor fit (especially during the period between 50 and 100 hours). The problems are mainly caused by the discontinuous shape of Eqs. [3] and [4] allowing many combinations of the Brooks-Corey parameters to fit the outflow data. We suggest that users treat the inverse solutions of the Brooks-Corey parameters with considerable suspicion. When possible we suggest using the direct fits of the Brooks-Corey parameters to the static retention data. 
Table 1. Minimum, maximum, average values and standard deviations of the hydraulic parameters or RMSE values. The first column lists the type of data being evaluated and the number of samples available. Abbreviations in the second column are $\min =$ minimum, $\max =$ maximum, avg=average, and $\mathrm{s}=$ standard deviation (corrected for one degree of freedom). RMSE values for the inverse $\mathrm{VG}$ and $\mathrm{BC}$ solutions were not corrected for the degrees of freedom. Results for $\mathrm{K}_{\mathrm{s}}$ and $\mathrm{K}_{0}$ are given for the appropriate data type (see text). For $\mathrm{n}$ or $\lambda$ and $\mathrm{K}_{\mathrm{s}}$ we also list results based on logarithmic (base 10) values of the parameters; the average and standard deviation of $\log \left(\mathrm{K}_{\mathrm{s}}\right)$ and $\log \left(\mathrm{K}_{0}\right)$ are based on the entire dataset and not on the average of $\mathrm{K}_{\mathrm{s}}$ or $\mathrm{K}_{0}$.

\begin{tabular}{|c|c|c|c|c|c|c|c|c|c|c|}
\hline & & $\begin{array}{c}\theta_{\mathrm{r}} \\
\mathrm{cm}^{3} / \mathrm{cm}^{3}\end{array}$ & $\begin{array}{c}\theta_{\mathrm{s}} \\
\mathrm{cm}^{3} / \mathrm{cm}^{3} \\
\end{array}$ & $\begin{array}{c}\alpha \\
1 / \mathrm{cm}\end{array}$ & $\begin{array}{c}n \text { or } \lambda \\
- \\
\end{array}$ & $\begin{array}{c}\log (n) \\
- \\
\end{array}$ & $\begin{array}{c}\text { RMSE } \\
\mathrm{cm}^{3} / \mathrm{cm}^{3}\end{array}$ & $\begin{array}{l}K_{\mathrm{s}} \text { or } K_{0} \\
\mathrm{~cm} / \text { day }\end{array}$ & $\log \left(K_{s}\right)$ & $\begin{array}{l}L \\
-\end{array}$ \\
\hline \multirow[t]{2}{*}{ Ks } & $\min$ & & & & & & & $3.55 \mathrm{E}+01$ & 1.550 & \\
\hline & $\max$ & & & & & & & $9.12 E+03$ & 3.960 & \\
\hline \multirow[t]{2}{*}{$N=54$} & avg & & & & & & & 2.07E+03 & 3.003 & \\
\hline & $\sigma$ & & & & & & & $2.28 E+03$ & 0.599 & \\
\hline \multirow[t]{2}{*}{ Fit VG } & $\min$ & 0.000 & 0.271 & 0.008 & 1.400 & 0.146 & 0.0021 & & & \\
\hline & $\max$ & 0.059 & 0.474 & 0.349 & 12.038 & 1.081 & 0.0173 & & & \\
\hline \multirow[t]{2}{*}{$N=53$} & avg & 0.033 & 0.364 & 0.078 & 2.693 & 0.371 & 0.0085 & & & \\
\hline & $\sigma$ & 0.012 & 0.050 & 0.064 & 1.810 & 0.208 & 0.0032 & & & \\
\hline \multirow{2}{*}{ Fit BC } & $\min$ & 0.000 & 0.188 & 0.012 & 0.359 & -0.445 & 0.0016 & & & \\
\hline & $\max$ & 0.058 & 0.474 & 0.239 & 2.690 & 0.430 & 0.0255 & & & \\
\hline \multirow[t]{2}{*}{$N=53$} & avg & 0.030 & 0.303 & 0.067 & 1.088 & -0.035 & 0.0078 & & & \\
\hline & $\sigma$ & 0.011 & 0.053 & 0.042 & 0.643 & 0.251 & 0.0040 & & & \\
\hline \multirow[t]{2}{*}{ Inv VG } & $\min$ & 0.001 & 0.267 & 0.008 & 1.513 & 0.180 & 0.005 & $1.11 \mathrm{E}+00$ & 0.190 & -3.144 \\
\hline & $\max$ & 0.077 & 0.435 & 0.127 & 8.776 & 0.943 & 0.133 & $4.06 \mathrm{E}+02$ & 2.609 & 4.353 \\
\hline \multirow[t]{2}{*}{$N=51$} & avg & 0.035 & 0.344 & 0.051 & 3.146 & 0.459 & 0.016 & $9.36 \mathrm{E}+01$ & 1.709 & 0.535 \\
\hline & $\sigma$ & 0.014 & 0.041 & 0.023 & 1.525 & 0.189 & 0.018 & $9.74 \mathrm{E}+01$ & 0.562 & 1.112 \\
\hline \multirow[t]{2}{*}{ Inv BC } & $\min$ & 0.001 & 0.250 & 0.010 & 0.125 & -0.904 & 0.005 & $1.21 \mathrm{E}+00$ & 0.083 & -3.152 \\
\hline & $\max$ & 0.050 & 0.400 & 0.252 & 3.494 & 0.543 & 0.093 & $3.80 E+02$ & 2.580 & 6.418 \\
\hline \multirow[t]{2}{*}{$N=51$} & avg & 0.024 & 0.319 & 0.070 & 1.300 & 0.015 & 0.016 & $9.21 E+01$ & 1.648 & 1.006 \\
\hline & $\sigma$ & 0.013 & 0.034 & 0.038 & 0.880 & 0.321 & 0.013 & $9.78 \mathrm{E}+01$ & 0.641 & 1.799 \\
\hline
\end{tabular}



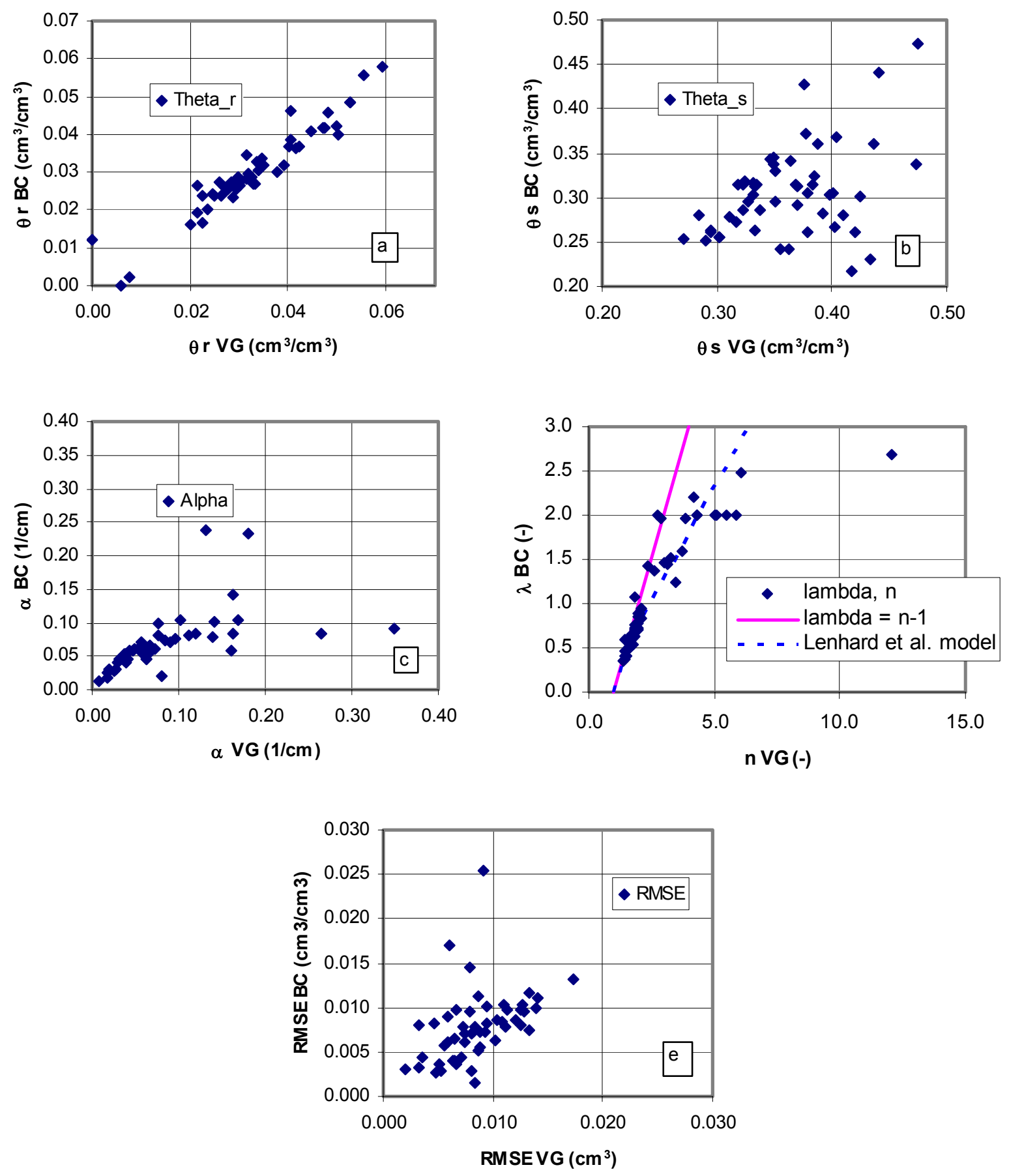

Figure 9. Distributions of the direct fits of Brooks-Corey parameters (vertical) to static retention data versus the distribution of the direct fits van Genuchten parameters (horizontal). Plot e shows root mean square residual errors (RMSE) of the BC fits versus RMSE of the VG fits. Plot d also contains the lines $\lambda=n-1$ and the $\lambda(n)$ relationship from Lenhard et al. (1989) (see text). 

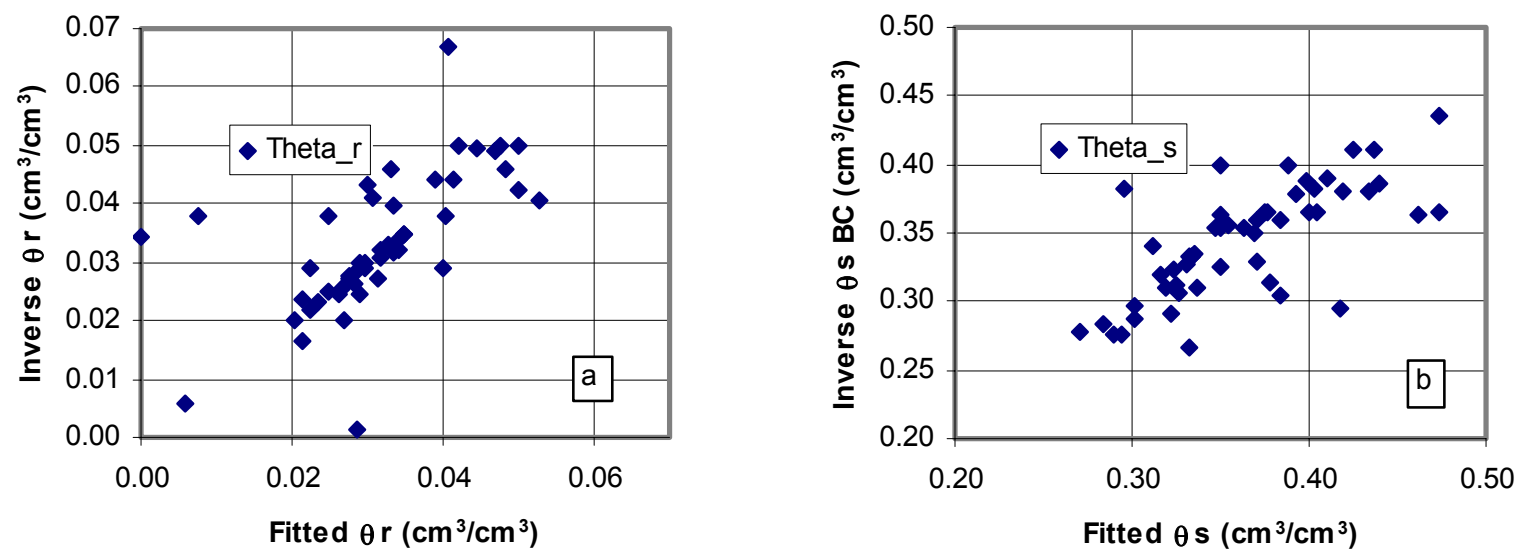

Fitted $\theta s\left(\mathrm{~cm}^{3} / \mathrm{cm}^{3}\right)$
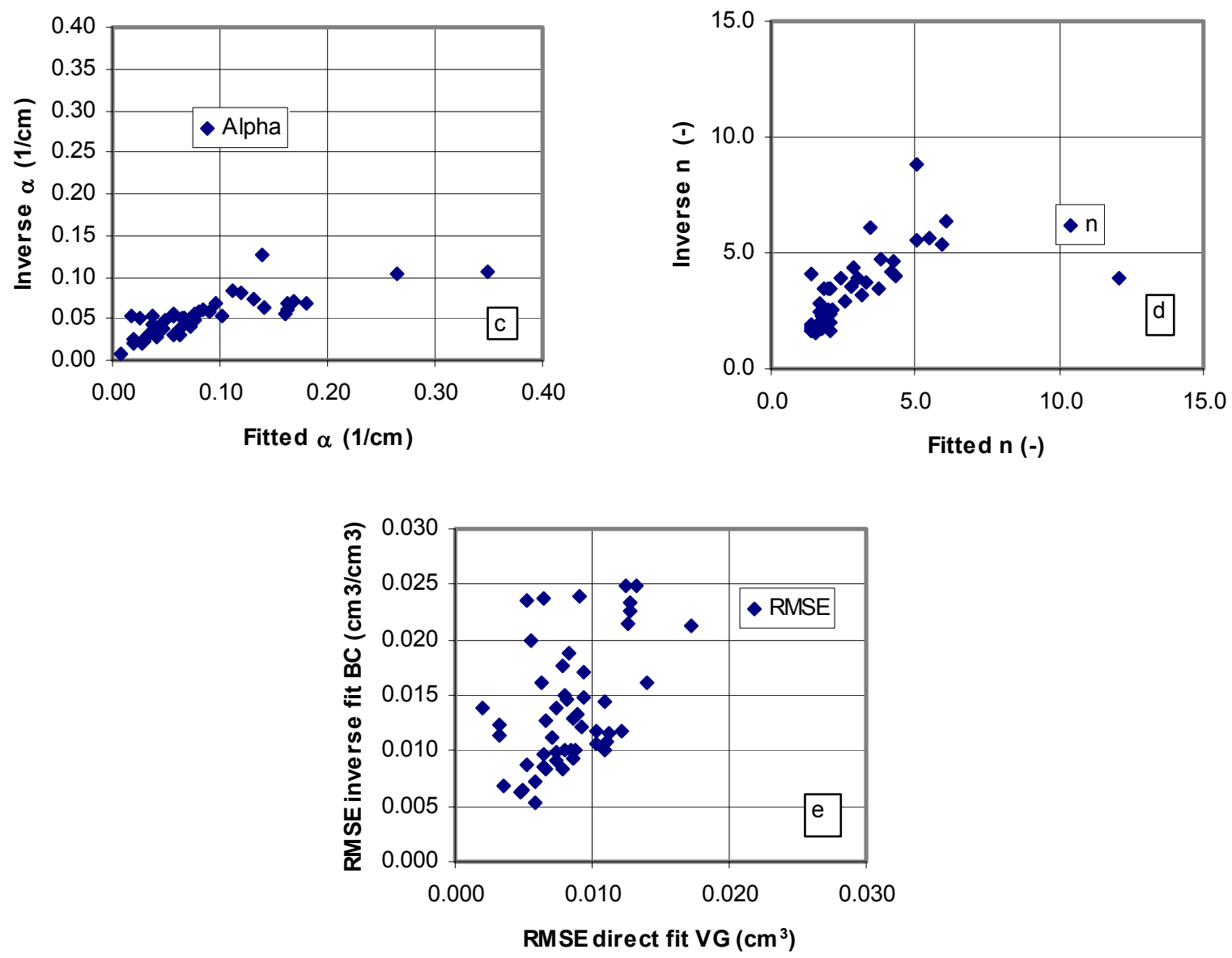

Figure 10. Distributions of the inverse optimizations of the van Genuchten parameters (vertical) versus direct fits to static retention data. (horizontal). Plot e shows root mean square residual errors (RMSE) of the inverse optimization versus RMSE of the direct fits 

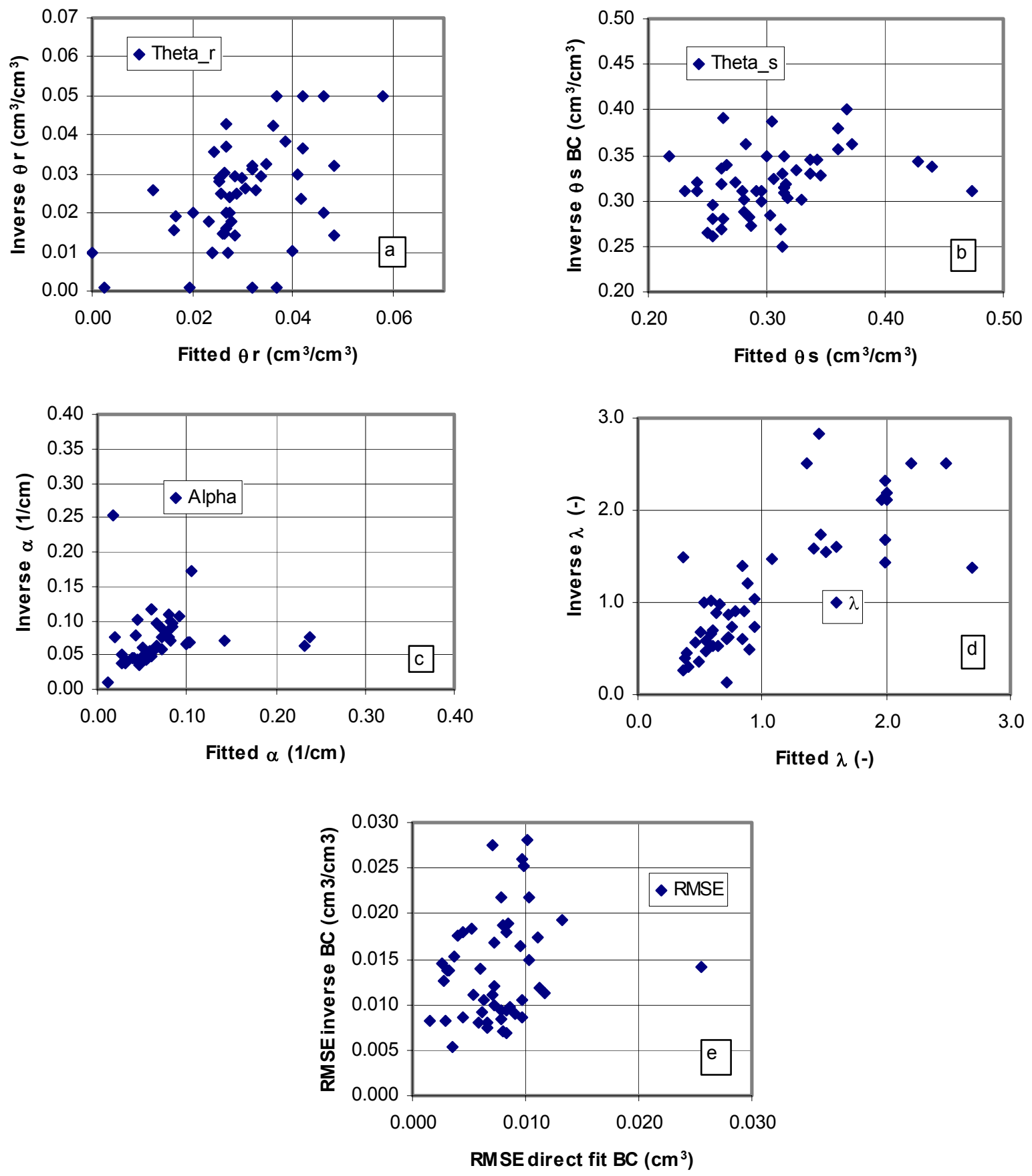

Figure 11. Distributions of the inverse optimizations of the Brooks-Corey parameters (vertical) versus direct fits to static retention data. (horizontal). Plot e shows root mean square residual errors (RMSE) of the inverse optimization versus RMSE of the direct fits. 



\subsection{Summary and Conclusions}

This report presents sampling and measurement procedures and measurement results for 60 samples from the S-1, S-2, and S-3 bore holes at the Vadose Zone Transport Field Study Leak Simulation Test Site, located at the Sisson and Lu (1984) injection site in the 200 East Area of the Hanford Site. Measured data and estimated parameters appear in the appendices and include particle size distributions (19 points), bulk densities (and bulk density-derived porosity), water retention characteristics (16 static points), and saturated and unsaturated hydraulic conductivity.

The coring and sub sampling procedures led to partially, and occasionally completely, disturbed samples. Textural analyses showed that most of the samples could be classified as sand, some as loamy sands, and two as sandy loams. The multi-step outflow method failed for seven samples, yielding 53 samples for which hydraulic parameters were available. Van Genuchten and Brooks-Corey water retention parameters were determined using static retention points (derived from multi-step outflow time series). Inverse analyses of the multi-step outflow data yielded additional unsaturated hydraulic conductivity parameters. Unfortunately, the inverse analyses had some problems in reaching stable solutions. Therefore, we sometimes fixed saturated and residual water contents and saturated hydraulic conductivities at initial values. Even then, it was not possible to reach a solution for two samples leaving the total number of samples for which inverse solutions were available at 51 . We also noticed that Brooks-Corey-type inversions were of lesser quality than van Genuchten inversions. We suggest that Brooks-Corey inversions be treated carefully and that, where possible, the far more reliable direct fits of the Brooks-Corey curve to the static retention data be used. 



\subsection{References}

Brooks, R.H., and A.T. Corey. 1964. "Hydraulic properties of porous media." Hydrol. Pap. 3, Colorado State University, Fort Collins.

Carsel, R.F., and R.S. Parrish. 1988. "Developing joint probability distributions of soil water retention characteristics." Water Resour. Res., 24:755-769.

Gee, G.W., and D. Or. 2002. "Particle-size analysis." in Dane, J.H. and G.C. Topp (eds.), Methods of Soil Analysis, Part 4, Physical methods, Soil Science Soc. Am., Inc., Madison, WI, pp. 255-293.

Dane, J.H. and G.C. Topp. 2002. Methods of Soil Analysis, Part 4, Physical methods. Soil Science Soc. Am., Inc., Madison, WI.

Last, G.V. and T.G. Caldwell. 2001. Core sampling in Support of the Vadose Zone Transport Field Study. $P N N L-13454$, Pacific Northwest National Laboratory, Richland, WA.

Lenhard, R. J., J. C. Parker, and S. Mishra. 1989. "On the correspondence between Brooks-Corey and van Genuchten models." J. Irrigation and Drainage Engineering, 115(4):744-751.

Marquardt, D. W. 1963. “An algorithm for least-squares estimation of nonlinear parameters." SIAMJ. Appl. Math., 11, 431-441.

Mualem, Y. 1976. "A new model for predicting the hydraulic conductivity of unsaturated porous media." Water Resour. Res., 12:513-522.

Reynolds, W.D., D.E. Elrick, E.G. Young, A. Amoozegar, H.W.G. Booltink, and J. Bouma. 2002. "Saturated and Field-saturated water flow parameters." in Dane, J.H. and G.C. Topp, Methods of Soil Analysis, Part 4, Physical methods, Soil Science Soc. Am., Inc., Madison, WI, pp. 797-878.

Rawls, W.J. and D.L. Brakensiek. 1985. "Prediction of soil water properties for hydrologic modeling." In Jones, E.B., and T.J. Ward (eds), Watershed management in the 80's, Proc. Irrig. Drain. Div., Am. Soc. Civ. Eng., New York, pp. 293-299.

Schaap, M.G. and F.J.Leij. 2000. "Improved prediction of unsaturated hydraulic conductivity with the Mualem-van Genuchten model.” Soil Sci. Soc. Am. J., 64:843-851.

Šimůnek, J., M. Th. van Genuchten, M. M. Gribb, and J. W. Hopmans. 1998. "Parameter estimation of unsaturated soil hydraulic properties from transient flow processes." Soil \& Tillage Research, 47/1-2, pp. 27-36.

Sisson, J.B. and A.H. Lu. 1984. Field calibration of computer models for applications to buried liquid discharges: a status report. Tech. Rep. RHO-ST-46-P, Rockwell Hanford Operations, Richland, WA. 
van Genuchten, M.Th.. 1980. "A closed-form equation for predicting the hydraulic conductivity of unsaturated soils.” Soil Sci. Soc. Am. J., 44:892-898. 


\title{
Appendix A
}

\author{
Data Tables
}





\section{Appendix A}

\section{Data Tables}

\section{A.1 Field Data}

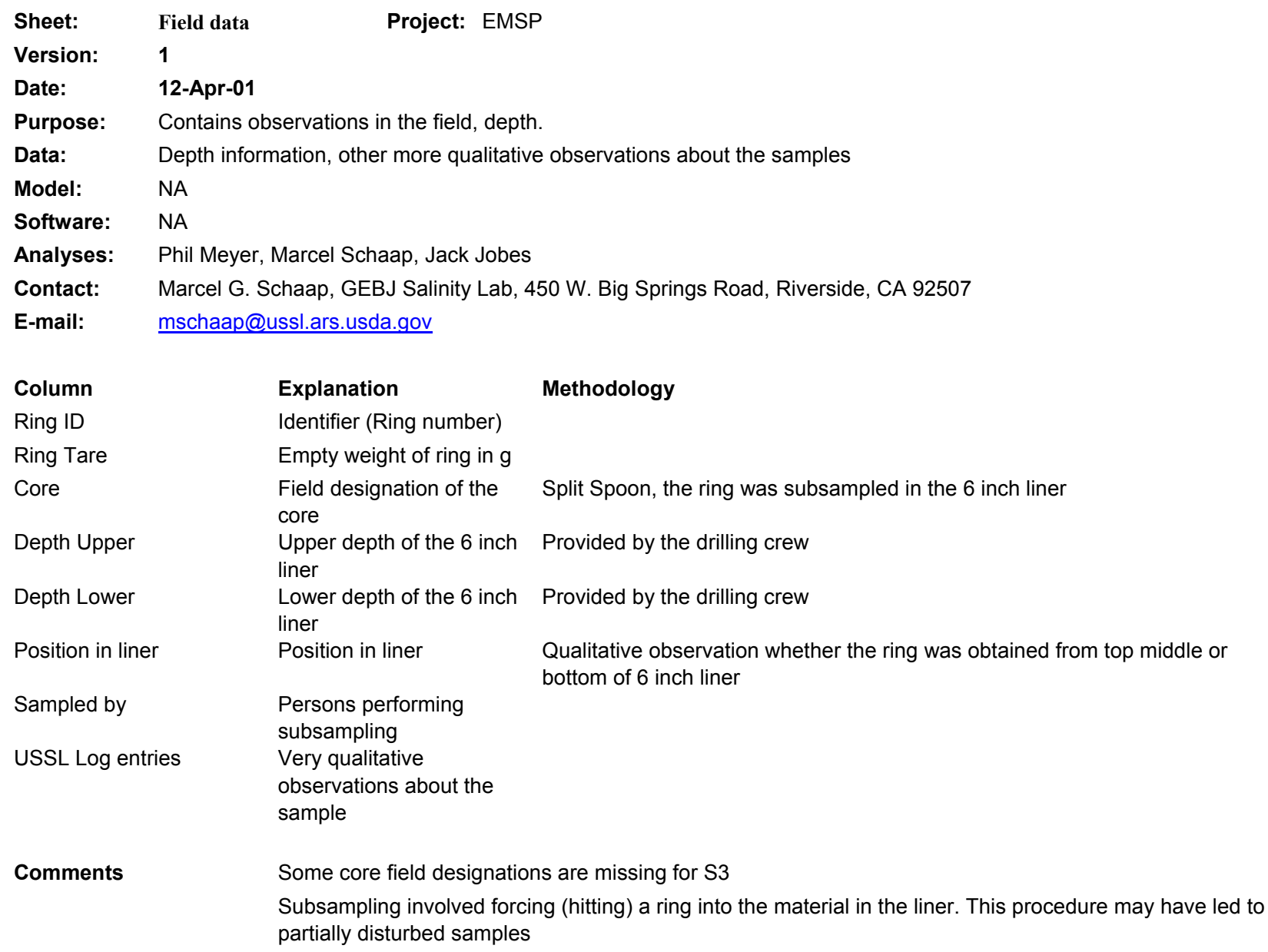

(continues on next page) 


\begin{tabular}{|c|c|c|c|c|c|c|c|}
\hline Ring ID & Ring Tare (g) & $\begin{array}{l}\text { liner field } \\
\text { designation }\end{array}$ & $\begin{array}{l}\text { liner } \\
\text { top }\end{array}$ & $\begin{array}{l}\text { liner } \\
\text { bottom }\end{array}$ & $\begin{array}{l}\text { Position in } \\
\text { liner } \\
t=\text { top } \\
\text { b=bottom } \\
\text { m=middle } \\
d=\text { disturbed }\end{array}$ & $\begin{array}{l}\text { Sampled by } \\
\text { PM: Phil Meyer } \\
\text { MS: Marcel Schaap } \\
\text { JJ: Jack Jobes }\end{array}$ & $\begin{array}{l}\text { USSL log entries (texture indication is } \\
\text { a subjective estimate) }\end{array}$ \\
\hline 1 & 146.6 & $S-1 / 24$ & 18 & 19 & d & PM\&MS & $\begin{array}{l}\text { Disturbed (ring filled by hand) contains } \\
\text { plant roots, medium coarse }\end{array}$ \\
\hline 2 & 147.08 & $S-1 / 25$ & 19 & 19.5 & $d$ & PM\&MS & $\begin{array}{l}\text { Disturbed (ring filled by hand) contains } \\
\text { plant roots, medium coarse/coarse }\end{array}$ \\
\hline 3 & 142.71 & $S-1 / 26 B$ & 19.5 & 20 & $\mathrm{t}$ & PM\&MS & undisturbed, wet, coarse sand \\
\hline 4 & 147.38 & $S-1 / 26 C$ & 20 & 20.5 & $\mathrm{t}$ & PM\&MS & $\begin{array}{l}\text { undisturbed/disturbed, wet, coarse } \\
\text { sand, subsample rose in the ring }\end{array}$ \\
\hline 5 & 142.71 & $S-1 / 26 D$ & 20.5 & 21 & $\mathrm{~b}$ & PM\&MS & undisturbed, wet, coarse sand \\
\hline 6 & 147.18 & S-1/27B & 21 & 21.5 & $\mathrm{t}$ & PM\&MS & undisturbed, wet, coarse sand \\
\hline 7 & 142.61 & $S-1 / 27 C$ & 21.5 & 22 & $\mathrm{t}$ & PM\&MS & undisturbed, wet, (medium) coarse sand \\
\hline 8 & 142.97 & S-1/27D & 22 & 22.5 & $\mathrm{~b}$ & PM\&MS & undisturbed, coarse sand/almost gravel \\
\hline 9 & 142.72 & $S-1 / 29$ & 23.5 & 25.5 & $d$ & PM\&MS & $\begin{array}{l}\text { Disturbed (ring filled by hand). Obtained } \\
\text { only a small amount of grab sample }\end{array}$ \\
\hline 10 & 144.65 & $S-1 / 32 B$ & 25.5 & 26 & $\mathrm{t}$ & PM\&MS & $\begin{array}{l}\text { undisturbed, coarse sand/almost gravel, } \\
\text { dry }\end{array}$ \\
\hline 11 & 146.43 & $\mathrm{~S}-1 / 32 \mathrm{C}$ & 26 & 26.5 & $\mathrm{t}$ & PM\&MS & undisturbed, coarse sand \\
\hline 12 & 146.87 & $S-1 / 34 B$ & 27.5 & 28 & $\mathrm{t}$ & PM\&MS & undisturbed, coarse sand \\
\hline 13 & 146.32 & $S-1 / 34 C$ & 28 & 28.5 & $\mathrm{t}$ & PM\&MS & $\begin{array}{l}\text { undisturbed, medium coarse/coarse } \\
\text { sand }\end{array}$ \\
\hline 14 & 146.59 & $S-1 / 34 D$ & 28.5 & 29 & $\mathrm{~m}$ & PM\&MS & $\begin{array}{l}\text { undisturbed, medium coarse/coarse } \\
\text { sand }\end{array}$ \\
\hline 15 & 146.32 & $S-1 / 36 B$ & 29.5 & 30 & $\mathrm{t}$ & PM\&MS & undisturbed, medium coarse sand \\
\hline 16 & 147.2 & $S-1 / 36 C$ & 30 & 30.5 & $\mathrm{t}$ & PM\&MS & undisturbed, medium coarse sand \\
\hline 17 & 144.99 & $S-1 / 36 D$ & 30.5 & 31 & $\mathrm{~m}$ & PM\&MS & undisturbed, medium coarse sand \\
\hline 18 & 145.35 & $\mathrm{~S}-1 / 38 \mathrm{~B}$ & 31.5 & 32 & $\mathrm{t}$ & PM\&MS & undisturbed, medium coarse sand \\
\hline 19 & 142.2 & $S-1 / 38 C$ & 32 & 32.5 & $\mathrm{t}$ & PM\&MS & undisturbed, medium coarse sand \\
\hline 20 & 146.92 & $S-1 / 38 D$ & 32.5 & 33 & $\mathrm{~m}$ & PM\&MS & $\begin{array}{l}\text { undisturbed, fine/medium coarse } \\
\text { sand/coarse sand (middle?, not on the } \\
\text { outside of the liner) }\end{array}$ \\
\hline 21 & 147.1 & $\mathrm{~S}-1 / 40 \mathrm{~B}$ & 33 & 33.5 & $\mathrm{~b}$ & PM\&MS & $\begin{array}{l}\text { undisturbed, coarse sand/almost gravel, } \\
\text { fine at bottom }\end{array}$ \\
\hline 22 & 146.6 & $S-1 / 40 C$ & 33.5 & 34 & $\mathrm{t}$ & PM\&MS & undisturbed, coarse sand(almost gravel) \\
\hline 23 & 146.06 & $S-1 / 40 D$ & 34 & 34.5 & $\mathrm{~m}$ & PM\&MS & undisturbed, coarse sand(almost gravel) \\
\hline 24 & 143.15 & $S-1 / 42 B$ & 35.5 & 36 & $\mathrm{t}$ & PM\&MS & undisturbed, coarse sand \\
\hline 25 & 147.25 & $S-1 / 42 C$ & 36 & 36.5 & $\mathrm{t}$ & PM\&MS & $\begin{array}{l}\text { undisturbed, coarse sand at top, fine at } \\
\text { bottom }\end{array}$ \\
\hline 26 & 146.91 & $S-1 / 42 D$ & 36.5 & 37 & $\mathrm{t}$ & PM\&MS & undisturbed, fine sand \\
\hline 27 & 146.32 & S-1/43C & 37 & 37.5 & $\mathrm{t}$ & PM\&MS & $\begin{array}{l}\text { undisturbed, fine sand at top, coarse at } \\
\text { bottom, wet }\end{array}$ \\
\hline 28 & 142.97 & S-1/42D & 36.5 & 37.5 & $\mathrm{~b}$ & PM\&MS & $\begin{array}{l}\text { extra subsample of } 26(\mathrm{~S}-1 / 42 \mathrm{D}) \\
\text { probably pretty disturbed. This is at the } \\
\text { bottom of the liner. NO GRAB SAMPLES }\end{array}$ \\
\hline 29 & 147.45 & $S-1 / 43 C$ & 36 & 36.5 & $\mathrm{~b}$ & PM\&MS & $\begin{array}{l}\text { extra subsample of } 25(\mathrm{~S}-1 / 42 \mathrm{C}) \text {, } \\
\text { probably pretty disturbed. This is at the } \\
\text { bottom of the liner. No real fine material. } \\
\text { NO GRAB SAMPLES }\end{array}$ \\
\hline 30 & 147.01 & S-1/43D & 37.5 & 38 & $\mathrm{~b}$ & PM\&MS & (un)disturbed, coarse sand \\
\hline 31 & 142.23 & S-1/45B & 38.5 & 39 & $\mathrm{t}$ & PM\&MS & (un)disturbed, fine sand at top, coarse at \\
\hline
\end{tabular}




\begin{tabular}{|c|c|c|c|c|}
\hline 32 & 145.39 & S-1/45C & 39 & 39.5 \\
\hline 33 & 146.99 & S-1/45D & 39.5 & 40 \\
\hline 34 & 147.23 & S-2/1B & 13.5 & 14 \\
\hline 35 & 146.82 & $\mathrm{~S}-2 / 5 \mathrm{C}$ & 17 & 17.5 \\
\hline 36 & 146.71 & $S-2 / 9 B$ & 21.5 & 22 \\
\hline 37 & 146.98 & S-2/11B & 23.5 & 24 \\
\hline 38 & 146.08 & $S-2 / 13 C$ & 22 & 22.5 \\
\hline 39 & 146.98 & S-2/15B & 27.5 & 28 \\
\hline 40 & 146.22 & S-2/19B & 31.5 & 32 \\
\hline 41 & 141.23 & $\mathrm{~S}-2 / 21 \mathrm{~B}$ & 33.5 & 34 \\
\hline 42 & 147.25 & S-2/23B & 35.5 & 36 \\
\hline 43 & 147.35 & $\mathrm{~S}-2 / 25 \mathrm{C}$ & 37 & 37.5 \\
\hline 44 & 146.93 & S-2/24B & 37.5 & 38 \\
\hline 45 & 147.18 & $\mathrm{~S}-2 / 30 \mathrm{C}$ & 52 & 52.5 \\
\hline 46 & 147.57 & S-3/NOID* & 16 & 16.5 \\
\hline 47 & 146.7 & S-3/3'C & 18 & 18.5 \\
\hline 48 & 146.97 & $S-3 / 8 C$ & 19.5 & 20 \\
\hline 49 & 147.25 & S-3/8B & 20 & 20.5 \\
\hline 50 & 145.45 & S-3/10B & 22 & 22.5 \\
\hline 51 & 146.95 & S-3/12C & 24 & 24.5 \\
\hline 52 & 147.09 & S-3/14C & 26 & 26.5 \\
\hline 53 & 146.94 & S-3/16B & 28.5 & 29 \\
\hline 54 & 146.85 & S-3/20C & 32.5 & 33 \\
\hline 55 & 147.07 & S-3/20B & 33 & 33.5 \\
\hline 56 & 141.78 & S-3/22C & 34.5 & 35 \\
\hline 57 & 148.5 & S-3/??C* & 36.5 & 37 \\
\hline 58 & 147.28 & S-3/??B* & 44 & 44.5 \\
\hline 59 & 146.93 & S-3/??C* & 47.5 & 48 \\
\hline 60 & 147.38 & S-3/??C* & 55 & 55.5 \\
\hline
\end{tabular}

PM\&MS

PM\&MS

PM\&JJ

PM\&JJ

PM\&JJ

PM\&JJ

PM\&JJ

PM\&JJ

PM\&JJ

PM\&JJ

PM\&JJ

PM\&JJ

PM\&JJ

PM\&JJ

PM\&JJ

PM\&JJ

PM\&JJ

PM\&JJ

PM\&JJ

PM\&JJ

PM\&JJ

PM\&JJ

PM\&JJ

PM\&JJ

PM\&JJ

PM\&JJ

PM\&JJ

PM\&JJ

PM\&JJ bottom, wet

(un)disturbed, coarse sand dry (un)disturbed, coarse sand dry undisturbed $0.9 \mathrm{~cm}$ high damp, loose undisturbed $0.9 \mathrm{~cm}$ high damp undisturbed $1.2 \mathrm{~cm}$ high wet semi solid undisturbed $1.5 \mathrm{~cm}$ high damp undisturbed $1.4 \mathrm{~cm}$ high damp disturbed finer cemented undisturbed $1.2 \mathrm{~cm}$ high semi undisturbed fine, cemented $0.6 \mathrm{~cm}$ high coarse dry level coarse loose damp level coarse damp $0.3 \mathrm{~cm}$ very dry loose $0.8 \mathrm{~cm}$ damp loose $0.9 \mathrm{~cm}$ damp loose $0.4 \mathrm{~cm}$ fines \& sand damp $0.6 \mathrm{~cm}$ damp coarse damp coarse $1.1 \mathrm{~cm}$ damp fine cemented damp medium fine sand $1.3 \mathrm{~cm}$ high damp loose $0.5 \mathrm{~cm}$ high some silt, damp loose $1.1 \mathrm{~cm}$ high damp loose some silt $0.9 \mathrm{~cm}$ wet silt, compacted $0.7 \mathrm{~cm}$ damp silt sand $0.6 \mathrm{~cm}$ dry loose average sand level very dry loose level damp loose sand

ID 


\section{A.2 Basic Sample Data}

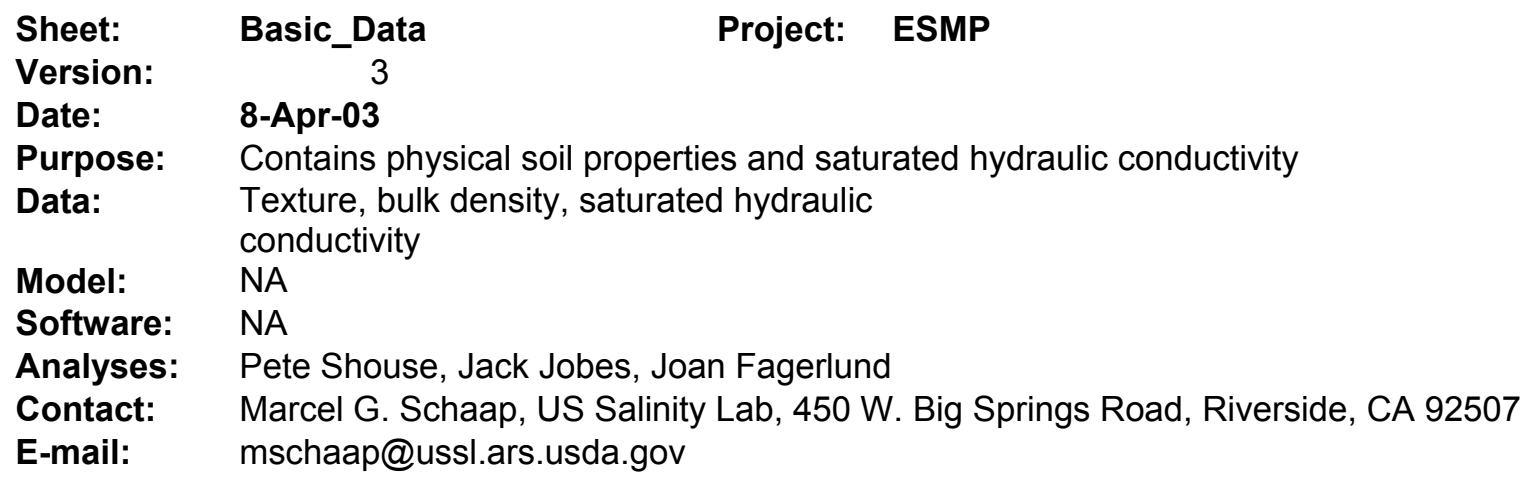

Column

ID

Gravel

Sand

Silt

Clay

BD

Porosity

Ks

Log Ks

Comments

\section{Explanation}

Identifier (Ring number)

Gravel percentage

Sand content (weight \%)

Silt content (weight \%)

Clay content (weight \%)

Bulk density $(\mathrm{g} / \mathrm{cm} 3)$

Calculated pore volume $(\mathrm{cm} 3 / \mathrm{cm} 3)$

Saturated conductivity

(cm/day)

Logarithm (base 10) of Ks

Missing data are left blank

\section{Methodology}

Wet sieving until 90 microns, sedimentation for sizes smaller than 90 microns

Based on core, weighing and drying.

Based on $\mathrm{BD}$; porosity $=1-\mathrm{BD} / 2.65$

Constant Head

(continued on next page) 
Gravel Weight \%

Sand Weight \%

Silt

Weight \%

Clay

Weight \%

4.36

1.95

1.47

0.33

0.25

0.18

0.32

0.14

0.77

0.27

0.63

1.37

0.74

0.40

0.38

0.59

0.17

0.54

0.21

0.00

3.80

0.94

1.28

0.43

0.43

0.28

0.15

3.22

1.72

2.00

0.14

0.41

0.00

0.00

1.69

1.21

4.46

1.18

2.46

0.07

0.54

0.73

0.31

1.14

0.84

0.78

$\begin{array}{rr}81.24 & 10.66 \\ 94.74 & 2.06 \\ 88.33 & 7.70 \\ 93.83 & 3.34 \\ 97.71 & 0.79 \\ 92.32 & 5.00 \\ 91.30 & 5.88 \\ 84.76 & 11.35 \\ 88.67 & 6.81 \\ 98.48 & 0.00 \\ 98.12 & 0.00 \\ 96.13 & 1.25 \\ 98.01 & 0.00 \\ 97.10 & 1.25 \\ 89.07 & 8.06 \\ 96.91 & 1.25 \\ 97.33 & 1.25 \\ 88.55 & 7.16 \\ 93.16 & 5.38 \\ 90.21 & 6.04 \\ 90.10 & 3.60 \\ 94.27 & 2.30 \\ 96.22 & 0.00 \\ 89.85 & 5.97 \\ 93.54 & 3.53 \\ 74.23 & 21.75 \\ 90.02 & 6.08 \\ 76.11 & 15.67 \\ 85.77 & 8.76 \\ 85.49 & 8.76 \\ 82.15 & 11.46 \\ 97.09 & 0.00 \\ 95.24 & 1.01 \\ 92.67 & 3.58 \\ 90.81 & 3.75 \\ 85.29 & 7.25 \\ 90.54 & 1.25 \\ 82.70 & 9.87 \\ 78.89 & 12.41 \\ 88.17 & 6.76 \\ 72.65 & 21.93 \\ 87.51 & 8.01 \\ 85.25 & 10.69 \\ 89.36 & 7.00 \\ 85.61 & 9.80 \\ 91.96 & 2.26\end{array}$

3.75
1.25
2.50
2.50
1.25
2.50
2.50
3.75
3.75
1.25
1.25
1.25
1.25
1.25
2.50
1.25
1.25
3.75
1.25
3.75
2.50
2.50
2.50
3.75
2.50
3.75
3.75
5.00
3.75
3.75
6.25
2.50
3.75
3.75
3.75
6.25
3.75
6.25
6.25
5.00
4.88
3.75
3.75
2.50
3.75
5.00

BD

Weight \%

1.654

1.532

1.620

1.590

1.540

1.590

1.621

1.420

1.454

1.420

1.420

1.520

1.450

1.645

1.500

1.456

1.674

1.597

1.394

1.700

1.615

1.580

1.658

1.581

1.633

1.700
1.527
1.472
1.582
1.529
1.638
1.630
1.660
1.440
1.710
1.570
1.564
1.590
1.520
1.534
Porosity Ks cm $3 / \mathrm{cm} 3 \mathrm{~cm} /$ day

$\begin{array}{lll}0.376 & 1.125 \mathrm{E}+02 & 2.051 \\ 0.422 & 1.187 \mathrm{E}+03 & 3.074 \\ 0.389 & 3.067 \mathrm{E}+02 & 2.487 \\ 0.400 & 1.084 \mathrm{E}+03 & 3.035 \\ 0.418 & 2.880 \mathrm{E}+03 & 3.459 \\ 0.399 & 1.512 \mathrm{E}+03 & 3.180 \\ & 1.757 \mathrm{E}+03 & 3.245 \\ 0.388 & 2.254 \mathrm{E}+02 & 2.353 \\ 0.464 & 1.670 \mathrm{E}+03 & 3.223 \\ 0.452 & 9.122 \mathrm{E}+03 & 3.960 \\ 0.463 & 4.514 \mathrm{E}+03 & 3.655 \\ 0.464 & 7.006 \mathrm{E}+03 & 3.845 \\ 0.427 & 5.105 \mathrm{E}+03 & 3.708 \\ 0.452 & 4.565 \mathrm{E}+03 & 3.659 \\ 0.379 & 7.942 \mathrm{E}+02 & 2.900 \\ 0.433 & 4.140 \mathrm{E}+03 & 3.617 \\ 0.451 & 3.557 \mathrm{E}+03 & 3.551 \\ 0.369 & 1.757 \mathrm{E}+02 & 2.245 \\ 0.397 & 3.000 \mathrm{E}+02 & 2.477 \\ 0.474 & 1.699 \mathrm{E}+02 & 2.230 \\ 0.359 & 3.924 \mathrm{E}+02 & 2.594 \\ 0.391 & 1.886 \mathrm{E}+03 & 3.276 \\ 0.404 & 2.354 \mathrm{E}+03 & 3.372 \\ 0.374 & 4.385 \mathrm{E}+02 & 2.642 \\ & & \\ 0.403 & 9.360 \mathrm{E}+01 & 1.971 \\ 0.384 & 2.556 \mathrm{E}+02 & 2.408\end{array}$

0.360

$1.591 \mathrm{E}+02$

2.202

$0.424 \quad 4.212 \mathrm{E}+03$

3.624

0.445

$8.971 \mathrm{E}+03$

3.953

$0.403 \quad 1.395 \mathrm{E}+03$

3.144

0.423

$1.445 \mathrm{E}+03$

3.160

$0.382 \quad 1.519 \mathrm{E}+03$

3.182

$0.386 \quad 1.670 \mathrm{E}+03 \quad 3.223$

$0.374 \quad 3.528 \mathrm{E}+02 \quad 2.548$

$0.456 \quad 2.599 \mathrm{E}+03 \quad 3.415$

$0.356 \quad 8.448 \mathrm{E}+01 \quad 1.927$

$0.406 \quad 3.233 \mathrm{E}+03 \quad 3.510$

$0.410 \quad 5.609 \mathrm{E}+02 \quad 2.749$

$0.401 \quad 1.584 \mathrm{E}+02 \quad 2.200$

$0.430 \quad 5.076 \mathrm{E}+02 \quad 2.706$

$0.421 \quad 3.485 E+03 \quad 3.542$ 


$\begin{array}{llrrrrrrr}47 & 1.92 & 90.58 & 2.50 & 5.00 & 1.512 & 0.430 & 1.061 \mathrm{E}+03 & 3.026 \\ 48 & 2.99 & 92.01 & 1.25 & 3.75 & 1.514 & 0.429 & 2.570 \mathrm{E}+03 & 3.410 \\ 49 & 1.79 & 90.95 & 4.76 & 2.50 & 1.610 & 0.392 & 1.966 \mathrm{E}+03 & 3.293 \\ 50 & 0.08 & 94.93 & 2.50 & 2.50 & 1.510 & 0.431 & 8.179 \mathrm{E}+03 & 3.913 \\ 51 & 0.96 & 84.19 & 9.86 & 5.00 & 1.696 & 0.360 & 4.709 \mathrm{E}+02 & 2.673 \\ 52 & 1.23 & 85.19 & 8.59 & 5.00 & 1.695 & 0.360 & 1.563 \mathrm{E}+03 & 3.194 \\ 53 & 0.35 & 95.90 & 1.25 & 2.50 & 1.464 & 0.448 & 3.514 \mathrm{E}+03 & 3.546 \\ 54 & 0.37 & 84.78 & 9.86 & 5.00 & 1.561 & 0.411 & 4.291 \mathrm{E}+02 & 2.633 \\ 55 & 0.00 & 87.68 & 7.32 & 5.00 & 1.450 & 0.453 & 3.552 \mathrm{E}+01 & 1.550 \\ 56 & 0.61 & 84.65 & 11.00 & 3.75 & 1.674 & 0.368 & 4.234 \mathrm{E}+02 & 2.627 \\ 57 & 0.56 & 74.64 & 17.31 & 7.50 & 1.711 & 0.354 & 1.282 \mathrm{E}+02 & 2.108 \\ 58 & 2.23 & 91.52 & 3.75 & 2.50 & & & & \\ 59 & 0.19 & 92.62 & 3.43 & 3.75 & 1.526 & 0.424 & 3.254 \mathrm{E}+03 & 3.512 \\ 60 & 0.00 & 92.50 & 3.75 & 3.75 & 1.550 & 0.415 & 2.441 \mathrm{E}+03 & 3.388 \\ & & & & & & & & \\ & & & & & & & & \\ \text { Min } & 0.00 & 72.65 & 0.00 & 1.25 & 1.394 & 0.354 & 3.552 \mathrm{E}+01 & 1.550 \\ \text { Max } & 4.46 & 98.48 & 21.93 & 7.50 & 1.711 & 0.474 & 9.122 \mathrm{E}+03 & 3.960 \\ \text { Average } & 0.98 & 89.49 & 6.10 & 3.44 & 1.566 & 0.409 & 2.074 \mathrm{E}+03 & 3.003 \\ \text { Stddev } & 1.07 & 6.23 & 5.04 & 1.50 & 0.088 & 0.033 & 2.276 \mathrm{E}+03 & 0.599\end{array}$




\section{A.3 Particle Size Distribution Data}

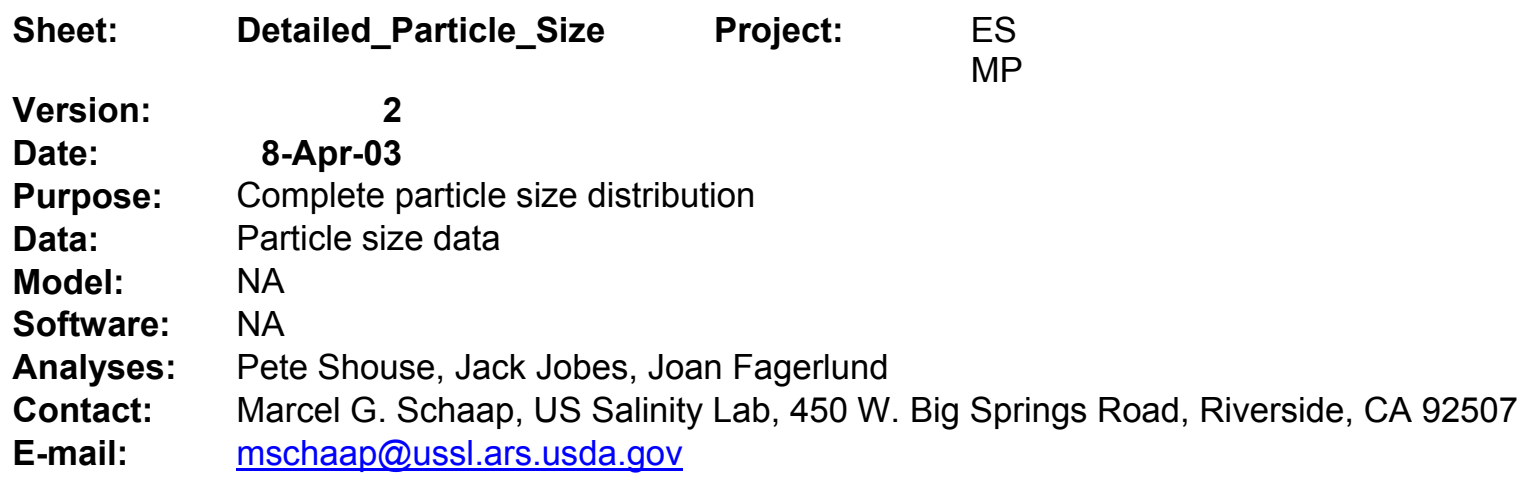

Column

ID

Npoints

Psize

Frac

\section{Explanation}

Identifier (Ring number)

Number of particle points

19 columns with particle size points

19 columns with percentages scaled to $100 \%$-Gravel\%

Percentage indicates relative amount smaller than the indicated size

\section{Methodology}

Wet sieving for sizes larger than 90 microns, sedimentation for the smaller fractions

Note: gravel content represents the large 'sand' particles that didn't pass through the 2000 micron sieve Most gravel particles seemed smaller than 3000 micron.

Small particle sizes have relatively large measurement uncertainty because of low clay content

(continued on next page) 


\begin{tabular}{|c|c|c|c|c|c|c|c|c|}
\hline ID & 1 & 2 & 3 & 4 & 5 & 6 & 7 & 8 \\
\hline Npoints & 19 & 19 & 19 & 19 & 19 & 19 & 19 & 19 \\
\hline Psize & 2000 & 2000 & 2000 & 2000 & 2000 & 2000 & 2000 & 2000 \\
\hline Psize & 1400 & 1400 & 1400 & 1400 & 1400 & 1400 & 1400 & 1400 \\
\hline Psize & 1000 & 1000 & 1000 & 1000 & 1000 & 1000 & 1000 & 1000 \\
\hline Psize & 700 & 700 & 700 & 700 & 700 & 700 & 700 & 700 \\
\hline Psize & 500 & 500 & 500 & 500 & 500 & 500 & 500 & 500 \\
\hline Psize & 355 & 355 & 355 & 355 & 355 & 355 & 355 & 355 \\
\hline Psize & 250 & 250 & 250 & 250 & 250 & 250 & 250 & 250 \\
\hline Psize & 180 & 180 & 180 & 180 & 180 & 180 & 180 & 180 \\
\hline Psize & 147 & 147 & 147 & 147 & 147 & 147 & 147 & 147 \\
\hline Psize & 105 & 105 & 105 & 105 & 105 & 105 & 105 & 105 \\
\hline Psize & 90 & 90 & 90 & 90 & 90 & 90 & 90 & 90 \\
\hline Psize & 52.40 & 53.64 & 52.82 & 53.37 & 53.78 & 53.23 & 53.09 & 52.26 \\
\hline Psize & 43.01 & 43.91 & 43.46 & 43.69 & 44.02 & 43.46 & 43.46 & 43.12 \\
\hline Psize & 30.57 & 31.05 & 30.97 & 31.05 & 31.13 & 30.81 & 30.81 & 30.81 \\
\hline Psize & 21.73 & 21.96 & 21.96 & 21.96 & 22.01 & 21.84 & 21.79 & 21.84 \\
\hline Psize & 10.30 & 10.57 & 10.76 & 10.76 & 10.64 & 9.88 & 10.70 & 10.70 \\
\hline Psize & 4.26 & 4.19 & 3.91 & 4.06 & 4.24 & 4.42 & 3.99 & 4.01 \\
\hline Psize & 2.66 & 2.66 & 2.76 & 2.80 & 2.86 & 2.66 & 2.63 & 2.67 \\
\hline Psize & 1.41 & 1.43 & 1.42 & 1.43 & 1.43 & 1.43 & 1.43 & 1.43 \\
\hline Frac & 95.64 & 98.05 & 98.53 & 99.67 & 99.75 & 99.82 & 99.68 & 99.86 \\
\hline Frac & 92.46 & 96.40 & 90.76 & 94.61 & 98.96 & 94.63 & 97.45 & 98.42 \\
\hline Frac & 88.96 & 92.62 & 75.00 & 82.34 & 96.81 & 79.80 & 91.24 & 92.56 \\
\hline Frac & 78.95 & 80.71 & 48.07 & 45.43 & 88.52 & 44.73 & 67.57 & 65.66 \\
\hline Frac & 64.38 & 61.98 & 33.07 & 25.33 & 69.45 & 29.45 & 41.48 & 41.74 \\
\hline Frac & 47.98 & 36.61 & 27.96 & 18.08 & 38.33 & 22.63 & 28.97 & 33.90 \\
\hline Frac & 38.01 & 21.83 & 26.33 & 15.68 & 20.41 & 19.53 & 23.94 & 32.30 \\
\hline Frac & 33.36 & 15.75 & 25.45 & 14.42 & 12.27 & 17.61 & 21.33 & 31.45 \\
\hline Frac & 31.03 & 13.93 & 24.90 & 13.87 & 9.66 & 16.69 & 20.01 & 31.06 \\
\hline Frac & 26.99 & 11.85 & 23.72 & 12.79 & 6.64 & 14.94 & 17.69 & 30.21 \\
\hline Frac & 25.55 & 11.33 & 23.13 & 12.45 & 6.07 & 14.42 & 16.92 & 29.70 \\
\hline Frac & 15 & 3.75 & 11.25 & 6.25 & 2.5 & 7.5 & 8.75 & 16.25 \\
\hline Frac & 12.5 & 2.5 & 7.5 & 5 & 1.25 & 7.5 & 7.5 & 11.25 \\
\hline Frac & 10 & 2.5 & 3.75 & 2.5 & 1.25 & 6.25 & 6.25 & 6.25 \\
\hline Frac & 7.5 & 2.5 & 2.5 & 2.5 & 1.25 & 5 & 6.25 & 5 \\
\hline Frac & 5 & 1.25 & 2.5 & 2.5 & 1.25 & 2.5 & 5 & 5 \\
\hline Frac & 5 & 1.25 & 2.5 & 2.5 & 1.25 & 2.5 & 3.75 & 5 \\
\hline Frac & 3.75 & 1.25 & 2.5 & 2.5 & 1.25 & 2.5 & 2.5 & 3.75 \\
\hline Frac & 3.75 & 1.25 & 2.5 & 2.5 & 1.25 & 2.5 & 2.5 & 3.75 \\
\hline
\end{tabular}




\begin{tabular}{|c|c|c|c|c|c|c|c|c|}
\hline 9 & 10 & 11 & 12 & 13 & 14 & 15 & 16 & 17 \\
\hline 19 & 19 & 19 & 19 & 19 & 19 & 19 & 19 & 19 \\
\hline 2000 & 2000 & 2000 & 2000 & 2000 & 2000 & 2000 & 2000 & 2000 \\
\hline 1400 & 1400 & 1400 & 1400 & 1400 & 1400 & 1400 & 1400 & 1400 \\
\hline 1000 & 1000 & 1000 & 1000 & 1000 & 1000 & 1000 & 1000 & 1000 \\
\hline 700 & 700 & 700 & 700 & 700 & 700 & 700 & 700 & 700 \\
\hline 500 & 500 & 500 & 500 & 500 & 500 & 500 & 500 & 500 \\
\hline 355 & 355 & 355 & 355 & 355 & 355 & 355 & 355 & 355 \\
\hline 250 & 250 & 250 & 250 & 250 & 250 & 250 & 250 & 250 \\
\hline 180 & 180 & 180 & 180 & 180 & 180 & 180 & 180 & 180 \\
\hline 147 & 147 & 147 & 147 & 147 & 147 & 147 & 147 & 147 \\
\hline 105 & 105 & 105 & 105 & 105 & 105 & 105 & 105 & 105 \\
\hline 90 & 90 & 90 & 90 & 90 & 90 & 90 & 90 & 90 \\
\hline 52.82 & 53.92 & 53.92 & 52.83 & 53.59 & 53.78 & 52.82 & 53.78 & 53.78 \\
\hline 43.35 & 44.02 & 44.02 & 43.13 & 43.76 & 43.91 & 43.35 & 43.91 & 43.91 \\
\hline 30.73 & 31.13 & 31.13 & 30.50 & 30.94 & 31.13 & 30.73 & 31.05 & 31.05 \\
\hline 21.79 & 22.01 & 22.01 & 21.57 & 21.88 & 22.01 & 21.73 & 21.96 & 21.96 \\
\hline 10.70 & 10.78 & 10.78 & 10.57 & 10.72 & 10.78 & 10.47 & 10.76 & 10.82 \\
\hline 4.12 & 4.10 & 3.99 & 3.94 & 4.14 & 4.32 & 4.47 & 3.94 & 4.08 \\
\hline 2.71 & 2.77 & 2.70 & 2.53 & 2.74 & 2.79 & 2.82 & 2.77 & 2.82 \\
\hline 1.44 & 1.46 & 1.46 & 1.40 & 1.47 & 1.47 & 1.48 & 1.49 & 1.50 \\
\hline 99.23 & 99.73 & 99.37 & 98.63 & 99.26 & 99.60 & 99.62 & 99.41 & 99.83 \\
\hline 95.42 & 98.04 & 97.98 & 97.28 & 97.91 & 98.68 & 98.73 & 98.96 & 99.39 \\
\hline 85.50 & 93.30 & 93.93 & 94.42 & 94.53 & 95.99 & 97.24 & 97.45 & 98.54 \\
\hline 58.84 & 74.48 & 66.74 & 79.21 & 81.52 & 83.53 & 90.51 & 90.93 & 95.19 \\
\hline 39.71 & 44.52 & 43.36 & 53.87 & 61.31 & 56.43 & 76.24 & 74.66 & 89.46 \\
\hline 30.15 & 17.74 & 21.76 & 24.17 & 30.23 & 25.90 & 47.28 & 43.25 & 69.90 \\
\hline 26.30 & 7.92 & 11.32 & 10.62 & 13.07 & 9.19 & 32.39 & 19.92 & 35.79 \\
\hline 23.99 & 5.11 & 7.33 & 6.57 & 7.71 & 3.34 & 25.17 & 11.35 & 17.17 \\
\hline 22.95 & 4.19 & 6.05 & 5.27 & 6.30 & 3.49 & 22.12 & 8.64 & 11.44 \\
\hline 20.85 & 3.21 & 4.25 & 3.79 & 4.56 & 3.38 & 17.64 & 5.39 & 6.86 \\
\hline 20.23 & 2.95 & 3.90 & 3.44 & 4.22 & 2.90 & 16.39 & 4.81 & 5.66 \\
\hline 11.25 & 1.25 & 1.25 & 2.5 & 1.25 & 2.5 & 11.25 & 2.5 & 2.5 \\
\hline 8.75 & 1.25 & 1.25 & 2.5 & 1.25 & 2.5 & 8.75 & 2.5 & 2.5 \\
\hline 7.5 & 1.25 & 1.25 & 2.5 & 1.25 & 1.25 & 7.5 & 2.5 & 2.5 \\
\hline 6.25 & 1.25 & 1.25 & 2.5 & 1.25 & 1.25 & 7.5 & 2.5 & 2.5 \\
\hline 5 & 1.25 & 1.25 & 2.5 & 1.25 & 1.25 & 6.25 & 2.5 & 2.5 \\
\hline 3.75 & 1.25 & 1.25 & 2.5 & 1.25 & 1.25 & 5 & 1.25 & 1.25 \\
\hline 3.75 & 1.25 & 1.25 & 2.5 & 1.25 & 1.25 & 3.75 & 1.25 & 1.25 \\
\hline 3.75 & 1.25 & 1.25 & 1.25 & 1.25 & 1.25 & 2.5 & 1.25 & 1.25 \\
\hline
\end{tabular}




\begin{tabular}{|c|c|c|c|c|c|c|c|c|}
\hline 18 & 19 & 20 & 21 & 22 & 23 & 24 & 25 & 26 \\
\hline 19 & 19 & 19 & 19 & 19 & 19 & 19 & 19 & 19 \\
\hline 2000 & 2000 & 2000 & 2000 & 2000 & 2000 & 2000 & 2000 & 2000 \\
\hline 1400 & 1400 & 1400 & 1400 & 1400 & 1400 & 1400 & 1400 & 1400 \\
\hline 1000 & 1000 & 1000 & 1000 & 1000 & 1000 & 1000 & 1000 & 1000 \\
\hline 700 & 700 & 700 & 700 & 700 & 700 & 700 & 700 & 700 \\
\hline 500 & 500 & 500 & 500 & 500 & 500 & 500 & 500 & 500 \\
\hline 355 & 355 & 355 & 355 & 355 & 355 & 355 & 355 & 355 \\
\hline 250 & 250 & 250 & 250 & 250 & 250 & 250 & 250 & 250 \\
\hline 180 & 180 & 180 & 180 & 180 & 180 & 180 & 180 & 180 \\
\hline 147 & 147 & 147 & 147 & 147 & 147 & 147 & 147 & 147 \\
\hline 105 & 105 & 105 & 105 & 105 & 105 & 105 & 105 & 105 \\
\hline 90 & 90 & 90 & 90 & 90 & 90 & 90 & 90 & 90 \\
\hline 52.82 & 53.55 & 50.82 & 51.22 & 51.65 & 51.91 & 51.11 & 51.81 & 49.48 \\
\hline 43.24 & 43.95 & 41.71 & 41.93 & 42.28 & 42.38 & 41.95 & 42.41 & 41.18 \\
\hline 30.73 & 31.24 & 29.57 & 29.72 & 29.97 & 29.97 & 29.82 & 29.99 & 29.66 \\
\hline 21.73 & 22.09 & 20.96 & 21.02 & 21.19 & 21.19 & 21.08 & 21.21 & 21.03 \\
\hline 10.74 & 10.82 & 10.33 & 10.42 & 10.05 & 10.01 & 10.33 & 10.39 & 10.39 \\
\hline 4.22 & 4.46 & 3.82 & 4.00 & 4.09 & 3.69 & 3.79 & 3.93 & 3.88 \\
\hline 2.86 & 2.93 & 2.59 & 2.52 & 2.66 & 2.57 & 2.61 & 2.48 & 2.51 \\
\hline 1.50 & 1.52 & 1.39 & 1.40 & 1.41 & 1.42 & 1.40 & 1.41 & 1.42 \\
\hline 99.46 & 99.79 & 100.00 & 96.20 & 99.06 & 98.72 & 99.57 & 99.57 & 99.72 \\
\hline 97.89 & 98.19 & 99.81 & 82.97 & 93.16 & 92.38 & 97.22 & 96.32 & 97.70 \\
\hline 95.79 & 92.07 & 99.34 & 65.37 & 78.22 & 77.70 & 88.89 & 85.60 & 92.46 \\
\hline 85.77 & 60.04 & 97.75 & 36.02 & 41.66 & 40.01 & 49.00 & 52.27 & 81.33 \\
\hline 69.75 & 29.70 & 94.26 & 23.37 & 22.79 & 17.62 & 30.23 & 30.79 & 74.35 \\
\hline 47.44 & 17.11 & 85.93 & 19.15 & 16.76 & 11.23 & 22.68 & 24.11 & 71.81 \\
\hline 31.78 & 14.76 & 73.89 & 17.71 & 14.90 & 9.62 & 20.04 & 22.50 & 70.93 \\
\hline 24.79 & 13.51 & 63.86 & 16.91 & 13.78 & 8.83 & 18.48 & 21.61 & 70.29 \\
\hline 22.29 & 13.01 & 56.65 & 16.53 & 13.22 & 8.42 & 17.73 & 21.20 & 69.84 \\
\hline 18.29 & 12.06 & 38.14 & 15.83 & 12.42 & 7.85 & 16.43 & 20.08 & 68.27 \\
\hline 17.21 & 11.74 & 33.24 & 15.54 & 11.99 & 7.61 & 15.88 & 19.59 & 67.17 \\
\hline 11.25 & 7.5 & 10 & 6.25 & 5 & 2.5 & 10 & 6.25 & 25 \\
\hline 10 & 5 & 7.5 & 5 & 3.75 & 2.5 & 7.5 & 5 & 16.25 \\
\hline 7.5 & 2.5 & 6.25 & 3.75 & 2.5 & 2.5 & 5 & 5 & 7.5 \\
\hline 7.5 & 2.5 & 5 & 3.75 & 2.5 & 2.5 & 5 & 5 & 6.25 \\
\hline 6.25 & 2.5 & 5 & 3.75 & 2.5 & 2.5 & 5 & 5 & 5 \\
\hline 5 & 2.5 & 5 & 2.5 & 2.5 & 2.5 & 5 & 5 & 3.75 \\
\hline 3.75 & 1.25 & 3.75 & 2.5 & 2.5 & 2.5 & 3.75 & 2.5 & 3.75 \\
\hline 3.75 & 1.25 & 3.75 & 2.5 & 2.5 & 2.5 & 3.75 & 2.5 & 3.75 \\
\hline
\end{tabular}




$\begin{array}{rrrrrrrrr}27 & 28 & 29 & 30 & 31 & 32 & 33 & 34 & 35 \\ 19 & 19 & 19 & 19 & 19 & 19 & 19 & 19 & 19 \\ 2000 & 2000 & 2000 & 2000 & 2000 & 2000 & 2000 & 2000 & 2000 \\ 1400 & 1400 & 1400 & 1400 & 1400 & 1400 & 1400 & 1400 & 1400 \\ 1000 & 1000 & 1000 & 1000 & 1000 & 1000 & 1000 & 1000 & 1000 \\ 700 & 700 & 700 & 700 & 700 & 700 & 700 & 700 & 700 \\ 500 & 500 & 500 & 500 & 500 & 500 & 500 & 500 & 500 \\ 355 & 355 & 355 & 355 & 355 & 355 & 355 & 355 & 355 \\ 250 & 250 & 250 & 250 & 250 & 250 & 250 & 250 & 250 \\ 180 & 180 & 180 & 180 & 180 & 180 & 180 & 180 & 180 \\ 147 & 147 & 147 & 147 & 147 & 147 & 147 & 147 & 147 \\ 105 & 105 & 105 & 105 & 105 & 105 & 105 & 105 & 105 \\ 90 & 90 & 90 & 90 & 90 & 90 & 90 & 90 & 90 \\ 51.41 & 49.18 & 49.98 & 49.98 & 49.17 & 50.74 & 51.95 & 51.38 & 51.68 \\ 42.09 & 40.81 & 41.02 & 41.02 & 40.36 & 41.43 & 42.52 & 42.06 & 42.20 \\ 29.91 & 29.24 & 29.24 & 29.24 & 28.69 & 29.30 & 30.07 & 29.74 & 29.91 \\ 21.15 & 20.73 & 20.73 & 20.73 & 20.34 & 20.71 & 21.26 & 21.03 & 21.15 \\ 10.19 & 10.15 & 10.15 & 10.15 & 9.99 & 11.64 & 10.27 & 10.36 & 10.16 \\ 4.03 & 3.64 & 3.78 & 3.78 & 3.92 & 4.13 & 3.76 & 3.89 & 3.82 \\ 2.55 & 2.58 & 2.62 & 2.62 & 2.65 & 2.72 & 2.62 & 2.59 & 2.64 \\ 1.42 & 1.42 & 1.41 & 1.41 & 1.41 & 1.43 & 1.40 & 1.40 & 1.41 \\ 99.85 & 96.78 & 98.28 & 98.00 & 99.86 & 99.59 & 100.00 & 100.00 & 98.31 \\ 98.69 & 94.26 & 97.89 & 88.39 & 97.75 & 98.54 & 99.37 & 99.37 & 97.11 \\ 93.49 & 90.85 & 99.17 & 73.92 & 92.17 & 94.28 & 95.67 & 95.67 & 94.89 \\ 65.27 & 77.98 & 90.16 & 44.45 & 69.69 & 68.69 & 64.15 & 64.15 & 86.63 \\ 39.68 & 62.58 & 74.65 & 28.94 & 48.87 & 37.26 & 31.80 & 31.80 & 69.82 \\ 30.41 & 52.64 & 68.22 & 24.72 & 39.42 & 17.21 & 13.43 & 13.43 & 42.21 \\ 28.71 & 49.73 & 60.25 & 23.88 & 35.34 & 10.72 & 8.01 & 8.01 & 21.38 \\ 27.66 & 48.80 & 54.24 & 23.44 & 32.96 & 8.23 & 6.12 & 6.12 & 13.89 \\ 27.13 & 48.41 & 51.16 & 23.25 & 31.88 & 7.25 & 5.43 & 5.43 & 11.32 \\ 25.99 & 47.17 & 52.86 & 22.80 & 29.97 & 6.16 & 4.61 & 4.61 & 8.52 \\ 25.42 & 46.37 & 51.36 & 22.53 & 29.35 & 5.83 & 4.39 & 4.39 & 7.84 \\ 10 & 20 & 12.5 & 12.5 & 17.5 & 2.5 & 5 & 7.5 & 7.5 \\ 8.75 & 12.5 & 10 & 10 & 15 & 2.5 & 3.75 & 6.25 & 7.5 \\ 6.25 & 6.25 & 6.25 & 6.25 & 12.5 & 2.5 & 3.75 & 6.25 & 6.25 \\ 6.25 & 5 & 5 & 5 & 11.25 & 2.5 & 3.75 & 6.25 & 6.25 \\ 5 & 5 & 5 & 5 & 10 & 2.5 & 3.75 & 6.25 & 6.25 \\ 5 & 5 & 3.75 & 3.75 & 6.25 & 2.5 & 3.75 & 5 & 5 \\ 3.75 & 5 & 3.75 & 3.75 & 6.25 & 2.5 & 3.75 & 5 & 5 \\ 3.75 & 5 & 3.75 & 3.75 & 6.25 & 2.5 & 3.75 & 3.75 & 3.75\end{array}$




\begin{tabular}{|c|c|c|c|c|c|c|c|c|}
\hline 36 & 37 & 38 & 39 & 40 & 41 & 42 & 43 & 44 \\
\hline 19 & 19 & 19 & 19 & 19 & 19 & 19 & 19 & 19 \\
\hline 2000 & 2000 & 2000 & 2000 & 2000 & 2000 & 2000 & 2000 & 2000 \\
\hline 1400 & 1400 & 1400 & 1400 & 1400 & 1400 & 1400 & 1400 & 1400 \\
\hline 1000 & 1000 & 1000 & 1000 & 1000 & 1000 & 1000 & 1000 & 1000 \\
\hline 700 & 700 & 700 & 700 & 700 & 700 & 700 & 700 & 700 \\
\hline 500 & 500 & 500 & 500 & 500 & 500 & 500 & 500 & 500 \\
\hline 355 & 355 & 355 & 355 & 355 & 355 & 355 & 355 & 355 \\
\hline 250 & 250 & 250 & 250 & 250 & 250 & 250 & 250 & 250 \\
\hline 180 & 180 & 180 & 180 & 180 & 180 & 180 & 180 & 180 \\
\hline 147 & 147 & 147 & 147 & 147 & 147 & 147 & 147 & 147 \\
\hline 105 & 105 & 105 & 105 & 105 & 105 & 105 & 105 & 105 \\
\hline 90 & 90 & 90 & 90 & 90 & 90 & 90 & 90 & 90 \\
\hline 51.00 & 52.25 & 51.03 & 50.75 & 51.44 & 50.07 & 51.44 & 51.47 & 52.02 \\
\hline 41.87 & 42.66 & 41.78 & 41.55 & 42.44 & 41.11 & 42.44 & 42.36 & 42.69 \\
\hline 29.76 & 30.17 & 29.62 & 29.54 & 30.09 & 29.23 & 30.17 & 30.19 & 30.34 \\
\hline 21.10 & 21.33 & 21.00 & 20.94 & 21.33 & 20.84 & 21.33 & 21.40 & 21.51 \\
\hline 10.19 & 10.06 & 10.32 & 10.11 & 10.45 & 10.27 & 10.45 & 10.51 & 10.54 \\
\hline 3.95 & 4.02 & 4.05 & 4.22 & 3.89 & 4.02 & 4.04 & 3.88 & 3.89 \\
\hline 2.57 & 2.54 & 2.56 & 2.60 & 2.66 & 2.60 & 2.56 & 2.62 & 2.57 \\
\hline 1.39 & 1.41 & 1.39 & 1.42 & 1.41 & 1.41 & 1.41 & 1.42 & 1.43 \\
\hline 98.79 & 95.54 & 98.82 & 97.54 & 99.93 & 99.46 & 99.27 & 99.69 & 98.86 \\
\hline 92.09 & 91.42 & 96.50 & 94.72 & 99.45 & 98.35 & 95.44 & 98.00 & 92.83 \\
\hline 74.62 & 83.88 & 92.23 & 89.58 & 97.63 & 96.29 & 85.18 & 92.67 & 80.65 \\
\hline 43.66 & 44.68 & 74.56 & 68.27 & 85.80 & 89.59 & 47.28 & 69.73 & 49.13 \\
\hline 32.90 & 22.37 & 53.03 & 55.67 & 71.11 & 80.46 & 25.51 & 45.55 & 28.86 \\
\hline 28.12 & 12.72 & 35.22 & 45.34 & 43.61 & 63.87 & 19.07 & 36.09 & 22.37 \\
\hline 26.30 & 9.49 & 28.78 & 39.13 & 21.96 & 53.97 & 17.29 & 32.92 & 20.89 \\
\hline 25.07 & 7.76 & 25.09 & 35.65 & 14.06 & 47.74 & 16.36 & 31.16 & 20.20 \\
\hline 24.28 & 6.89 & 23.39 & 33.84 & 11.44 & 44.79 & 15.97 & 30.30 & 19.86 \\
\hline 22.66 & 5.87 & 20.59 & 30.43 & 8.30 & 39.61 & 15.24 & 28.92 & 19.15 \\
\hline 22.01 & 5.55 & 19.67 & 29.28 & 7.69 & 38.37 & 14.97 & 28.31 & 18.67 \\
\hline 13.75 & 5 & 16.25 & 18.75 & 12.5 & 26.83 & 12.5 & 15 & 10 \\
\hline 11.25 & 5 & 15 & 17.5 & 7.5 & 24.39 & 7.5 & 11.25 & 7.5 \\
\hline 8.75 & 5 & 13.75 & 15 & 6.25 & 21.95 & 5 & 7.5 & 5 \\
\hline 7.5 & 5 & 12.5 & 13.75 & 5 & 18.29 & 5 & 6.25 & 3.75 \\
\hline 7.5 & 5 & 11.25 & 11.25 & 5 & 15.85 & 5 & 5 & 3.75 \\
\hline 7.5 & 3.75 & 7.5 & 8.75 & 5 & 8.54 & 5 & 3.75 & 2.5 \\
\hline 6.25 & 3.75 & 6.25 & 7.5 & 5 & 8.54 & 3.75 & 3.75 & 2.5 \\
\hline 6.25 & 3.75 & 6.25 & 6.25 & 5 & 4.88 & 3.75 & 3.75 & 2.5 \\
\hline
\end{tabular}




\begin{tabular}{|c|c|c|c|c|c|c|c|c|}
\hline 45 & 46 & 47 & 48 & 49 & 50 & 51 & 52 & 53 \\
\hline 19 & 19 & 19 & 19 & 19 & 19 & 19 & 19 & 19 \\
\hline 2000 & 2000 & 2000 & 2000 & 2000 & 2000 & 2000 & 2000 & 2000 \\
\hline 1400 & 1400 & 1400 & 1400 & 1400 & 1400 & 1400 & 1400 & 1400 \\
\hline 1000 & 1000 & 1000 & 1000 & 1000 & 1000 & 1000 & 1000 & 1000 \\
\hline 700 & 700 & 700 & 700 & 700 & 700 & 700 & 700 & 700 \\
\hline 500 & 500 & 500 & 500 & 500 & 500 & 500 & 500 & 500 \\
\hline 355 & 355 & 355 & 355 & 355 & 355 & 355 & 355 & 355 \\
\hline 250 & 250 & 250 & 250 & 250 & 250 & 250 & 250 & 250 \\
\hline 180 & 180 & 180 & 180 & 180 & 180 & 180 & 180 & 180 \\
\hline 147 & 147 & 147 & 147 & 147 & 147 & 147 & 147 & 147 \\
\hline 105 & 105 & 105 & 105 & 105 & 105 & 105 & 105 & 105 \\
\hline 90 & 90 & 90 & 90 & 90 & 90 & 90 & 90 & 90 \\
\hline 51.61 & 51.98 & 51.98 & 52.25 & 51.98 & 52.25 & 51.17 & 51.30 & 52.69 \\
\hline 42.25 & 42.55 & 42.44 & 42.66 & 42.55 & 42.66 & 41.89 & 42.00 & 43.02 \\
\hline 29.95 & 30.09 & 30.01 & 30.17 & 30.17 & 30.17 & 29.70 & 29.78 & 30.42 \\
\hline 21.24 & 21.28 & 21.22 & 21.33 & 21.33 & 21.33 & 21.06 & 21.11 & 21.51 \\
\hline 10.43 & 10.03 & 10.40 & 10.45 & 10.45 & 10.48 & 10.34 & 10.40 & 10.36 \\
\hline 3.95 & 3.93 & 4.08 & 4.15 & 3.92 & 3.93 & 4.04 & 4.00 & 4.14 \\
\hline 2.60 & 2.59 & 2.63 & 2.68 & 2.57 & 2.62 & 2.66 & 2.55 & 2.66 \\
\hline 1.43 & 1.42 & 1.42 & 1.43 & 1.34 & 1.35 & 1.35 & 1.35 & 1.44 \\
\hline 99.16 & 99.22 & 98.08 & 97.01 & 98.21 & 99.93 & 99.04 & 98.77 & 99.65 \\
\hline 96.33 & 97.67 & 95.86 & 92.92 & 93.21 & 98.59 & 93.38 & 96.44 & 98.46 \\
\hline 92.44 & 95.31 & 91.92 & 86.26 & 76.01 & 93.06 & 81.95 & 90.88 & 94.65 \\
\hline 80.49 & 81.63 & 79.91 & 70.38 & 42.58 & 49.85 & 57.29 & 65.13 & 72.22 \\
\hline 66.55 & 62.48 & 62.29 & 52.71 & 25.81 & 21.38 & 41.61 & 37.73 & 45.47 \\
\hline 48.58 & 33.91 & 38.21 & 29.85 & 11.86 & 10.96 & 33.57 & 26.64 & 21.27 \\
\hline 36.07 & 18.03 & 22.31 & 14.27 & 9.83 & 8.77 & 29.51 & 23.26 & 10.26 \\
\hline 29.63 & 12.62 & 15.58 & 8.33 & 8.65 & 7.78 & 27.03 & 21.52 & 6.53 \\
\hline 26.91 & 10.98 & 13.44 & 6.72 & 7.98 & 7.36 & 25.77 & 20.64 & 5.54 \\
\hline 22.83 & 8.91 & 10.59 & 5.15 & 6.75 & 6.72 & 23.54 & 18.86 & 4.17 \\
\hline 21.55 & 8.50 & 9.91 & 4.83 & 6.16 & 6.50 & 22.81 & 18.31 & 3.90 \\
\hline 13.75 & 7.5 & 7.5 & 5 & 7.5 & 5 & 15 & 13.75 & 3.75 \\
\hline 12.5 & 6.25 & 7.5 & 5 & 6.25 & 5 & 13.75 & 12.5 & 3.75 \\
\hline 11.25 & 6.25 & 7.5 & 5 & 5 & 5 & 12.5 & 11.25 & 3.75 \\
\hline 10 & 6.25 & 7.5 & 5 & 5 & 5 & 11.25 & 10 & 3.75 \\
\hline 8.75 & 6.25 & 7.5 & 5 & 5 & 3.75 & 10 & 7.5 & 2.5 \\
\hline 5 & 6.25 & 7.5 & 5 & 3.75 & 2.5 & 6.25 & 5 & 2.5 \\
\hline 5 & 6.25 & 6.25 & 5 & 2.5 & 2.5 & 6.25 & 5 & 2.5 \\
\hline 3.75 & 5 & 5 & 3.75 & 2.5 & 2.5 & 5 & 5 & 2.5 \\
\hline
\end{tabular}




$\begin{array}{rrrrrrr}54 & 55 & 56 & 57 & 58 & 59 & 60 \\ 19 & 19 & 19 & 19 & 19 & 19 & 19 \\ 2000 & 2000 & 2000 & 2000 & 2000 & 2000 & 2000 \\ 1400 & 1400 & 1400 & 1400 & 1400 & 1400 & 1400 \\ 1000 & 1000 & 1000 & 1000 & 1000 & 1000 & 1000 \\ 700 & 700 & 700 & 700 & 700 & 700 & 700 \\ 500 & 500 & 500 & 500 & 500 & 500 & 500 \\ 355 & 355 & 355 & 355 & 355 & 355 & 355 \\ 250 & 250 & 250 & 250 & 250 & 250 & 250 \\ 180 & 180 & 180 & 180 & 180 & 180 & 180 \\ 147 & 147 & 147 & 147 & 147 & 147 & 147 \\ 105 & 105 & 105 & 105 & 105 & 105 & 105 \\ 90 & 90 & 90 & 90 & 90 & 90 & 90 \\ 51.17 & 51.44 & 52.08 & 50.77 & 52.73 & 52.60 & 52.60 \\ 41.89 & 42.11 & 42.64 & 41.69 & 43.06 & 43.06 & 42.95 \\ 29.70 & 29.93 & 30.31 & 29.64 & 30.45 & 30.45 & 30.45 \\ 21.06 & 21.22 & 21.49 & 21.07 & 21.53 & 21.53 & 18.64 \\ 10.32 & 10.40 & 10.49 & 10.15 & 10.37 & 10.55 & 10.57 \\ 3.78 & 3.93 & 3.84 & 3.92 & 3.82 & 3.95 & 4.12 \\ 2.58 & 2.63 & 2.57 & 2.59 & 2.54 & 2.58 & 2.62 \\ 1.36 & 1.36 & 1.40 & 1.40 & 1.42 & 1.42 & 1.43 \\ 99.63 & 100.00 & 99.39 & 99.44 & 97.77 & 99.81 & 100.00 \\ 98.91 & 99.94 & 96.57 & 97.19 & 90.78 & 97.21 & 99.44 \\ 97.41 & 99.67 & 90.70 & 93.68 & 78.66 & 89.44 & 95.87 \\ 93.32 & 96.58 & 75.50 & 85.13 & 51.66 & 58.56 & 66.27 \\ 87.08 & 89.98 & 64.56 & 75.72 & 31.72 & 32.34 & 43.53 \\ 71.04 & 83.73 & 53.66 & 65.30 & 17.67 & 16.71 & 29.87 \\ 49.17 & 77.13 & 41.50 & 54.94 & 11.76 & 11.23 & 23.37 \\ 35.86 & 68.27 & 33.44 & 48.65 & 9.04 & 8.81 & 19.72 \\ 30.77 & 59.51 & 29.47 & 45.65 & 7.84 & 8.00 & 17.89 \\ 24.36 & 36.84 & 21.68 & 37.79 & 6.50 & 6.57 & 14.57 \\ 22.79 & 31.30 & 19.72 & 35.09 & 5.99 & 6.22 & 13.16 \\ 15 & 12.5 & 15 & 25 & 6.25 & 7.5 & 7.5 \\ 13.75 & 11.25 & 13.75 & 22.5 & 6.25 & 6.25 & 7.5 \\ 12.5 & 8.75 & 11.25 & 20 & 6.25 & 6.25 & 6.25 \\ 11.25 & 7.5 & 10 & 17.5 & 6.25 & 6.25 & 6.25 \\ 11.25 & 7.5 & 10 & 15 & 5 & 6.25 & 5 \\ 6.25 & 6.25 & 5 & 11.25 & 3.75 & 3.75 & 5 \\ 6.25 & 6.25 & 5 & 8.75 & 3.75 & 3.75 & 3.75 \\ 5 & 5 & 3.75 & 7.5 & 2.5 & 3.75 & 3.75\end{array}$




\section{A.4 Water Retention Data}

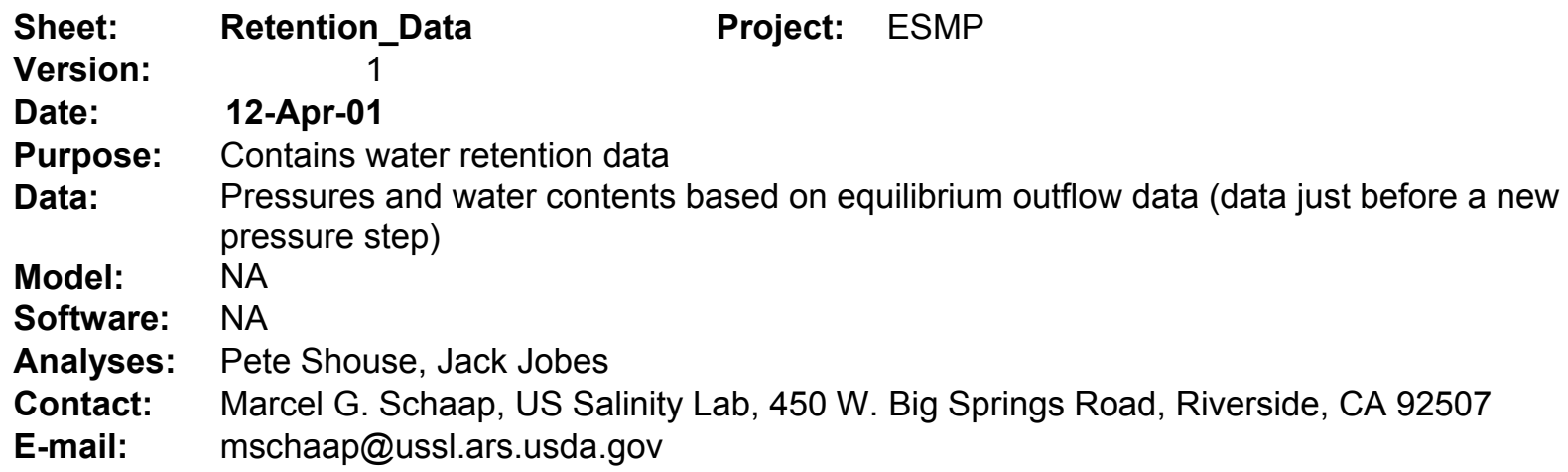

Date:

1

Purpose: Contains water retention data

Data: $\quad$ Pressures and water contents based on equilibrium outflow data (data just before a new pressure step)

Model: $\quad$ NA

Software: NA

Analyses: Pete Shouse, Jack Jobes

Contact: $\quad$ Marcel G. Schaap, US Salinity Lab, 450 W. Big Springs Road, Riverside, CA 92507

E-mail: mschaap@ussl.ars.usda.gov

Row

ID

Npoints

Pressure

Theta

Comments

\section{Explanation}

Identifier (Ring number)

Number of valid retention points

$(0,15$ or 16$)$

16 rows with pressure data $(\mathrm{cm})$

16 rows with water contents $(\mathrm{cm} 3 / \mathrm{cm} 3)$
Methodology

Multistep outflow for pressures $<500 \mathrm{~cm}$, pressure cookers for higher pressures

(continued on next page)

Missing data are denoted with ' -9.9 '

No data for samples 7, 25,28,29,30,37,58 : (Multi step outflow repeatedly failed) 


\begin{tabular}{|c|c|c|c|c|c|c|c|c|}
\hline \multirow{2}{*}{\multicolumn{2}{|c|}{$\begin{array}{l}\text { ID } \\
\text { Npoints }\end{array}$}} & 1 & 2 & 3 & 4 & 5 & 6 & 7 \\
\hline & & 16 & 16 & 16 & 15 & 15 & 16 & 0 \\
\hline pressure & cm & 12.4 & 12.4 & 12.4 & 10 & 10 & 12.4 & -9.9 \\
\hline pressure & cm & 20.2 & 20.2 & 20.2 & 20.2 & 20.2 & 20.2 & -9.9 \\
\hline pressure & $\mathrm{cm}$ & 29.4 & 29.4 & 29.4 & 29.4 & 29.4 & 29.4 & -9.9 \\
\hline pressure & $\mathrm{cm}$ & 47.77 & 47.77 & 47.77 & 48 & 48 & 47.77 & -9.9 \\
\hline pressure & $\mathrm{cm}$ & 102.89 & 102.89 & 102.89 & 103 & 103 & 102.89 & -9.9 \\
\hline pressure & $\mathrm{cm}$ & 149.04 & 149.04 & 149.04 & 213 & 213 & 149.04 & -9.9 \\
\hline pressure & $\mathrm{cm}$ & 213.44 & 213.44 & 213.44 & 310.5 & 310.5 & 213.44 & -9.9 \\
\hline pressure & $\mathrm{cm}$ & 307 & 307 & 307 & 333 & 333 & 307 & -9.9 \\
\hline pressure & $\mathrm{cm}$ & 333 & 333 & 333 & 459.4 & 459.4 & 333 & -9.9 \\
\hline pressure & $\mathrm{cm}$ & 460 & 460 & 460 & 551.2 & 551.2 & 460 & -9.9 \\
\hline pressure & $\mathrm{cm}$ & 552 & 552 & 552 & 735 & 735 & 552 & -9.9 \\
\hline pressure & $\mathrm{cm}$ & 736 & 736 & 736 & 1000 & 1000 & 736 & -9.9 \\
\hline pressure & $\mathrm{cm}$ & 1000 & 1000 & 1000 & 3000 & 3000 & 1000 & -9.9 \\
\hline pressure & $\mathrm{cm}$ & 3000 & 3000 & 3000 & 8000 & 8000 & 3000 & -9.9 \\
\hline pressure & $\mathrm{cm}$ & 8000 & 8000 & 8000 & 15000 & 15000 & 8000 & -9.9 \\
\hline pressure & $\mathbf{c m}$ & 15000 & 15000 & 15000 & & & 15000 & -9.9 \\
\hline theta & $\mathrm{cm} 3 / \mathrm{cm} 3$ & 0.2624 & 0.2853 & 0.2959 & 0.282 & 0.2664 & 0.2817 & -9.9 \\
\hline theta & $\mathrm{cm} 3 / \mathrm{cm} 3$ & 0.2587 & 0.2707 & 0.2558 & 0.1783 & 0.179 & 0.2198 & -9.9 \\
\hline theta & $\mathrm{cm} 3 / \mathrm{cm} 3$ & 0.2405 & 0.1965 & 0.234 & 0.1437 & 0.1536 & 0.1761 & -9.9 \\
\hline theta & $\mathrm{cm} 3 / \mathrm{cm} 3$ & 0.2078 & 0.1012 & 0.2034 & 0.1219 & 0.1354 & 0.1361 & -9.9 \\
\hline eta & $\mathrm{cm} 3 / \mathrm{cm} 3$ & 0.1634 & 0.0648 & 0.1361 & 0.0801 & 0.0881 & 0.0852 & -9.9 \\
\hline leta & $\mathrm{cm} 3 / \mathrm{cm} 3$ & 0.1488 & 0.056 & 0.0983 & 0.0509 & 0.0553 & 0.067 & -9.9 \\
\hline eta & $\mathrm{cm} 3 / \mathrm{cm} 3$ & 0.1215 & 0.0488 & 0.0691 & 0.0466 & 0.0335 & 0.0553 & -9.9 \\
\hline eta & $\mathrm{cm} 3 / \mathrm{cm} 3$ & 0.1033 & 0.0466 & 0.0546 & 0.0462 & 0.0333 & 0.0499 & -9.9 \\
\hline eta & $\mathrm{cm} 3 / \mathrm{cm} 3$ & 0.101 & 0.0459 & 0.0543 & 0.0415 & 0.026 & 0.0496 & -9.9 \\
\hline eta & $\mathrm{cm} 3 / \mathrm{cm} 3$ & 0.0888 & 0.0437 & 0.0459 & 0.0375 & 0.0223 & 0.0462 & -9.9 \\
\hline eta & $\mathrm{cm} 3 / \mathrm{cm} 3$ & 0.0844 & 0.0422 & 0.0437 & 0.0338 & 0.0204 & 0.0437 & -9.9 \\
\hline eta & $\mathrm{cm} 3 / \mathrm{cm} 3$ & 0.0742 & 0.0408 & 0.0422 & 0.0292 & 0.0187 & 0.0382 & -9.9 \\
\hline eta & $\mathrm{cm} 3 / \mathrm{cm} 3$ & 0.0655 & 0.0394 & 0.0416 & 0.0218 & 0.0175 & 0.0371 & -9.9 \\
\hline eta & $\mathrm{cm} 3 / \mathrm{cm} 3$ & 0.0579 & 0.0349 & 0.0364 & 0.0193 & 0.0162 & 0.0325 & -9.9 \\
\hline eta & $\mathrm{cm} 3 / \mathrm{cm} 3$ & 0.0575 & 0.0313 & 0.0319 & 0.0191 & 0.016 & 0.0306 & -9.9 \\
\hline eta & $\mathrm{cm} 3 / \mathrm{cm} 3$ & 0.0571 & 0.0306 & 0.0313 & & & 0.0298 & -9.9 \\
\hline
\end{tabular}




$\begin{array}{rrrrrrrrr}8 & 9 & 10 & 11 & 12 & 13 & 14 & 15 & 16 \\ 15 & 15 & 16 & 15 & 16 & 15 & 15 & 16 & 15 \\ 10 & 10 & 12.4 & 10 & 12.4 & 10 & 10 & 12.4 & 10 \\ 20.2 & 20.2 & 20.2 & 20.2 & 20.2 & 20.2 & 20.2 & 20.2 & 20.2 \\ 29.4 & 29.4 & 29.4 & 29.4 & 29.4 & 29.4 & 29.4 & 29.4 & 29.4 \\ 48 & 48 & 47.77 & 48 & 47.77 & 48 & 48 & 47.77 & 48 \\ 103 & 103 & 102.89 & 103 & 102.89 & 103 & 103 & 102.89 & 103 \\ 213 & 213 & 149.04 & 213 & 149.04 & 213 & 213 & 149.04 & 213 \\ 310.5 & 310.5 & 213.44 & 310.5 & 213.44 & 310.5 & 310.5 & 213.44 & 310.5 \\ 333 & 333 & 307 & 333 & 307 & 333 & 333 & 307 & 333 \\ 459.4 & 459.4 & 333 & 459.4 & 333 & 459.4 & 459.4 & 333 & 459.4 \\ 551.2 & 551.2 & 460 & 551.2 & 460 & 551.2 & 551.2 & 460 & 551.2 \\ 735 & 735 & 552 & 735 & 552 & 735 & 735 & 552 & 735 \\ 1000 & 1000 & 736 & 1000 & 736 & 1000 & 1000 & 736 & 1000 \\ 3000 & 3000 & 1000 & 3000 & 1000 & 3000 & 3000 & 1000 & 3000 \\ 8000 & 8000 & 3000 & 8000 & 3000 & 8000 & 8000 & 3000 & 8000 \\ 15000 & 15000 & 8000 & 15000 & 8000 & 15000 & 15000 & 8000 & 15000 \\ & & 15000 & & 15000 & & & 15000 & \\ 0.3108 & 0.3001 & 0.1697 & 0.3372 & 0.337 & 0.3429 & 0.3454 & 0.2962 & 0.3179 \\ 0.2072 & 0.2072 & 0.1042 & 0.23 & 0.2678 & 0.2929 & 0.3026 & 0.2758 & 0.2893 \\ 0.1929 & 0.1643 & 0.0751 & 0.1086 & 0.1368 & 0.1286 & 0.1597 & 0.2394 & 0.1607 \\ 0.1786 & 0.1357 & 0.0606 & 0.0604 & 0.0932 & 0.0572 & 0.0597 & 0.1594 & 0.0679 \\ 0.1465 & 0.0929 & 0.046 & 0.0389 & 0.064 & 0.0429 & 0.0454 & 0.103 & 0.0536 \\ 0.0964 & 0.07 & 0.0445 & 0.0318 & 0.0495 & 0.0321 & 0.0382 & 0.0866 & 0.0429 \\ 0.0786 & 0.0643 & 0.0358 & 0.0282 & 0.04 & 0.0286 & 0.0347 & 0.0757 & 0.0357 \\ 0.0765 & 0.06 & 0.0322 & 0.0275 & 0.0349 & 0.0276 & 0.0345 & 0.0655 & 0.0354 \\ 0.07 & 0.0579 & 0.032 & 0.0264 & 0.0343 & 0.0271 & 0.0329 & 0.0626 & 0.0336 \\ 0.0672 & 0.0557 & 0.0313 & 0.0257 & 0.0262 & 0.0268 & 0.0307 & 0.0546 & 0.0316 \\ 0.0664 & 0.0543 & 0.0291 & 0.025 & 0.0226 & 0.0264 & 0.0286 & 0.0473 & 0.0271 \\ 0.0657 & 0.0446 & 0.0269 & 0.0243 & 0.0204 & 0.0261 & 0.0271 & 0.04 & 0.0243 \\ 0.0321 & 0.0307 & 0.0244 & 0.0229 & 0.0189 & 0.0214 & 0.0243 & 0.0364 & 0.0214 \\ 0.0243 & 0.0293 & 0.0233 & 0.0221 & 0.0175 & 0.02 & 0.0229 & 0.0328 & 0.0207 \\ 0.024 & 0.0286 & 0.0233 & 0.0216 & 0.0167 & 0.0191 & 0.0221 & 0.0306 & 0.0204 \\ & & 0.0233 & & 0.016 & & & 0.0284 & \end{array}$




$\begin{array}{rrrrrrrrr}17 & 18 & 19 & 20 & 21 & 22 & 23 & 24 & 25 \\ 15 & 16 & 15 & 15 & 16 & 15 & 15 & 15 & 0 \\ 10 & 12.4 & 10 & 10 & 12.4 & 10 & 10 & 10 & -9.9 \\ 20.2 & 20.2 & 20.2 & 20.2 & 20.2 & 20.2 & 20.2 & 20.2 & -9.9 \\ 29.4 & 29.4 & 29.4 & 29.4 & 29.4 & 29.4 & 29.4 & 29.4 & -9.9 \\ 48 & 47.77 & 48 & 48 & 47.77 & 48 & 48 & 48 & -9.9 \\ 103 & 102.89 & 103 & 103 & 102.89 & 103 & 103 & 103 & -9.9 \\ 213 & 149.04 & 213 & 213 & 149.04 & 213 & 213 & 213 & -9.9 \\ 310.5 & 213.44 & 310.5 & 310.5 & 213.44 & 310.5 & 310.5 & 310.5 & -9.9 \\ 333 & 307 & 333 & 333 & 307 & 333 & 333 & 333 & -9.9 \\ 459.4 & 333 & 459.4 & 459.4 & 333 & 459.4 & 459.4 & 459.4 & -9.9 \\ 551.2 & 460 & 551.2 & 551.2 & 460 & 551.2 & 551.2 & 551.2 & -9.9 \\ 735 & 552 & 735 & 735 & 552 & 735 & 735 & 735 & -9.9 \\ 1000 & 736 & 1000 & 1000 & 736 & 1000 & 1000 & 1000 & -9.9 \\ 3000 & 1000 & 3000 & 3000 & 1000 & 3000 & 3000 & 3000 & -9.9 \\ 8000 & 3000 & 8000 & 8000 & 3000 & 8000 & 8000 & 8000 & -9.9 \\ 15000 & 8000 & 15000 & 15000 & 8000 & 15000 & 15000 & 15000 & -9.9 \\ & 15000 & & & 15000 & & & & -9.9 \\ 0.3215 & 0.298 & 0.3144 & 0.3765 & 0.3148 & 0.3051 & 0.2808 & 0.3251 & -9.9 \\ 0.3019 & 0.2929 & 0.2679 & 0.3694 & 0.2566 & 0.1622 & 0.2793 & 0.2411 & -9.9 \\ 0.2322 & 0.2697 & 0.1465 & 0.3336 & 0.2129 & 0.1265 & 0.1007 & 0.1947 & -9.9 \\ 0.1072 & 0.194 & 0.0607 & 0.2979 & 0.1765 & 0.1086 & 0.0793 & 0.1625 & -9.9 \\ 0.075 & 0.1212 & 0.05 & 0.1765 & 0.1255 & 0.0729 & 0.0579 & 0.109 & -9.9 \\ 0.0536 & 0.1004 & 0.0429 & 0.1015 & 0.0935 & 0.0479 & 0.0364 & 0.0643 & -9.9 \\ 0.0393 & 0.0815 & 0.0411 & 0.0943 & 0.0717 & 0.0443 & 0.0329 & 0.0579 & -9.9 \\ 0.0386 & 0.0706 & 0.0407 & 0.0936 & 0.0546 & 0.0441 & 0.0321 & 0.0572 & -9.9 \\ 0.0336 & 0.067 & 0.0393 & 0.0836 & 0.0528 & 0.0405 & 0.0293 & 0.0464 & -9.9 \\ 0.0314 & 0.0633 & 0.0375 & 0.08 & 0.0473 & 0.0357 & 0.0279 & 0.0429 & -9.9 \\ 0.0293 & 0.0597 & 0.0357 & 0.0764 & 0.0455 & 0.0343 & 0.0243 & 0.0393 & -9.9 \\ 0.0271 & 0.0524 & 0.0343 & 0.0607 & 0.0437 & 0.0314 & 0.0233 & 0.035 & -9.9 \\ 0.025 & 0.0473 & 0.02 & 0.0464 & 0.0429 & 0.0221 & 0.0226 & 0.0279 & -9.9 \\ 0.0229 & 0.0364 & 0.0171 & 0.0429 & 0.04 & 0.02 & 0.0223 & 0.0271 & -9.9 \\ 0.0222 & 0.0286 & 0.0158 & 0.0411 & 0.0364 & 0.0186 & 0.0222 & 0.0268 & -9.9 \\ & 0.0255 & & & 0.0331 & & & & -9.9\end{array}$




$\begin{array}{rrrrrrrrr}26 & 27 & 28 & 29 & 30 & 31 & 32 & 33 & 34 \\ 15 & 15 & 0 & 0 & 0 & 16 & 15 & 15 & 15 \\ 10 & 10 & -9.9 & -9.9 & -9.9 & 12.4 & 10 & 10 & 12.4 \\ 20.2 & 20.2 & -9.9 & -9.9 & -9.9 & 20.2 & 20.2 & 20.2 & 20.2 \\ 29.4 & 29.4 & -9.9 & -9.9 & -9.9 & 29.4 & 29.4 & 29.4 & 29.4 \\ 48 & 48 & -9.9 & -9.9 & -9.9 & 47.77 & 48 & 48 & 47.77 \\ 103 & 103 & -9.9 & -9.9 & -9.9 & 102.89 & 103 & 103 & 102.89 \\ 213 & 213 & -9.9 & -9.9 & -9.9 & 149.04 & 213 & 213 & 184 \\ 310.5 & 310.5 & -9.9 & -9.9 & -9.9 & 213.44 & 310.5 & 310.5 & 306 \\ 333 & 333 & -9.9 & -9.9 & -9.9 & 307 & 333 & 333 & 333 \\ 459.4 & 459.4 & -9.9 & -9.9 & -9.9 & 333 & 459.4 & 459.4 & 459.4 \\ 551.2 & 551.2 & -9.9 & -9.9 & -9.9 & 460 & 551.2 & 551.2 & 551.2 \\ 735 & 735 & -9.9 & -9.9 & -9.9 & 552 & 735 & 735 & 735 \\ 1000 & 1000 & -9.9 & -9.9 & -9.9 & 736 & 1000 & 1000 & 1000 \\ 3000 & 3000 & -9.9 & -9.9 & -9.9 & 1000 & 3000 & 3000 & 3000 \\ 8000 & 8000 & -9.9 & -9.9 & -9.9 & 3000 & 8000 & 8000 & 8000 \\ 15000 & 15000 & -9.9 & -9.9 & -9.9 & 8000 & 15000 & 15000 & 15000 \\ & & -9.9 & -9.9 & -9.9 & 15000 & & & \\ 0.3772 & 0.3072 & -9.9 & -9.9 & -9.9 & 0.2802 & 0.2951 & 0.3301 & 0.2868 \\ 0.3737 & 0.2443 & -9.9 & -9.9 & -9.9 & 0.2656 & 0.1808 & 0.1765 & 0.2413 \\ 0.3701 & 0.2186 & -9.9 & -9.9 & -9.9 & 0.2438 & 0.095 & 0.0693 & 0.1467 \\ 0.3665 & 0.1958 & -9.9 & -9.9 & -9.9 & 0.2074 & 0.0664 & 0.0479 & 0.0921 \\ 0.2951 & 0.1557 & -9.9 & -9.9 & -9.9 & 0.1419 & 0.0414 & 0.0336 & 0.063 \\ 0.1093 & 0.1143 & -9.9 & -9.9 & -9.9 & 0.1128 & 0.0379 & 0.0264 & 0.0539 \\ 0.095 & 0.0929 & -9.9 & -9.9 & -9.9 & 0.091 & 0.0343 & 0.0229 & 0.0466 \\ 0.0929 & 0.0886 & -9.9 & -9.9 & -9.9 & 0.0837 & 0.0332 & 0.0226 & 0.0464 \\ 0.0772 & 0.075 & -9.9 & -9.9 & -9.9 & 0.082 & 0.0307 & 0.0214 & 0.0437 \\ 0.07 & 0.0607 & -9.9 & -9.9 & -9.9 & 0.0764 & 0.0271 & 0.02 & 0.0415 \\ 0.0629 & 0.0536 & -9.9 & -9.9 & -9.9 & 0.0728 & 0.0236 & 0.0186 & 0.0378 \\ 0.0572 & 0.0429 & -9.9 & -9.9 & -9.9 & 0.0655 & 0.0207 & 0.0181 & 0.0367 \\ 0.0429 & 0.0304 & -9.9 & -9.9 & -9.9 & 0.0582 & 0.0193 & 0.0157 & 0.0349 \\ 0.0343 & 0.0246 & -9.9 & -9.9 & -9.9 & 0.0497 & 0.0179 & 0.015 & 0.0318 \\ 0.0336 & 0.0232 & -9.9 & -9.9 & -9.9 & 0.0444 & 0.0179 & 0.015 & 0.0317 \\ & & -9.9 & -9.9 & -9.9 & 0.0437 & & & \end{array}$




$\begin{array}{rrrrrrrrr}35 & 36 & 37 & 38 & 39 & 40 & 41 & 42 & 43 \\ 15 & 16 & 0 & 16 & 16 & 16 & 16 & 16 & 16 \\ 12.4 & 12.4 & -9.9 & 12.4 & 12.4 & 12.4 & 12.4 & 12.4 & 12.4 \\ 20.2 & 20.2 & -9.9 & 20.2 & 20.2 & 20.2 & 20.2 & 20.2 & 20.2 \\ 29.4 & 29.4 & -9.9 & 29.4 & 29.4 & 29.4 & 29.4 & 29.4 & 29.4 \\ 47.77 & 47.77 & -9.9 & 47.77 & 47.77 & 47.77 & 47.77 & 47.77 & 47.77 \\ 102.89 & 102.89 & -9.9 & 102.89 & 102.89 & 102.89 & 102.89 & 102.89 & 102.89 \\ 184 & 149.04 & -9.9 & 149.04 & 149.04 & 149.04 & 149.04 & 149.04 & 149.04 \\ 306 & 213.44 & -9.9 & 213.44 & 213.44 & 213.44 & 213.44 & 213.44 & 213.44 \\ 333 & 307 & -9.9 & 307 & 307 & 307 & 307 & 307 & 307 \\ 459.4 & 333 & -9.9 & 333 & 333 & 333 & 333 & 333 & 333 \\ 551.2 & 460 & -9.9 & 460 & 460 & 460 & 460 & 460 & 460 \\ 735 & 552 & -9.9 & 552 & 552 & 552 & 552 & 552 & 552 \\ 1000 & 736 & -9.9 & 736 & 736 & 736 & 736 & 736 & 736 \\ 3000 & 1000 & -9.9 & 1000 & 1000 & 1000 & 1000 & 1000 & 1000 \\ 8000 & 3000 & -9.9 & 3000 & 3000 & 3000 & 3000 & 3000 & 3000 \\ 15000 & 8000 & -9.9 & 8000 & 8000 & 8000 & 8000 & 8000 & 8000 \\ & 15000 & -9.9 & 15000 & 15000 & 15000 & 15000 & 15000 & 15000 \\ 0.317 & 0.2409 & -9.9 & 0.3137 & 0.2729 & 0.2653 & 0.2933 & 0.2176 & 0.2693 \\ 0.3133 & 0.1856 & -9.9 & 0.2882 & 0.2438 & 0.2362 & 0.2642 & 0.1303 & 0.2169 \\ 0.2151 & 0.1623 & -9.9 & 0.2263 & 0.2147 & 0.1779 & 0.2496 & 0.1041 & 0.1747 \\ 0.115 & 0.1317 & -9.9 & 0.1463 & 0.1856 & 0.0979 & 0.2256 & 0.0859 & 0.1543 \\ 0.0568 & 0.1026 & -9.9 & 0.0953 & 0.1274 & 0.056 & 0.171 & 0.064 & 0.1252 \\ 0.0422 & 0.0852 & -9.9 & 0.0855 & 0.1092 & 0.0524 & 0.1565 & 0.0531 & 0.1092 \\ 0.0378 & 0.0648 & -9.9 & 0.0819 & 0.0961 & 0.0451 & 0.1419 & 0.0422 & 0.1019 \\ 0.0375 & 0.0531 & -9.9 & 0.0775 & 0.0859 & 0.0386 & 0.1328 & 0.0328 & 0.0946 \\ 0.0364 & 0.0503 & -9.9 & 0.0753 & 0.083 & 0.0382 & 0.1274 & 0.0315 & 0.0918 \\ 0.0342 & 0.0473 & -9.9 & 0.0735 & 0.0786 & 0.0371 & 0.1092 & 0.0291 & 0.0873 \\ 0.0328 & 0.0444 & -9.9 & 0.0691 & 0.0771 & 0.0342 & 0.1019 & 0.0277 & 0.0801 \\ 0.0316 & 0.0422 & -9.9 & 0.0655 & 0.0713 & 0.0306 & 0.0892 & 0.0266 & 0.0728 \\ 0.0306 & 0.0378 & -9.9 & 0.0582 & 0.0663 & 0.0287 & 0.0815 & 0.0255 & 0.0655 \\ 0.0304 & 0.0328 & -9.9 & 0.0397 & 0.0509 & 0.0255 & 0.0721 & 0.0247 & 0.0437 \\ 0.0303 & 0.0315 & -9.9 & 0.0364 & 0.0437 & 0.0247 & 0.067 & 0.024 & 0.0364 \\ & 0.0314 & -9.9 & 0.0364 & 0.04 & 0.0247 & 0.064 & 0.0233 & 0.0353\end{array}$




\begin{tabular}{|c|c|c|c|c|c|c|c|c|}
\hline 44 & 45 & 46 & 47 & 48 & 49 & 50 & 51 & 52 \\
\hline 16 & 16 & 15 & 15 & 15 & 15 & 15 & 16 & 15 \\
\hline 12.4 & 12.4 & 12.4 & 12.4 & 12.4 & 12.4 & 12.4 & 12.4 & 12.4 \\
\hline 20.2 & 20.2 & 20.2 & 20.2 & 20.2 & 20.2 & 20.2 & 20.2 & 20.2 \\
\hline 29.4 & 29.4 & 29.4 & 29.4 & 29.4 & 29.4 & 29.4 & 29.4 & 29.4 \\
\hline 47.77 & 47.77 & 47.77 & 47.77 & 47.77 & 47.77 & 47.77 & 47.77 & 47.77 \\
\hline 102.89 & 102.89 & 102.89 & 102.89 & 102.89 & 102.89 & 102.89 & 102.89 & 102.89 \\
\hline 149.04 & 149.04 & 184 & 184 & 184 & 184 & 184 & 149.04 & 184 \\
\hline 213.44 & 213.44 & 306 & 306 & 306 & 306 & 306 & 213.44 & 306 \\
\hline 307 & 307 & 333 & 333 & 333 & 333 & 333 & 307 & 333 \\
\hline 333 & 333 & 459.4 & 459.4 & 459.4 & 459.4 & 459.4 & 333 & 459.4 \\
\hline 460 & 460 & 551.2 & 551.2 & 551.2 & 551.2 & 551.2 & 460 & 551.2 \\
\hline 552 & 552 & 735 & 735 & 735 & 735 & 735 & 552 & 735 \\
\hline 736 & 736 & 1000 & 1000 & 1000 & 1000 & 1000 & 736 & 1000 \\
\hline 1000 & 1000 & 3000 & 3000 & 3000 & 3000 & 3000 & 1000 & 3000 \\
\hline 3000 & 3000 & 8000 & 8000 & 8000 & 8000 & 8000 & 3000 & 8000 \\
\hline 8000 & 8000 & 15000 & 15000 & 15000 & 15000 & 15000 & 8000 & 15000 \\
\hline 15000 & 15000 & & & & & & 15000 & \\
\hline 0.3443 & 0.3603 & 0.3141 & 0.2627 & 0.3159 & 0.27 & 0.3051 & 0.291 & 0.2413 \\
\hline 0.3421 & 0.3166 & 0.2905 & 0.2227 & 0.2838 & 0.1754 & 0.1159 & 0.2474 & 0.183 \\
\hline 0.3384 & 0.2529 & 0.1413 & 0.1608 & 0.1587 & 0.1463 & 0.0831 & 0.2092 & 0.1467 \\
\hline 0.313 & 0.1983 & 0.0667 & 0.1099 & 0.0802 & 0.1226 & 0.0613 & 0.1509 & 0.1212 \\
\hline 0.171 & 0.1365 & 0.0485 & 0.0735 & 0.0552 & 0.0862 & 0.046 & 0.1201 & 0.0993 \\
\hline 0.1528 & 0.1201 & 0.0394 & 0.0553 & 0.048 & 0.06 & 0.0351 & 0.1128 & 0.0939 \\
\hline 0.131 & 0.1074 & 0.0339 & 0.0466 & 0.04 & 0.0491 & 0.0278 & 0.1026 & 0.0902 \\
\hline 0.1092 & 0.0946 & 0.0338 & 0.0453 & 0.0394 & 0.0473 & 0.0277 & 0.0946 & 0.0866 \\
\hline 0.1021 & 0.0882 & 0.032 & 0.0386 & 0.0364 & 0.04 & 0.0242 & 0.0926 & 0.0801 \\
\hline 0.0946 & 0.0837 & 0.0301 & 0.0349 & 0.0329 & 0.0364 & 0.0231 & 0.0837 & 0.0764 \\
\hline 0.0837 & 0.0801 & 0.0291 & 0.032 & 0.0293 & 0.0328 & 0.0218 & 0.0801 & 0.0728 \\
\hline 0.0655 & 0.0691 & 0.027 & 0.0313 & 0.0257 & 0.032 & 0.0211 & 0.0728 & 0.0691 \\
\hline 0.0582 & 0.0619 & 0.0247 & 0.0298 & 0.0251 & 0.029 & 0.0207 & 0.0673 & 0.0582 \\
\hline 0.0437 & 0.0473 & 0.024 & 0.0291 & 0.0251 & 0.0287 & 0.0204 & 0.0473 & 0.0509 \\
\hline 0.0364 & 0.0422 & 0.0233 & 0.0284 & 0.025 & 0.0287 & 0.0204 & 0.0426 & 0.0508 \\
\hline 0.0317 & 0.04 & & & & & & 0.0424 & \\
\hline
\end{tabular}




$\begin{array}{rrrrrrrr}53 & 54 & 55 & 56 & 57 & 58 & 59 & 60 \\ 16 & 15 & 15 & 15 & 16 & 0 & 15 & 15 \\ 12.4 & 12.4 & 12.4 & 12.4 & 12.4 & -9.9 & 12.4 & 12.4 \\ 20.2 & 20.2 & 20.2 & 20.2 & 20.2 & -9.9 & 20.2 & 20.2 \\ 29.4 & 29.4 & 29.4 & 29.4 & 29.4 & -9.9 & 29.4 & 29.4 \\ 47.77 & 47.77 & 47.77 & 47.77 & 47.77 & -9.9 & 47.77 & 47.77 \\ 102.89 & 102.89 & 102.89 & 102.89 & 102.89 & -9.9 & 102.89 & 102.89 \\ 149.04 & 184 & 184 & 184 & 149.04 & -9.9 & 184 & 184 \\ 213.44 & 306 & 306 & 306 & 213.44 & -9.9 & 306 & 306 \\ 307 & 333 & 333 & 333 & 307 & -9.9 & 333 & 333 \\ 333 & 459.4 & 459.4 & 459.4 & 333 & -9.9 & 459.4 & 459.4 \\ 460 & 551.2 & 551.2 & 551.2 & 460 & -9.9 & 551.2 & 551.2 \\ 552 & 735 & 735 & 735 & 552 & -9.9 & 735 & 735 \\ 736 & 1000 & 1000 & 1000 & 736 & -9.9 & 1000 & 1000 \\ 1000 & 3000 & 3000 & 3000 & 1000 & -9.9 & 3000 & 3000 \\ 3000 & 8000 & 8000 & 8000 & 3000 & -9.9 & 8000 & 8000 \\ 8000 & 15000 & 15000 & 15000 & 8000 & -9.9 & 15000 & 15000 \\ 15000 & & & & 15000 & -9.9 & & \\ 0.3035 & 0.3042 & 0.389 & 0.2613 & 0.263 & -9.9 & 0.2365 & 0.3006 \\ 0.2489 & 0.3035 & 0.3839 & 0.2576 & 0.247 & -9.9 & 0.1164 & 0.2169 \\ 0.1543 & 0.2489 & 0.3785 & 0.2103 & 0.2339 & -9.9 & 0.091 & 0.1587 \\ 0.0815 & 0.1798 & 0.3202 & 0.163 & 0.2121 & -9.9 & 0.0764 & 0.1186 \\ 0.0415 & 0.1274 & 0.2475 & 0.1303 & 0.1568 & -9.9 & 0.0564 & 0.0677 \\ 0.0342 & 0.1146 & 0.1747 & 0.1179 & 0.1422 & -9.9 & 0.0455 & 0.0473 \\ 0.0324 & 0.1074 & 0.131 & 0.1092 & 0.1357 & -9.9 & 0.0418 & 0.0382 \\ 0.0309 & 0.1057 & 0.1266 & 0.1071 & 0.1295 & -9.9 & 0.0413 & 0.0371 \\ 0.0306 & 0.1001 & 0.1092 & 0.1004 & 0.129 & -9.9 & 0.0346 & 0.0346 \\ 0.0291 & 0.0946 & 0.1019 & 0.0946 & 0.1208 & -9.9 & 0.0328 & 0.0328 \\ 0.0262 & 0.0873 & 0.0946 & 0.0873 & 0.1179 & -9.9 & 0.0291 & 0.0298 \\ 0.024 & 0.0764 & 0.0764 & 0.0837 & 0.1121 & -9.9 & 0.0275 & 0.0296 \\ 0.0226 & 0.0582 & 0.0509 & 0.0619 & 0.1042 & -9.9 & 0.0255 & 0.0295 \\ 0.0218 & 0.0531 & 0.0473 & 0.0517 & 0.0801 & -9.9 & 0.0247 & 0.0295 \\ 0.0218 & 0.0525 & 0.0437 & 0.0509 & 0.0684 & -9.9 & 0.0247 & 0.0295 \\ 0.0218 & & & & 0.068 & -9.9 & & \end{array}$




\title{
A.5 Directly Fitted "van Genuchten" Parameters
}

\author{
Sheet: Retention Parameters VG Project: ESMP \\ Version: 1 \\ Date: 12-Apr-01 \\ Purpose: Contains van Genuchten parameters fitted to water retention \\ Data: $\quad$ Equilibrium outflow data from multistep outflow experiment (Sheet: retention) \\ Model: $\quad$ van Genuchten (1980) \\ Software: MATLAB with dedicated optimization software \\ Analyses: Marcel G. Schaap \\ Contact: $\quad$ Marcel G. Schaap, US Salinity Lab, 450 W. Big Springs Road, Riverside, CA 92507 \\ E-mail: $\quad$ mschaap@ussl.ars.usda.gov
}

\begin{tabular}{|c|c|c|}
\hline Column & Explanation & Methodology \\
\hline ID & Identifier (Ring number) & \\
\hline$\theta_{\mathrm{r}}$ & Residual water content in $\mathrm{cm}^{3} / \mathrm{cm}^{3}$ & $\begin{array}{l}\theta_{\mathrm{r}} \text { constrained to be greater or equal } \\
\text { than } 0\end{array}$ \\
\hline$\theta_{\mathrm{s}}$ & Saturated water content in $\mathrm{cm}^{3} / \mathrm{cm}^{3}$ & $\begin{array}{l}\theta_{\mathrm{s}} \text { constrained to be smaller or equal } \\
\text { to porosity }\end{array}$ \\
\hline$\alpha$ & INVERSE of air entry pressure in $1 / \mathrm{cm}$ & $\alpha$ constrained between 0 and 1 \\
\hline$n$ & $\begin{array}{l}\text { Exponent in the van Genuchten } \\
\text { Equation }\end{array}$ & $\begin{array}{l}n \text { constrained to be greater that } 1 \text { and } \\
\text { smaller than } 20\end{array}$ \\
\hline RMSE_c & $\begin{array}{l}\text { Unbiassed Root Mean Square Error, cc } \\
\text { sqrt(sum }\left((\text { measured-predicted })^{\wedge} 2\right) /(\text { npc }\end{array}$ & $\begin{array}{l}\text { orrected for } 4 \text { parameters: } \\
\text { ints-4)) }\end{array}$ \\
\hline
\end{tabular}

Comments No data available for sample $7,25,28,29,30,37,58$

(continued on next page) 


\begin{tabular}{|c|c|c|c|c|c|}
\hline ID & $\begin{array}{c}\theta_{\mathrm{r}} \\
\mathrm{cm}^{3} / \mathrm{cm}^{3}\end{array}$ & $\begin{array}{c}\theta_{\mathrm{s}} \\
\mathrm{cm}^{3} / \mathrm{cm}^{3}\end{array}$ & $\begin{array}{c}\alpha \\
1 / \mathrm{cm}\end{array}$ & $\begin{array}{l}n \\
-\end{array}$ & $\begin{array}{l}\text { RMSE_c } \\
\mathrm{cm}^{3} / \mathrm{cm}^{3}\end{array}$ \\
\hline 1 & 0.0500 & 0.2711 & 0.0203 & 1.7645 & 0.0047 \\
\hline 2 & 0.0526 & 0.3022 & 0.0635 & 1.4002 & 0.0065 \\
\hline 3 & 0.0285 & 0.2949 & 0.0248 & 2.0282 & 0.0078 \\
\hline 4 & 0.0203 & 0.4100 & 0.1410 & 1.7346 & 0.0064 \\
\hline 5 & 0.0058 & 0.3757 & 0.1305 & 1.6357 & 0.0094 \\
\hline 6 & 0.0288 & 0.3922 & 0.0899 & 1.8455 & 0.0021 \\
\hline \multicolumn{6}{|l|}{7} \\
\hline 8 & 0.0077 & 0.3983 & 0.1678 & 1.4118 & 0.0132 \\
\hline 9 & 0.0301 & 0.4742 & 0.1813 & 1.6625 & 0.0052 \\
\hline 10 & 0.0215 & 0.4613 & 0.3487 & 1.8065 & 0.0071 \\
\hline 11 & 0.0270 & 0.3499 & 0.0483 & 4.1472 & 0.0064 \\
\hline 12 & 0.0226 & 0.4740 & 0.0734 & 2.3788 & 0.0140 \\
\hline 13 & 0.0283 & 0.3469 & 0.0401 & 6.0454 & 0.0086 \\
\hline 14 & 0.0315 & 0.3495 & 0.0383 & 5.4675 & 0.0074 \\
\hline 15 & 0.0306 & 0.3373 & 0.0415 & 1.9304 & 0.0074 \\
\hline 16 & 0.0319 & 0.3248 & 0.0372 & 5.0635 & 0.0109 \\
\hline 17 & 0.0334 & 0.3326 & 0.0321 & 3.4677 & 0.0127 \\
\hline 18 & 0.0330 & 0.3270 & 0.0298 & 1.9577 & 0.0081 \\
\hline 19 & 0.0342 & 0.3184 & 0.0392 & 5.0478 & 0.0110 \\
\hline 20 & 0.0470 & 0.3878 & 0.0204 & 2.0813 & 0.0086 \\
\hline 21 & 0.0288 & 0.3685 & 0.0577 & 1.7991 & 0.0079 \\
\hline 22 & 0.0296 & 0.4006 & 0.1021 & 2.0696 & 0.0125 \\
\hline 23 & 0.0341 & 0.2836 & 0.0374 & 12.0378 & 0.0173 \\
\hline 24 & 0.0225 & 0.3843 & 0.0760 & 1.7405 & 0.0056 \\
\hline \multicolumn{6}{|l|}{25} \\
\hline 26 & 0.0474 & 0.3767 & 0.0083 & 3.1346 & 0.0121 \\
\hline 27 & 0.0000 & 0.3547 & 0.0811 & 1.4266 & 0.0091 \\
\hline \multicolumn{6}{|c|}{28} \\
\hline \multicolumn{6}{|c|}{29} \\
\hline \multicolumn{6}{|l|}{30} \\
\hline 31 & 0.0446 & 0.2946 & 0.0266 & 1.8822 & 0.0033 \\
\hline 32 & 0.0261 & 0.3506 & 0.0675 & 2.8508 & 0.0084 \\
\hline 33 & 0.0214 & 0.3506 & 0.0564 & 4.2854 & 0.0073 \\
\hline 34 & 0.0404 & 0.3225 & 0.0467 & 3.0300 & 0.0088 \\
\hline 35 & 0.0349 & 0.3346 & 0.0327 & 3.6952 & 0.0084 \\
\hline 36 & 0.0235 & 0.3630 & 0.1384 & 1.6070 & 0.0059 \\
\hline \multicolumn{6}{|l|}{37} \\
\hline 38 & 0.0483 & 0.3835 & 0.0566 & 1.9860 & 0.0126 \\
\hline 39 & 0.0391 & 0.3161 & 0.0561 & 1.6150 & 0.0036 \\
\hline 40 & 0.0316 & 0.2901 & 0.0393 & 2.7473 & 0.0067 \\
\hline 41 & 0.0502 & 0.3115 & 0.0373 & 1.5159 & 0.0059 \\
\hline 42 & 0.0247 & 0.4176 & 0.1629 & 1.9448 & 0.0080 \\
\hline 43 & 0.0248 & 0.4198 & 0.2645 & 1.4123 & 0.0081 \\
\hline 44 & 0.0377 & 0.3645 & 0.0176 & 1.9474 & 0.0134 \\
\hline
\end{tabular}




$\begin{array}{lccccc}45 & 0.0415 & 0.4364 & 0.0672 & 1.6966 & 0.0067 \\ 46 & 0.0327 & 0.3234 & 0.0381 & 5.8945 & 0.0103 \\ 47 & 0.0297 & 0.3335 & 0.0641 & 2.0642 & 0.0053 \\ 48 & 0.0347 & 0.3319 & 0.0388 & 4.2772 & 0.0111 \\ 49 & 0.0274 & 0.4025 & 0.1202 & 1.8196 & 0.0093 \\ 50 & 0.0281 & 0.4402 & 0.0757 & 3.8406 & 0.0128 \\ 51 & 0.0422 & 0.3700 & 0.0960 & 1.5836 & 0.0089 \\ 52 & 0.0594 & 0.3704 & 0.1626 & 1.7096 & 0.0094 \\ 53 & 0.0264 & 0.3315 & 0.0435 & 3.2791 & 0.0049 \\ 54 & 0.0556 & 0.3787 & 0.0644 & 1.6662 & 0.0140 \\ 55 & 0.0401 & 0.4039 & 0.0167 & 1.8130 & 0.0060 \\ 56 & 0.0407 & 0.3783 & 0.1601 & 1.4268 & 0.0104 \\ 57 & 0.0526 & 0.3022 & 0.0635 & 1.4002 & 0.0065 \\ 58 & & & & & \\ 59 & 0.0336 & 0.4342 & 0.1112 & 2.5891 & 0.0113 \\ 60 & 0.0277 & 0.4251 & 0.0846 & 2.0899 & 0.0033 \\ & & & & & \\ \text { Min } & 0.0000 & 0.2711 & 0.0083 & 1.4002 & 0.0021 \\ \text { Max } & 0.0594 & 0.4742 & 0.3487 & 12.0378 & 0.0173 \\ \text { Average } & 0.0330 & 0.3637 & 0.0781 & 2.6935 & 0.0085 \\ \sigma & 0.0119 & 0.0496 & 0.0642 & 1.8103 & 0.0032\end{array}$




\title{
A.6 Directly Fitted "Brooks-Corey" Parameters
}

\author{
Sheet: Retention Parameters BC Project: ESMP \\ Version: 1 \\ Date: 12-Apr-01 \\ Purpose: Contains Brooks-Corey parameters fitted to water retention \\ Data: $\quad$ Equilibrium outflow data from multistep outflow experiment (Sheet: retention) \\ Model: $\quad$ Brooks-Corey (1964) \\ Software: MATLAB with dedicated optimization software \\ Analyses: Marcel G. Schaap \\ Contact: $\quad$ Marcel G. Schaap, US Salinity Lab, 450 W. Big Springs Road, Riverside, CA 92507 \\ E-mail: mschaap@ussl.ars.usda.gov \\ Column \\ ID \\ $\theta_{\mathrm{r}}$ \\ $\theta_{\mathrm{s}}$ \\ $\alpha$ \\ $\lambda$ \\ RMSE_c \\ Comments

\section{Explanation} \\ Identifier (Ring number) \\ Residual water content in $\mathrm{cm}^{3} / \mathrm{cm}^{3}$ \\ Saturated water content in $\mathrm{cm}^{3} / \mathrm{cm}^{3}$ \\ INVERSE of air entry pressure in $1 / \mathrm{cm}$ \\ Exponent in the Brooks-Corey \\ Equation \\ Unbiased Root Mean Square Error, corrected for 4 parameters: \\ $\operatorname{sqrt}\left(\right.$ sum $\left((\text { measured-predicted })^{\wedge} 2\right) /($ (npoints-4)) \\ No data available for sample $7,25,28,29,30,37,58$ \\ (continued on next page) \\ $\theta_{\mathrm{r}}$ constrained to be greater or equal \\ than 0 \\ $\theta_{\mathrm{s}}$ constrained to be smaller or equal \\ to porosity \\ $\alpha$ constrained between 0 and 1 \\ $\lambda$ constrained to be greater that 1 and \\ smaller than 20

\section{Methodology}




\begin{tabular}{|c|c|c|c|c|c|}
\hline ID & $\begin{array}{c}\theta_{\mathrm{r}} \\
\mathrm{cm}^{3} / \mathrm{cm}^{3}\end{array}$ & $\begin{array}{c}\theta_{\mathrm{s}} \\
\mathrm{cm}^{3} / \mathrm{cm}^{3}\end{array}$ & $\begin{array}{c}\alpha \\
1 / \mathrm{cm}\end{array}$ & $\begin{array}{l}\lambda \\
-\end{array}$ & $\begin{array}{l}\text { RMSE_c } \\
\mathrm{cm}^{3} / \mathrm{cm}^{3}\end{array}$ \\
\hline 1 & 0.0420 & 0.2539 & 0.0303 & 0.5440 & 0.0083 \\
\hline 2 & 0.0482 & 0.2550 & 0.0459 & 0.3593 & 0.0066 \\
\hline 3 & 0.0273 & 0.2619 & 0.0279 & 0.8906 & 0.0145 \\
\hline 4 & 0.0162 & 0.2806 & 0.1011 & 0.6311 & 0.0041 \\
\hline 5 & 0.0000 & 0.4279 & 0.2388 & 0.5323 & 0.0101 \\
\hline 6 & 0.0266 & 0.2817 & 0.0701 & 0.7519 & 0.0030 \\
\hline \multicolumn{6}{|l|}{7} \\
\hline 8 & 0.0023 & 0.3038 & 0.1048 & 0.3719 & 0.0117 \\
\hline 9 & 0.0265 & 0.4740 & 0.2323 & 0.5907 & 0.0037 \\
\hline 10 & 0.0266 & 0.1876 & 0.0920 & 1.0817 & 0.0045 \\
\hline 11 & 0.0260 & 0.3372 & 0.0602 & 2.2036 & 0.0041 \\
\hline 12 & 0.0239 & 0.3369 & 0.0610 & 1.4195 & 0.0111 \\
\hline 13 & 0.0264 & 0.3429 & 0.0531 & 2.4842 & 0.0052 \\
\hline 14 & 0.0284 & 0.3455 & 0.0534 & 1.9992 & 0.0071 \\
\hline 15 & 0.0279 & 0.2860 & 0.0452 & 0.7865 & 0.0060 \\
\hline 16 & 0.0297 & 0.3179 & 0.0519 & 1.9974 & 0.0084 \\
\hline 17 & 0.0268 & 0.3120 & 0.0463 & 1.2426 & 0.0103 \\
\hline 18 & 0.0270 & 0.2954 & 0.0395 & 0.7281 & 0.0029 \\
\hline 19 & 0.0319 & 0.3144 & 0.0542 & 1.9961 & 0.0104 \\
\hline 20 & 0.0417 & 0.3598 & 0.0271 & 0.8411 & 0.0112 \\
\hline 21 & 0.0233 & 0.3147 & 0.0664 & 0.6387 & 0.0096 \\
\hline 22 & 0.0254 & 0.3056 & 0.1033 & 0.8401 & 0.0080 \\
\hline 23 & 0.0307 & 0.2807 & 0.0499 & 2.6897 & 0.0132 \\
\hline 24 & 0.0166 & 0.3250 & 0.0813 & 0.6091 & 0.0058 \\
\hline \multicolumn{6}{|l|}{25} \\
\hline 26 & 0.0419 & 0.3719 & 0.0118 & 1.4521 & 0.0085 \\
\hline 27 & 0.0122 & 0.2415 & 0.0201 & 0.6014 & 0.0255 \\
\hline \multicolumn{6}{|l|}{28} \\
\hline \multicolumn{6}{|l|}{29} \\
\hline \multicolumn{6}{|l|}{30} \\
\hline 31 & 0.0410 & 0.2630 & 0.0312 & 0.7205 & 0.0080 \\
\hline 32 & 0.0273 & 0.2951 & 0.0657 & 1.9653 & 0.0079 \\
\hline 33 & 0.0193 & 0.3299 & 0.0718 & 1.9992 & 0.0078 \\
\hline 34 & 0.0385 & 0.2869 & 0.0575 & 1.4688 & 0.0055 \\
\hline 35 & 0.0319 & 0.3151 & 0.0447 & 1.5957 & 0.0016 \\
\hline 36 & 0.0202 & 0.2412 & 0.0792 & 0.5420 & 0.0062 \\
\hline \multicolumn{6}{|l|}{37} \\
\hline 38 & 0.0460 & 0.3137 & 0.0563 & 0.8544 & 0.0097 \\
\hline 39 & 0.0318 & 0.2730 & 0.0612 & 0.4916 & 0.0045 \\
\hline 40 & 0.0346 & 0.2507 & 0.0412 & 1.9960 & 0.0097 \\
\hline 41 & 0.0399 & 0.2787 & 0.0433 & 0.4006 & 0.0090 \\
\hline 42 & 0.0241 & 0.2179 & 0.0847 & 0.8873 & 0.0070 \\
\hline 43 & 0.0237 & 0.2617 & 0.0831 & 0.3982 & 0.0073 \\
\hline 44 & 0.0299 & 0.3416 & 0.0248 & 0.7084 & 0.0074 \\
\hline
\end{tabular}




$\begin{array}{llllll}45 & 0.0361 & 0.3604 & 0.0651 & 0.5927 & 0.0036 \\ 46 & 0.0289 & 0.3141 & 0.0522 & 2.0022 & 0.0062 \\ 47 & 0.0285 & 0.2626 & 0.0612 & 0.9395 & 0.0028 \\ 48 & 0.0335 & 0.3161 & 0.0523 & 1.9956 & 0.0078 \\ 49 & 0.0253 & 0.2659 & 0.0826 & 0.7299 & 0.0073 \\ 50 & 0.0263 & 0.4398 & 0.0993 & 1.9586 & 0.0096 \\ 51 & 0.0368 & 0.2914 & 0.0771 & 0.5005 & 0.0072 \\ 52 & 0.0578 & 0.3126 & 0.1430 & 0.6539 & 0.0082 \\ 53 & 0.0240 & 0.3036 & 0.0570 & 1.5208 & 0.0026 \\ 54 & 0.0558 & 0.3044 & 0.0519 & 0.6328 & 0.0100 \\ 55 & 0.0369 & 0.3679 & 0.0185 & 0.7126 & 0.0170 \\ 56 & 0.0460 & 0.2616 & 0.0586 & 0.4617 & 0.0087 \\ 57 & 0.0482 & 0.2550 & 0.0459 & 0.3593 & 0.0066 \\ 58 & & & & & \\ 59 & 0.0326 & 0.2303 & 0.0808 & 1.3613 & 0.0098 \\ 60 & 0.0256 & 0.3004 & 0.0726 & 0.9365 & 0.0032 \\ & & & & & \\ \text { Min } & 0.0000 & 0.1876 & 0.0118 & 0.3593 & 0.0016 \\ \text { Max } & 0.0578 & 0.4740 & 0.2388 & 2.6897 & 0.0255 \\ \text { Average } & 0.0303 & 0.3032 & 0.0666 & 1.0881 & 0.0078 \\ \sigma & 0.0111 & 0.0529 & 0.0419 & 0.6427 & 0.0040\end{array}$




\title{
A.7 Inversely Modeled "van Genuchten" Parameters
}

\author{
Sheet: Inverse Parameters_VG Project: ESMP \\ Version: $\quad 2$ \\ Date: 11-Mar-03 \\ Purpose: Contains inversely optimized Brooks-Corey parameters for retention and saturated hydraulic \\ conductivity \\ Data: Dynamic outflow data from multistep outflow experiment \\ Model: $\quad$ van Genuchten-Mualem \\ Software: Hydrus1D \\ Analyses: Pete Shouse, Jirka Simunek \\ Contact: $\quad$ Marcel G. Schaap, US Salinity Lab, 450 W. Big Springs Road, Riverside, CA 92507 \\ E-mail: $\quad$ mschaap@ussl.ars.usda.gov

\section{Column Explanation} \\ ID Identifier (Ring number) \\ $\theta_{\mathrm{r}} \quad$ Residual water content in $\mathrm{cm} 3 / \mathrm{cm} 3$ \\ $\theta_{\mathrm{s}} \quad$ Saturated water content in $\mathrm{cm} 3 / \mathrm{cm} 3$ \\ $\alpha \quad$ INVERSE of air entry pressure in $1 / \mathrm{cm}$ \\ $\boldsymbol{n} \quad$ Exponent in van Genuchten Equation \\ $K_{s} \quad$ Matching point in $\mathrm{cm} /$ day \\ $\boldsymbol{L} \quad$ Pore interaction term \\ RMSE Biased Root Mean Square Error for STATIC WATER RETENTION ONLY, \\ 1,2,3,4,5,6 Refer to the parameters Theta_r through L. A "0" indicates that this parameter \\ was optimized, a "1" indicates that this parameter was not optimized. In the latter \\ case the initial parameter value is given. This value did not change during the \\ optimization.
}

Comments Inverse method failed for samples 44 and 54. No hydraulic data were available for samples $7,25,28,29,30,37$, and 58

(continued on next page) 


\begin{tabular}{|c|c|c|c|c|c|c|c|c|c|c|c|c|c|}
\hline ID & $\begin{array}{c}\theta_{\mathrm{r}} \\
\mathrm{cm}^{3} / \mathrm{cm}^{3}\end{array}$ & $\begin{array}{c}\theta_{\mathrm{s}} \\
\mathrm{cm}^{3} / \mathrm{cm}^{3}\end{array}$ & $\begin{array}{c}\alpha \\
1 / \mathrm{cm}\end{array}$ & $\begin{array}{l}n \\
-\end{array}$ & $\begin{array}{c}K_{s} \\
\mathrm{~cm} / \text { day }\end{array}$ & $\begin{array}{l}L \\
-\end{array}$ & $\begin{array}{c}\text { RMSE } \\
\mathrm{cm}^{3} / \mathrm{cm}^{3}\end{array}$ & 1 & 2 & 3 & 4 & 5 & 6 \\
\hline 1 & 0.0426 & 0.2784 & 0.0196 & 1.7455 & $1.11 \mathrm{E}+00$ & 0.0022 & 0.0063 & 0 & 0 & 0 & 0 & 0 & 0 \\
\hline 2 & 0.0405 & 0.2880 & 0.0301 & 4.0787 & $4.94 \mathrm{E}+01$ & 1.3787 & 0.0086 & 0 & 0 & 0 & 0 & 0 & 0 \\
\hline 3 & 0.0012 & 0.3832 & 0.0501 & 1.6489 & $1.98 E+01$ & 0.9795 & 0.0176 & 0 & 0 & 0 & 0 & 0 & 0 \\
\hline 4 & 0.0200 & 0.3900 & 0.0641 & 2.3970 & $4.72 E+01$ & -0.0716 & 0.0237 & 1 & 1 & 0 & 0 & 0 & 0 \\
\hline 5 & 0.0060 & 0.3650 & 0.0736 & 1.9250 & $1.43 E+02$ & -3.1441 & 0.0171 & 1 & 1 & 0 & 1 & 0 & 0 \\
\hline 6 & 0.0245 & 0.3777 & 0.0579 & 2.0375 & $7.01 \mathrm{E}+01$ & 0.3258 & 0.0138 & 0 & 0 & 0 & 0 & 0 & 0 \\
\hline \multicolumn{14}{|l|}{7} \\
\hline 8 & 0.0380 & 0.3880 & 0.0703 & 1.9290 & $1.10 \mathrm{E}+01$ & 0.1053 & 0.0249 & 0 & 1 & 0 & 0 & 0 & 0 \\
\hline 9 & 0.0430 & 0.4350 & 0.0688 & 2.4528 & $7.25 E+01$ & -0.0002 & 0.0235 & 0 & 1 & 0 & 0 & 0 & 0 \\
\hline 10 & 0.0236 & 0.3627 & 0.1058 & 2.5173 & $4.06 \mathrm{E}+02$ & 0.0215 & 0.0112 & 0 & 0 & 0 & 0 & 0 & 0 \\
\hline 11 & 0.0200 & 0.4000 & 0.0488 & 4.1650 & $1.88 \mathrm{E}+02$ & 0.4623 & 0.0161 & 1 & 1 & 0 & 0 & 0 & 0 \\
\hline 12 & 0.0292 & 0.3660 & 0.0411 & 3.9461 & $2.92 E+02$ & 4.3529 & 0.0162 & 0 & 1 & 0 & 0 & 0 & 0 \\
\hline 13 & 0.0262 & 0.3540 & 0.0373 & 6.3455 & $2.13 E+02$ & 0.6000 & 0.0129 & 0 & 0 & 0 & 0 & 0 & 0 \\
\hline 14 & 0.0272 & 0.3260 & 0.0335 & 5.6385 & $1.90 E+02$ & 1.6514 & 0.0138 & 0 & 0 & 0 & 0 & 0 & 0 \\
\hline 15 & 0.0410 & 0.3100 & 0.0289 & 2.3656 & $2.09 \mathrm{E}+01$ & 0.3031 & 0.0092 & 1 & 1 & 0 & 0 & 0 & 0 \\
\hline 16 & 0.0320 & 0.3123 & 0.0354 & 5.5826 & $1.73 E+02$ & 0.8469 & 0.0101 & 0 & 0 & 0 & 0 & 0 & 0 \\
\hline 17 & 0.0395 & 0.2671 & 0.0286 & 6.1136 & $1.48 E+02$ & 0.2067 & 0.0233 & 0 & 0 & 0 & 0 & 0 & 0 \\
\hline 18 & 0.0460 & 0.3071 & 0.0228 & 2.4396 & $7.38 E+00$ & 0.0707 & 0.0101 & 0 & 0 & 0 & 0 & 0 & 0 \\
\hline 19 & 0.0322 & 0.3100 & 0.0352 & 8.7755 & $1.25 E+01$ & 0.0240 & 0.0144 & 0 & 0 & 0 & 0 & 0 & 1 \\
\hline 20 & 0.0491 & 0.3989 & 0.0248 & 2.0125 & $7.43 E+00$ & 0.1241 & 0.0093 & 0 & 0 & 0 & 0 & 0 & 0 \\
\hline 21 & 0.0297 & 0.3500 & 0.0557 & 1.8084 & $2.01 \mathrm{E}+01$ & 0.0312 & 0.0084 & 0 & 0 & 0 & 0 & 0 & 0 \\
\hline 22 & 0.0290 & 0.3650 & 0.0528 & 3.4499 & $7.87 E+01$ & 0.0065 & 0.0248 & 1 & 1 & 0 & 0 & 0 & 0 \\
\hline 23 & 0.0340 & 0.2840 & 0.0427 & 3.9120 & $9.81 E+01$ & 2.0305 & 0.0213 & 1 & 1 & 0 & 0 & 0 & 0 \\
\hline 24 & 0.0220 & 0.3600 & 0.0492 & 2.2546 & $1.91 E+01$ & 0.0358 & 0.0199 & 1 & 1 & 0 & 0 & 0 & 0 \\
\hline \multicolumn{14}{|l|}{25} \\
\hline 26 & 0.0500 & 0.3660 & 0.0082 & 3.2203 & $3.95 E+00$ & 0.8915 & 0.0118 & 0 & 0 & 0 & 0 & 0 & 0 \\
\hline 27 & 0.0344 & 0.3550 & 0.0592 & 1.8415 & $1.29 E+01$ & 0.0010 & 0.0240 & 0 & 1 & 0 & 0 & 0 & 0 \\
\hline \multicolumn{14}{|l|}{28} \\
\hline \multicolumn{14}{|l|}{29} \\
\hline \multicolumn{14}{|l|}{30} \\
\hline 31 & 0.0497 & 0.2761 & 0.0213 & 2.3262 & $1.55 E+00$ & 0.0035 & 0.0113 & 0 & 0 & 0 & 0 & 0 & 0 \\
\hline 32 & 0.0247 & 0.3636 & 0.0515 & 4.3353 & $1.76 \mathrm{E}+02$ & 0.0939 & 0.0187 & 0 & 0 & 0 & 0 & 0 & 0 \\
\hline 33 & 0.0165 & 0.3529 & 0.0534 & 4.0275 & $3.74 \mathrm{E}+02$ & 0.1234 & 0.0098 & 0 & 0 & 0 & 0 & 0 & 0 \\
\hline 34 & 0.0379 & 0.2920 & 0.0372 & 3.9131 & $5.81 E+01$ & -2.0336 & 0.0101 & 0 & 0 & 0 & 0 & 0 & 0 \\
\hline 35 & 0.0350 & 0.3350 & 0.0305 & 3.5000 & $6.01 E+01$ & 0.6846 & 0.0100 & 1 & 1 & 0 & 1 & 0 & 0 \\
\hline 36 & 0.0230 & 0.3530 & 0.1269 & 1.6070 & $1.23 E+02$ & 0.3192 & 0.0052 & 1 & 1 & 0 & 1 & 0 & 0 \\
\hline \multicolumn{14}{|l|}{37} \\
\hline 38 & 0.0460 & 0.3040 & 0.0292 & 3.4991 & $2.12 \mathrm{E}+01$ & 2.2133 & 0.0215 & 1 & 1 & 0 & 0 & 0 & 0 \\
\hline 39 & 0.0440 & 0.3200 & 0.0523 & 1.6265 & $2.07 E+01$ & 1.2043 & 0.0068 & 0 & 1 & 0 & 0 & 0 & 0 \\
\hline 40 & 0.0305 & 0.2765 & 0.0325 & 3.5786 & $1.08 E+02$ & 1.3272 & 0.0084 & 0 & 0 & 0 & 0 & 0 & 0 \\
\hline 41 & 0.0500 & 0.3410 & 0.0534 & 1.5129 & $5.80 E+00$ & -0.2413 & 0.0073 & 0 & 0 & 0 & 0 & 0 & 0 \\
\hline 42 & 0.0250 & 0.2950 & 0.0614 & 2.5541 & $1.38 E+02$ & 0.0364 & 0.0150 & 1 & 1 & 0 & 0 & 0 & 0 \\
\hline 43 & 0.0380 & 0.3800 & 0.1043 & 1.6555 & $3.94 E+01$ & 1.2713 & 0.0146 & 1 & 1 & 0 & 0 & 0 & 0 \\
\hline 44 & & & & & & & & & & & & & \\
\hline
\end{tabular}




$\begin{array}{llllllllllllll}45 & 0.0439 & 0.4100 & 0.0496 & 1.9129 & 2.42 \mathrm{E}+01 & 0.0041 & 0.0128 & 0 & 0 & 0 & 0 & 0 & 0 \\ 46 & 0.0330 & 0.3230 & 0.0364 & 5.4064 & 1.45 \mathrm{E}+02 & 0.6817 & 0.0107 & 1 & 1 & 0 & 0 & 0 & 0 \\ 47 & 0.0300 & 0.3330 & 0.0517 & 2.3195 & 4.61 \mathrm{E}+01 & 0.5928 & 0.0087 & 1 & 1 & 0 & 0 & 0 & 0 \\ 48 & 0.0350 & 0.3320 & 0.0367 & 4.6074 & 1.07 \mathrm{E}+02 & 0.4959 & 0.0108 & 1 & 1 & 0 & 0 & 0 & 0 \\ 49 & 0.0275 & 0.3829 & 0.0812 & 2.0900 & 9.32 \mathrm{E}+01 & -0.2282 & 0.0122 & 0 & 0 & 0 & 0 & 0 & 0 \\ 50 & 0.0280 & 0.3870 & 0.0562 & 4.7400 & 3.41 \mathrm{E}+02 & 0.0021 & 0.0226 & 1 & 1 & 0 & 1 & 0 & 0 \\ 51 & 0.0500 & 0.3600 & 0.0682 & 1.8458 & 2.45 \mathrm{E}+01 & 0.7420 & 0.0133 & 0 & 1 & 0 & 0 & 0 & 0 \\ 52 & 0.0705 & 0.3290 & 0.0684 & 2.7798 & 6.63 \mathrm{E}+01 & 0.8473 & 0.0148 & 0 & 1 & 0 & 0 & 0 & 0 \\ 53 & 0.0254 & 0.3274 & 0.0397 & 3.6825 & 1.46 \mathrm{E}+02 & 0.0696 & 0.0064 & 0 & 0 & 0 & 0 & 0 & 0 \\ 54 & & & & & & & & & & & & & \\ 55 & 0.0290 & 0.3650 & 0.0528 & 3.4499 & 7.87 \mathrm{E}+01 & 0.0065 & 0.1333 & 1 & 1 & 0 & 0 & 0 & 0 \\ 56 & 0.0670 & 0.3144 & 0.0545 & 1.7610 & 2.23 \mathrm{E}+01 & 3.0042 & 0.0117 & 0 & 0 & 0 & 0 & 0 & 0 \\ 57 & 0.0768 & 0.2971 & 0.0368 & 1.6751 & 6.62 \mathrm{E}+00 & 2.2825 & 0.0097 & 0 & 0 & 0 & 0 & 0 & 0 \\ 58 & & & & & & & & & & & & & \\ 59 & 0.0317 & 0.3800 & 0.0843 & 2.9227 & 1.38 \mathrm{E}+02 & 2.0074 & 0.0115 & 0 & 1 & 0 & 0 & 0 & 0 \\ 60 & 0.0271 & 0.4100 & 0.0606 & 2.5339 & 1.05 \mathrm{E}+02 & 0.5608 & 0.0123 & 0 & 0 & 0 & 0 & 0 & 0 \\ & & & & & & & & & & & & \\ \text { Min } & 0.0012 & 0.2671 & 0.0082 & 1.5129 & 1.11 \mathrm{E}+00 & -3.1441 & 0.0052 & & & & & \\ \text { Max } & 0.0768 & 0.4350 & 0.1269 & 8.7755 & 4.06 \mathrm{E}+02 & 4.3529 & 0.1333 & & & & & \\ \text { Avg } & 0.0348 & 0.3439 & 0.0505 & 3.1464 & 9.36 \mathrm{E}+01 & 0.5354 & 0.0161 & & & & & \\ \sigma & 0.0141 & 0.0406 & 0.0228 & 1.5248 & 9.74 \mathrm{E}+01 & 1.1115 & 0.0176 & & & & & \end{array}$




\title{
A.8 Inversely Modeled "Brooks-Corey" Parameters
}

\author{
Sheet: Inverse_Parameters_BC Project: ESMP \\ Version: 2 \\ Date: 11-Mar-03 \\ Purpose: Contains inversely optimized Brooks-Corey parameters for retention and saturated hydraulic \\ conductivity \\ Data: Dynamic outflow data from multistep outflow experiment \\ Model: Brooks-Corey-Mualem \\ Software: Hydrus1D \\ Analyses: Pete Shouse, Jirka Simunek \\ Contact: $\quad$ Marcel G. Schaap, US Salinity Lab, 450 W. Big Springs Road, Riverside, CA 92507 \\ E-mail: $\quad$ mschaap@ussl.ars.usda.gov

\section{Column Explanation} \\ ID Identifier (Ring number) \\ $\theta_{\mathrm{r}} \quad$ Residual water content in $\mathrm{cm} 3 / \mathrm{cm} 3$ \\ $\theta_{\mathbf{s}} \quad$ Saturated water content in $\mathrm{cm} 3 / \mathrm{cm} 3$ \\ $\alpha \quad$ INVERSE of air entry pressure in $1 / \mathrm{cm}$ \\ $\lambda \quad$ Exponent in Brooks-Corey Equation \\ $\boldsymbol{K}_{\boldsymbol{s}} \quad$ Matching point in $\mathrm{cm} /$ day \\ $L \quad$ Pore interaction term \\ RMSE Biased Root Mean Square Error for STATIC WATER RETENTION ONLY, \\ 1,2,3,4,5,6 Refer to the parameters $\theta_{\mathrm{r}}$ through $L$. A " 0 " indicates that this parameter was \\ optimized, a "1" indicates that this parameter was not optimized. In the latter case \\ the initial parameter value is given. This value did not change during the \\ optimization.
}

Comments Inverse method failed for samples 44 and 54. No hydraulic data were available for samples $7,25,28,29,30,37$, and 58

(continued on next page) 


\begin{tabular}{|c|c|c|c|c|c|c|c|c|c|c|c|c|c|}
\hline ID & $\begin{array}{c}\theta_{\mathrm{r}} \\
\mathrm{cm}^{3} / \mathrm{cm}^{3}\end{array}$ & $\begin{array}{c}\theta_{\mathrm{s}} \\
\mathrm{cm}^{3} / \mathrm{cm}^{3}\end{array}$ & $\begin{array}{c}\alpha \\
1 / \mathrm{cm}\end{array}$ & $\begin{array}{l}\lambda \\
-\end{array}$ & $\begin{array}{c}K_{s} \\
\mathrm{~cm} / \text { day }\end{array}$ & $\begin{array}{l}L \\
-\end{array}$ & $\begin{array}{c}\text { RMSE } \\
\mathrm{cm}^{3} / \mathrm{cm}^{3}\end{array}$ & 1 & 2 & 3 & 4 & 5 & 6 \\
\hline 1 & 0.0367 & 0.2606 & 0.0383 & 0.4747 & $4.68 \mathrm{E}+00$ & 0.9623 & 0.0069 & 0 & 0 & 0 & 0 & 1 & 0 \\
\hline 2 & 0.0323 & 0.2801 & 0.0442 & 1.4994 & $4.94 E+01$ & 1.0664 & 0.0074 & 0 & 0 & 0 & 0 & 0 & 0 \\
\hline 3 & 0.0200 & 0.3350 & 0.0513 & 0.4896 & $1.21 \mathrm{E}+00$ & 0.0050 & 0.0376 & 1 & 1 & 0 & 0 & 0 & 0 \\
\hline 4 & 0.0158 & 0.3005 & 0.0685 & 0.8849 & $4.52 E+01$ & 1.2321 & 0.0175 & 0 & 0 & 0 & 0 & 0 & 0 \\
\hline 5 & 0.0100 & 0.3439 & 0.0755 & 1.0017 & $6.96 \mathrm{E}+01$ & 2.9763 & 0.0282 & 1 & 0 & 0 & 0 & 0 & 0 \\
\hline 6 & 0.0200 & 0.3615 & 0.0917 & 0.7417 & $6.30 \mathrm{E}+01$ & 0.2042 & 0.0137 & 1 & 0 & 0 & 0 & 0 & 0 \\
\hline \multicolumn{14}{|l|}{7} \\
\hline 8 & 0.0010 & 0.3880 & 0.1727 & 0.3893 & $9.42 \mathrm{E}+00$ & 0.8146 & 0.0113 & 1 & 1 & 0 & 0 & 1 & 0 \\
\hline 9 & 0.0370 & 0.3106 & 0.0642 & 1.0192 & $6.96 \mathrm{E}+01$ & 1.5532 & 0.0153 & 0 & 0 & 0 & 0 & 0 & 0 \\
\hline 10 & 0.0160 & 0.3187 & 0.1060 & 1.4650 & $3.80 E+02$ & 1.6092 & 0.0180 & 1 & 0 & 0 & 0 & 0 & 0 \\
\hline 11 & 0.0149 & 0.3458 & 0.0483 & 2.5060 & $2.13 E+02$ & 0.4243 & 0.0336 & 0 & 0 & 0 & 0 & 0 & 0 \\
\hline 12 & 0.0100 & 0.3294 & 0.0553 & 1.5808 & $2.92 E+02$ & 6.1799 & 0.0174 & 1 & 0 & 0 & 0 & 0 & 0 \\
\hline 13 & 0.0149 & 0.3458 & 0.0483 & 2.5060 & $2.13 E+02$ & 0.4243 & 0.0184 & 0 & 0 & 0 & 0 & 0 & 0 \\
\hline 14 & 0.0294 & 0.3283 & 0.0425 & 3.0272 & $1.90 E+02$ & 1.5601 & 0.0111 & 0 & 0 & 0 & 0 & 0 & 0 \\
\hline 15 & 0.0180 & 0.2814 & 0.0419 & 0.8994 & $3.74 \mathrm{E}+01$ & -0.3659 & 0.0140 & 1 & 0 & 0 & 0 & 0 & 0 \\
\hline 16 & 0.0288 & 0.3031 & 0.0453 & 2.3142 & $1.73 E+02$ & 0.5824 & 0.0094 & 0 & 0 & 0 & 0 & 0 & 0 \\
\hline 17 & 0.0426 & 0.2686 & 0.0351 & 3.0534 & $1.48 E+02$ & 0.3253 & 0.0219 & 0 & 0 & 0 & 0 & 0 & 0 \\
\hline 18 & 0.0100 & 0.2993 & 0.0449 & 0.6194 & $7.32 E+00$ & 0.8356 & 0.0082 & 1 & 0 & 0 & 0 & 0 & 0 \\
\hline 19 & 0.0311 & 0.3098 & 0.0423 & 3.4937 & $1.25 \mathrm{E}+01$ & -0.5012 & 0.0149 & 0 & 0 & 0 & 0 & 1 & 0 \\
\hline 20 & 0.0234 & 0.3792 & 0.0388 & 0.6093 & $7.08 \mathrm{E}+00$ & 1.7687 & 0.0119 & 0 & 0 & 0 & 0 & 0 & 0 \\
\hline 21 & 0.0180 & 0.3500 & 0.0957 & 0.5325 & $1.64 \mathrm{E}+01$ & 0.0030 & 0.0105 & 1 & 0 & 0 & 0 & 0 & 0 \\
\hline 22 & 0.0290 & 0.3240 & 0.0688 & 1.3920 & $7.86 \mathrm{E}+01$ & 0.3893 & 0.0188 & 0 & 0 & 0 & 0 & 1 & 0 \\
\hline 23 & 0.0262 & 0.2884 & 0.0620 & 1.3714 & $9.81 E+01$ & 4.0536 & 0.0193 & 0 & 0 & 0 & 0 & 1 & 0 \\
\hline 24 & 0.0191 & 0.3333 & 0.0717 & 0.7008 & $1.83 E+01$ & 0.4420 & 0.0080 & 0 & 0 & 0 & 0 & 0 & 0 \\
\hline \multicolumn{14}{|l|}{25} \\
\hline 26 & 0.0500 & 0.3627 & 0.0103 & 2.8219 & $3.93 E+00$ & 0.1734 & 0.0189 & 0 & 0 & 0 & 0 & 1 & 0 \\
\hline 27 & 0.0258 & 0.3195 & 0.0764 & 0.5224 & $1.06 \mathrm{E}+01$ & 0.1032 & 0.0142 & 0 & 0 & 0 & 0 & 0 & 0 \\
\hline \multicolumn{14}{|l|}{28} \\
\hline \multicolumn{14}{|l|}{29} \\
\hline \multicolumn{14}{|l|}{30} \\
\hline 31 & 0.0300 & 0.2800 & 0.0423 & 0.6056 & $1.76 \mathrm{E}+02$ & 0.0012 & 0.0071 & 1 & 1 & 0 & 0 & 0 & 0 \\
\hline 32 & 0.0240 & 0.3104 & 0.0634 & 2.1102 & $1.76 \mathrm{E}+02$ & 0.0546 & 0.0093 & 0 & 0 & 0 & 0 & 1 & 0 \\
\hline 33 & 0.0010 & 0.3020 & 0.0585 & 2.1046 & $3.74 \mathrm{E}+02$ & 0.1637 & 0.0218 & 0 & 0 & 0 & 0 & 0 & 0 \\
\hline 34 & 0.0383 & 0.2723 & 0.0492 & 1.7414 & $5.81 E+01$ & 0.6111 & 0.0110 & 0 & 0 & 0 & 0 & 0 & 0 \\
\hline 35 & 0.0319 & 0.3151 & 0.0409 & 1.5957 & $4.47 E+00$ & 0.0531 & 0.0082 & 0 & 0 & 0 & 0 & 0 & 0 \\
\hline 36 & 0.0200 & 0.3100 & 0.1080 & 0.5795 & $6.30 \mathrm{E}+01$ & 0.4277 & 0.0091 & 1 & 1 & 0 & 0 & 0 & 0 \\
\hline \multicolumn{14}{|l|}{37} \\
\hline 38 & 0.0201 & 0.3300 & 0.0452 & 0.8967 & $1.20 E+02$ & 6.4180 & 0.0259 & 0 & 1 & 0 & 0 & 0 & 0 \\
\hline 39 & 0.0010 & 0.3200 & 0.1173 & 0.3561 & $1.47 E+01$ & 0.0934 & 0.0086 & 0 & 1 & 0 & 0 & 1 & 0 \\
\hline 40 & 0.0323 & 0.2641 & 0.0455 & 1.4319 & $1.08 E+02$ & 1.7715 & 0.0087 & 0 & 0 & 0 & 0 & 0 & 0 \\
\hline 41 & 0.0104 & 0.3100 & 0.0777 & 0.2945 & $3.52 E+00$ & -1.2747 & 0.0091 & 0 & 1 & 0 & 0 & 0 & 0 \\
\hline 42 & 0.0355 & 0.3500 & 0.0921 & 1.2014 & $1.35 E+02$ & 2.2013 & 0.0276 & 0 & 1 & 0 & 0 & 1 & 0 \\
\hline 43 & 0.0100 & 0.3180 & 0.0963 & 0.4494 & $2.34 \mathrm{E}+01$ & 4.9566 & 0.0169 & 1 & 0 & 0 & 0 & 0 & 0 \\
\hline
\end{tabular}




$\begin{array}{llllllllllllll}45 & 0.0422 & 0.3567 & 0.0579 & 0.6652 & 2.12 \mathrm{E}+01 & 1.9321 & 0.0054 & 0 & 0 & 0 & 0 & 0 & 0 \\ 46 & 0.0250 & 0.3153 & 0.0479 & 2.1864 & 1.45 \mathrm{E}+02 & 1.0750 & 0.0106 & 1 & 0 & 0 & 0 & 0 & 0 \\ 47 & 0.0141 & 0.3905 & 0.1160 & 0.7283 & 4.42 \mathrm{E}+01 & 0.0259 & 0.0126 & 0 & 0 & 0 & 0 & 0 & 0 \\ 48 & 0.0295 & 0.3193 & 0.0517 & 1.6809 & 1.07 \mathrm{E}+02 & 1.8002 & 0.0084 & 0 & 0 & 0 & 0 & 0 & 0 \\ 49 & 0.0279 & 0.3390 & 0.0989 & 0.8689 & 8.18 \mathrm{E}+01 & -3.1517 & 0.0099 & 0 & 0 & 0 & 0 & 0 & 0 \\ 50 & 0.0303 & 0.3383 & 0.0660 & 3.2003 & 3.41 \mathrm{E}+02 & 0.0596 & 0.0164 & 0 & 0 & 0 & 0 & 0 & 0 \\ 51 & 0.0500 & 0.3100 & 0.0844 & 0.6728 & 1.97 \mathrm{E}+01 & 0.0872 & 0.0121 & 0 & 1 & 0 & 0 & 0 & 0 \\ 52 & 0.0500 & 0.2501 & 0.0701 & 0.9881 & 6.51 \mathrm{E}+01 & 3.2812 & 0.0180 & 0 & 0 & 0 & 0 & 0 & 0 \\ 53 & 0.0100 & 0.2842 & 0.0507 & 1.5461 & 1.46 \mathrm{E}+02 & 0.1082 & 0.0144 & 1 & 0 & 0 & 0 & 0 & 0 \\ 54 & & & & & & & & & & & & & \\ 55 & 0.0010 & 0.4000 & 0.2520 & 0.1247 & 1.47 \mathrm{E}+00 & -1.4597 & 0.0927 & 1 & 0 & 0 & 0 & 0 & 0 \\ 56 & 0.0500 & 0.2691 & 0.0548 & 0.5600 & 1.76 \mathrm{E}+01 & 5.0836 & 0.0097 & 0 & 0 & 0 & 0 & 0 & 0 \\ 57 & 0.0144 & 0.2959 & 0.1000 & 0.2625 & 5.26 \mathrm{E}+00 & 0.0976 & 0.0081 & 0 & 0 & 0 & 0 & 0 & 0 \\ 58 & & & & & & & & & & & & & \\ 59 & 0.0260 & 0.3100 & 0.0763 & 2.5084 & 1.36 \mathrm{E}+02 & 0.0370 & 0.0252 & 1 & 1 & 0 & 0 & 1 & 0 \\ 60 & 0.0250 & 0.3500 & 0.0768 & 1.0312 & 1.02 \mathrm{E}+02 & 0.0173 & 0.0138 & 1 & 1 & 0 & 0 & 0 & 0 \\ & & & & & & & & & & & & \\ \text { Min } & 0.0010 & 0.2501 & 0.0103 & 0.1247 & 1.21 \mathrm{E}+00 & -3.1517 & 0.0054 & & & & & \\ \text { Max } & 0.0500 & 0.4000 & 0.2520 & 3.4937 & 3.80 \mathrm{E}+02 & 6.4180 & 0.0927 & & & & & \\ \text { Avg } & 0.0241 & 0.3192 & 0.0702 & 1.3001 & 9.21 \mathrm{E}+01 & 1.0057 & 0.0162 & & & & & \\ \sigma & 0.0130 & 0.0344 & 0.0382 & 0.8798 & 9.78 \mathrm{E}+01 & 1.7990 & 0.0130 & & & & & \end{array}$




\section{Distribution}

No. of

Copies

OFFSITE

9 GEBJ Salinity Laboratory 450 W. Big Springs Rd

Riverside, CA 92507-4617

M.G. Schaap (3)

P.J. Shouse (3)

M. Th. van Genuchten

J. Jobes

J. Fagerlund
No. of

Copies

ONSITE

1 Fluor Federal Services

R. Khaleel

$1 \underline{\mathrm{CH} 2 \mathrm{M} \text { Hill }}$

F.M. Mann

18 Pacific Northwest National Laboratory

M.J. Fayer

E.J. Freeman

M.D. Freshley

G.W. Gee

G.V. Last

P.D. Meyer (10)

M.L Rockhold

A.L. Ward

F. Zhang

Distr.1 